Florida International University FIU Digital Commons

$6-17-2014$

\title{
Advanced Placement and American Education: A Foucauldian Analysis of the Advanced Placement Program of the College Board
}

Jon C. Rehm

Florida International University, jonrehm@yahoo.com

DOI: $10.25148 /$ etd.FI14071159

Follow this and additional works at: https://digitalcommons.fiu.edu/etd

\section{Recommended Citation}

Rehm, Jon C., "Advanced Placement and American Education: A Foucauldian Analysis of the Advanced Placement Program of the College Board" (2014). FIU Electronic Theses and Dissertations. 1530.

https://digitalcommons.fiu.edu/etd/1530 


\section{FLORIDA INTERNATIONAL UNIVERSITY}

Miami, Florida

\section{ADVANCED PLACEMENT AND AMERICAN EDUCATION: A FOUCAULDIAN ANALYSIS OF THE ADVANCED PLACEMENT PROGRAM OF THE COLLEGE BOARD}

A dissertation submitted in partial fulfillment of the requirements for the degree of DOCTOR OF EDUCATION

in CURRICULUM AND INSTRUCTION

by

Jon Rehm 
To: Dean Delia C. Garcia

College of Education

This dissertation, written by Jon Rehm, and entitled Advanced Placement and American Education: A Foucauldian Analysis of the Advanced Placement Program of the College Board, having been approved in respect to style and intellectual content, is referred to you for judgment.

We have read this dissertation and recommend that it be approved.

Gwyn Davies

Sarah Mathews

$\begin{array}{r}\text { Sarah Mathews } \\ \hline \text { Joan Wynne } \\ \hline \text { Hilary Landorf, Major Professor }\end{array}$

Date of Defense: June 17, 2014

The dissertation of Jon Rehm is approved.

Dean Delia C. Garcia

College of Education

Dean Lakshmi N. Reddi

University Graduate School

Florida International University, 2014 
C Copyright 2014 by Jon Rehm

All rights reserved. 


\section{DEDICATION}

To my wife and daughter. 


\section{ACKNOWLEDGMENTS}

The idea for this dissertation sprung out of a discussion that was had after my comprehensive exams. I had planned on examining high stakes testing and often times the discussion turned back to the Advanced Placement program. Therefore, I would like to thank Dr. Landorf for pushing me to pursue the change in topic and guiding me through the process. I would also like to thank the other members of my committee for their support and patience in what has proven to be a very long process. Dr. Matthews and Dr. Wynne I am grateful for offering your help when you did not know who I am. Dr. Davies your historical perspective and discerning eye has helped make this writing leaner and stronger. 


\begin{abstract}
OF THE DISSERTATION
ADVANCED PLACEMENT AND AMERICAN EDUCATION: A FOUCAULDIAN ANALYSIS OF THE ADVANCED PLACEMENT PROGRAM OF THE COLLEGE BOARD

by
\end{abstract}

Jon Rehm

Florida International University, 2014

Miami, Florida

Professor Hilary Landorf, Major Professor

Advanced Placement is a series of courses and tests designed to determine mastery over introductory college material. It has become part of the American educational system. The changing conception of AP was examined using critical theory to determine what led to a view of continual success. The study utilized David Armstrong's variation of Michel Foucault's critical theory to construct an analytical framework. Black and Ubbes' data gathering techniques and Braun and Clark’s data analysis were utilized as the analytical framework. Data included 1135 documents: 641 journal articles, 421 newspaper articles and 82 government documents.

The study revealed three historical ruptures correlated to three themes containing subthemes. The first rupture was the Sputnik launch in 1958. Its correlated theme was AP leading to school reform with subthemes of AP as reform for able students and AP's gaining of acceptance from secondary schools and higher education. The second rupture was the Nation at Risk report published in 1983. Its correlated theme was AP's shift in emphasis from the exam to the course with the subthemes of AP as a course, a shift in 
AP's target population, using AP courses to promote equity, and AP courses modifying curricula. The passage of the No Child Left Behind Act of 2001 was the third rupture. Its correlated theme was AP as a means to narrow the achievement gap with the subthemes of AP as a college preparatory program and the shifting of AP to an open access program. The themes revealed a perception that progressively integrated the program into American education. The AP program changed emphasis from tests to curriculum, and is seen as the nation's premier academic program to promote reform and prepare students for college. It has become a major source of income for the College Board. In effect, AP has become an agent of privatization, spurring other private entities into competition for government funding. The change and growth of the program over the past 57 years resulted in a deep integration into American education. As such the program remains an intrinsic part of the system and continues to evolve within American education. 


\section{TABLE OF CONTENTS}

CHAPTER

PAGE

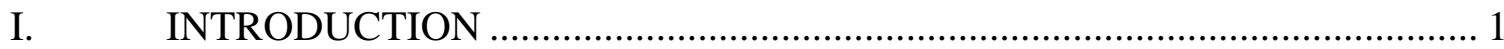

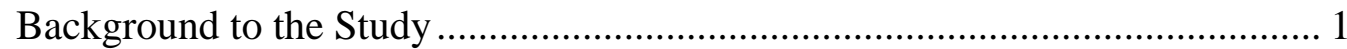

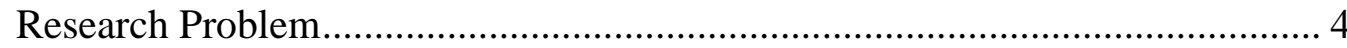

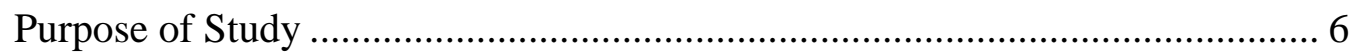

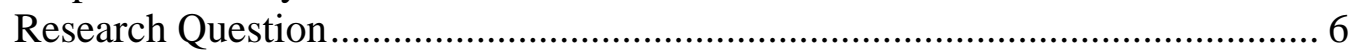

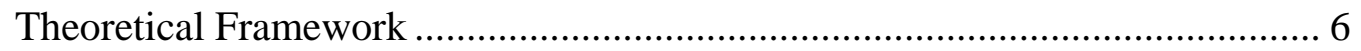

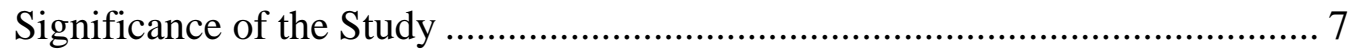

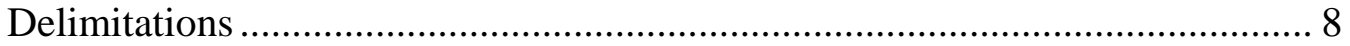

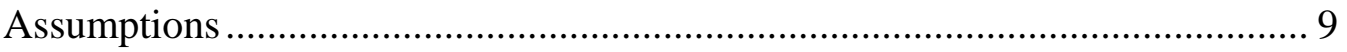

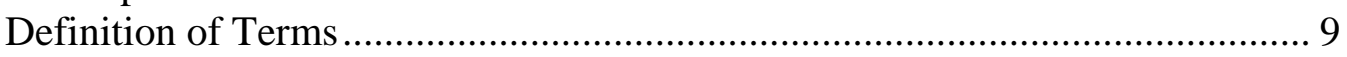

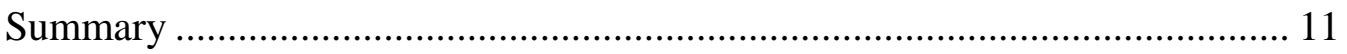

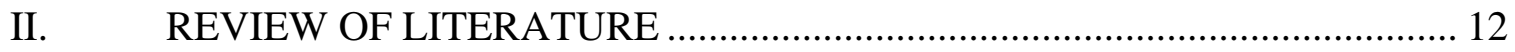

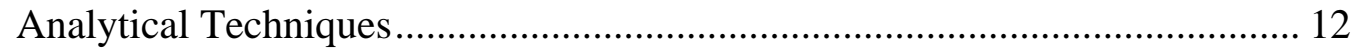

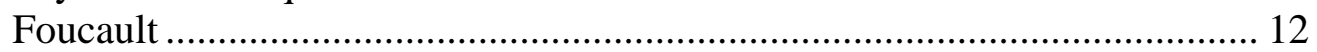

David Armstrong ............................................................................. 17

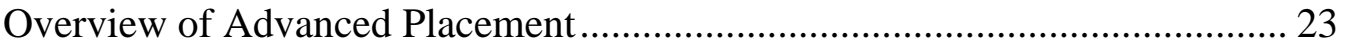

History of Advanced Placement ................................................................... 23

Current Advanced Placement Scope and Structure................................... 30

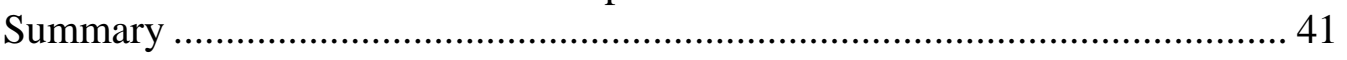

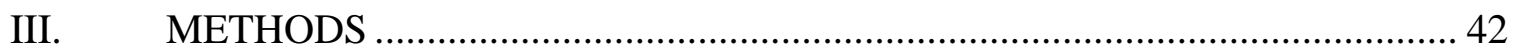

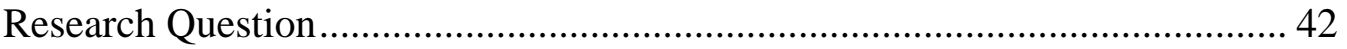

Methodological Framework ................................................................... 42

Research Design ............................................................................ 44

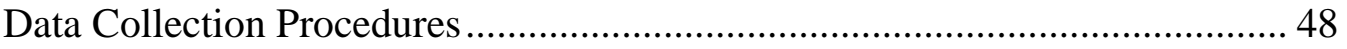

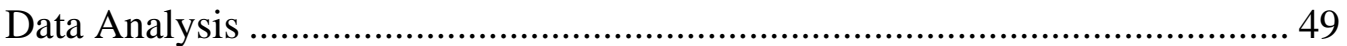

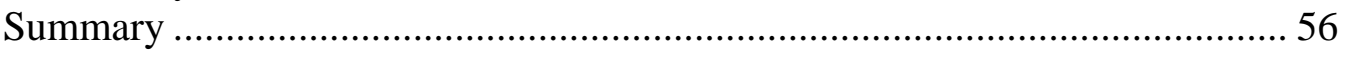

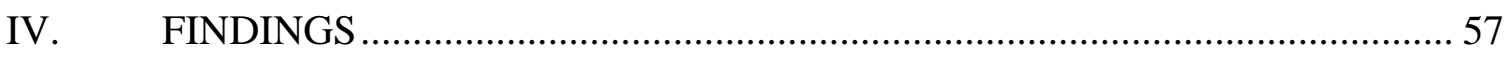

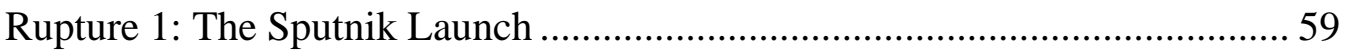

Theme 1: Role of AP Leading to School Reform ........................................ 61

Subtheme 1.1: AP as Reform for the Ablest Student ................................... 62

Subtheme 1.2: AP Gaining Acceptance as a Reform for Secondary Schools

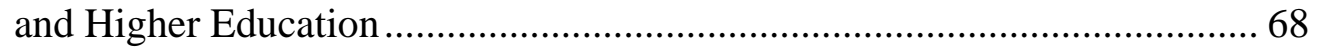

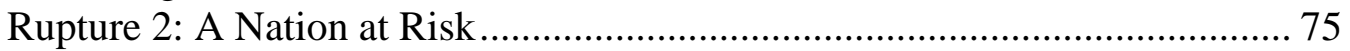

Theme 2: A Shift in Emphasis from the AP test to the AP Course.................. 76

Subtheme 2.1: AP as a Course................................................................. 76

Subtheme 2.2: A Shift in the Target AP Population.................................... 82

Subtheme 2.3: AP Courses used to Promote Equity ................................... 85

Subtheme 2.4: AP Courses Modifying Curricula .......................................... 88 
Rupture 3: No Child Left Behind............................................................. 92

Theme 3: AP as a Means to Narrow the Achievement Gap............................ 93

Subtheme 3.1: AP as a College Preparatory Program ................................... 96

Subtheme 3.2: Shift of AP to an Open Access Program ........................... 102

Summary .................................................................................. 107

V. DISCUSSION AND RECOMMENDATIONS ..................................... 108

Review of the Study and Research Question ............................................. 108

Discussion of the Research Question ......................................................... 112

The AP dichotomy............................................................................... 113

The AP program as an economic juggernaut............................................ 119

AP program as an agent of privatization .............................................. 122

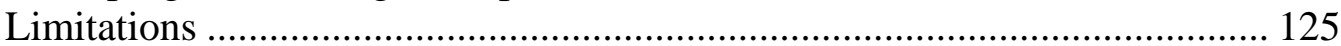

Recommendations for Practice and Policy............................................... 126

Recommendations for Research......................................................... 129

Summary and Final Thoughts ................................................................ 130

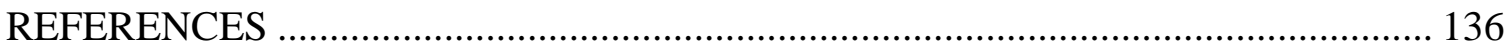

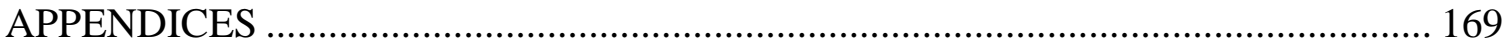

VITA

177 


\section{LIST OF FIGURES}

FIGURE

PAGE

1. Advanced Placement Timeline ……………………............................................... 25

2. List of Advanced Placement Tests.............................................................................. 35

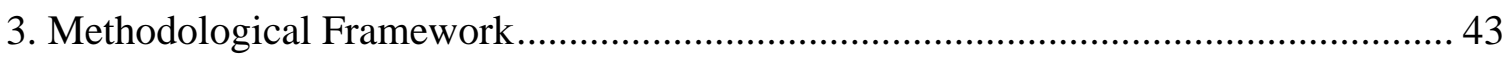

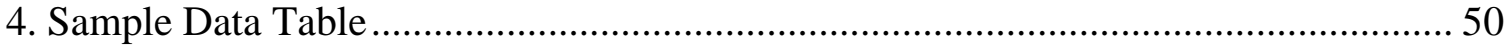

5. Braun \& Clark’s Six Phase Process for Thematic Analysis ……………………........... 51

6. Ruptures, Themes, \& Subthemes Flowchart................................................................... 59 


\section{ACRONYMS AND ABBREVIATIONS}

$\begin{array}{ll}\text { AP } & \text { Advanced Placement } \\ \text { CB } & \text { College Board } \\ \text { CEEB } & \text { College Entrance Examination Board } \\ \text { CDA } & \text { Critical Discourse Analysis } \\ \text { ETS } & \text { Educational Testing Services } \\ \text { FRQ } & \text { Free Response Question } \\ \text { NAR } & \text { A Nation at Risk } \\ \text { NCLB } & \text { No Child Left Behind }\end{array}$




\section{CHAPTER I \\ INTRODUCTION}

The purpose of this study was to create an historical account of the Advanced Placement Program (AP), as administered by the College Board (CB), since its inception in 1955 and to present a critical analysis of the history of the AP by using Foucauldian archaeology and genealogy within the framework of the American education system. This chapter provides an overview of the study including the background, a statement of the research problem and purpose, the research question, the theoretical framework, the study's significance, assumptions, and delimitations. The chapter concludes with an overview of succeeding chapters.

\section{Background to the Study}

The Advanced Placement (AP) program is a program that administers a series of tests in specific subject areas designed to determine whether students have achieved mastery over the material in introductory college courses taught in secondary schools. It is administered by the College Board (CB), an independent non-profit educational institution, with the goal of helping students in the transition process from secondary to higher education. The AP is viewed as a successful educational program within the larger American education system that many consider to be failing (Brandenburg, 2013). Academics, educators, the media, and politicians alike consider AP to be the "gold standard” of education (Byrd, Ellington, Gross, Jago, \& Stern, 2007). Educational and academic writers have lauded the program pointing to the benefits for students taking AP courses. These benefits include the greater likelihood of college acceptance, the ability to take more advanced courses once at the university level and the increased likelihood of 
graduating from college on schedule (Godfrey \& Matos-Elefonte, 2010; Jones, 1975;

Reichard, 1960; Wakelyn, 2009; Wolowelsky, 1982).

The US News and World Report has used the AP as an indicator of quality to rank the best high schools in the US, with AP participation and pass rates comprising the largest component of the variable used to rank college readiness (Newsweek/ Daily Beast, 2011a). Local newspapers, in towns across the US, publish lists of passing individuals and pass rates in their communities.

AP has been a favorite topic in the political discussion of education in both political parties since it was referred to in the 1983 controversial report "A Nation at Risk” (NAR). In his 2005 State of the Union Address George W. Bush made increased participation in the AP program an element of his educational initiative so as to encourage rigor in science and mathematics (New York Times, 2005). The program has also made its way into public policy; for example Part G of the No Child Left Behind Act (NCLB, 2001) specifically refers to AP. All 50 states have included AP in some form within their legislation (Education Commission of the States, 2013). Most recently the Obama administration has issued block grants to states to subsidize AP participation (Washington Times, 2012).

The AP program was not developed as a curriculum in the traditional sense but began as a program for administering a series of tests of subject matter covered in introductory college courses. To improve teaching and student performance on its tests, the CB created a network of professional development programs to accompany the courses and curricula dedicated to the test. The CB certifies these courses and curricula through an audit program. Currently, 34 AP tests guide 22 distinct curricula and 
accompanying professional development workshops sponsored by the College Board. In 2011, nearly one quarter of all high school students took an AP test so that 1,973,545 students took 3,456,020 tests in 18,340 secondary schools (College Board, 2011a).

Colleges and universities now use student performance in courses derived from the AP tests in making admissions decisions. A pattern has emerged whereby the courses that continue to be developed from the tests have come to represent college readiness and simultaneously the achievement of college level proficiency allowing the student to bypass certain introductory courses once in college.

An irony has emerged between the AP test and the curriculum it spawned. AP tests led to the creation of curricula to facilitate student performance on the test. The tests themselves have become the determining factors in the curricular design of the AP courses as opposed to the model of creating a curriculum and then devising a test to determine if students have understood and obtained proficiency in the skills and subject matter in the course material.

The ironical relationship between testing and curricula in AP mirrors the trends in the relationship between testing and curricula in American education. Testing is an integral part of the educational process where tests assess the knowledge and skills that learners have attained. Since the nineteenth century, the test has played an increasingly important role in the American educational system (Ravitch, 2003). The test is less a measurement of outcome, than a guide for a curriculum to pass the test (Popham, 1987). High stakes testing in America has spread this educational relationship between curriculum and testing throughout the nation. This educational system, which governs American curricula, is criticized as failing; simultaneously the AP program is praised for 
its success. Most parties in education contend the AP works, infusing rigor and relevance whereas the testing in the rest of American education does not.

AP tests differ from the majority of other tests. First, AP tests are voluntary.

Students are not required to pass an AP test in order to pass the high school course in that subject. Second, the outcome of the AP tests makes them unique. The students take the tests in an attempt to enjoy advanced standings upon arrival in college. Passing an AP test may allow the student to bypass introductory college courses at the university level (College Board, 2011b).

AP tests were designed to determine whether the established curriculum of the school and the rate of progress of the student sufficed to replace the introductory course at a university. The original intent of the AP program was to empower exceptional students at a limited number of preparatory schools in the Northeast (Rothschild, 1999). Private preparatory schools routinely sent their students to Ivy League institutions. The upper echelon of students from these schools found the very thing that qualified them for those institutions also made their college freshman year redundant because the series of courses most students took in their freshman year repeated the course work undertaken in their junior and senior years of high school (Casserly, 1968b). The tests allowed students to exempt themselves from the introductory course at the private universities where those students tended to attend and eliminate redundant curricula (Casserly, 1968a).

\section{Research Problem}

Every year the number of students taking AP tests increases with a growth rate averaging between 5-10\% (College Board, 2011c). Approximately two million students took an AP test in 2013 with the potential for an additional 300,000 tests to be added in 
2014. With continuing growth, participation may double over the next decade (College Board, 2011c). This greater participation in the AP program could lead universities to look for more AP courses on student transcripts as an indicator of rigorous course work when admitting students. With the continued growth of the AP program within the fabric of American education system and thus American society there is a need for a critical historical analysis of the AP program in order to understand the AP's role within the broader educational landscape in America.

Since AP's inception in 1956, few analytical histories of the program have been written. There are two histories of the $\mathrm{CB}$, the AP's governing body, and both include accounts of the origin of the AP (Fuesas, 1967; Valentine, 1987). These histories were commissioned by the College Board to commemorate, respectively, the $50^{\text {th }}$ and $75^{\text {th }}$ anniversaries of the Board's founding. Their topic was not the program; rather a history of AP was created incidentally. Neither history adequately analyzes the AP program. These histories inevitably present a biased account given that the CB commissioned and published them.

In addition to the two histories commissioned by the $\mathrm{CB}$, a number of articles have established a chronology of the program (DiYanni, 2002; Hanson, 1980; Marland, 1975; Rothschild, 1999). Each author was connected to the CB in some way with either the articles being published in College Board Review, or the author being employed by the $\mathrm{CB}$, or both. A recent book on the AP has included a discussion of the issues that AP has with minority student access, program rigor and profits (Sadler, Sonnert, Tai \& Klopfenstein, 2010). While evaluative and critical of the program, Sadler et al.'s work leaves unexplored themes related specifically to critical analysis. 


\section{Purpose of Study}

This study traced the historical origins of the AP from its founding in 1956 to the present day. The study used a narrative structure and Foucauldian analysis of the educational discourse related to the AP program in order to place the program within the larger confines of the American educational system.

\section{Research Question}

The research question is as follows:

What have been the changing conceptions of the Advanced Placement Program from its inception in1956 through 2012?

\section{Theoretical Framework}

The narrative structure of a history allows a brief sketch of the important milestones in the AP program and the alignment of these with significant events in American education. The study used a method of historical analysis modeled after the work of David Armstrong in his analysis of England's medical system. Armstrong (2002) utilized a method fashioned upon Foucauldian archaeology and used Foucault as a means to analyze medical texts. In his article "Silence and Truth in Death and Dying," Armstrong (1987) mapped the socio-medical literature created since 1960 to create a discourse as to society's overall views on death. Subsequently Armstrong (2002) created categories as a means to analyze texts; then he examined the discourse in existing literature to focus on specific events in given time frames related to the topic. Armstrong's $(1984,1987)$ articles provide a sketch of how the field of medicine (and thus, society) has changed over the course of the $20^{\text {th }}$ century. This study used Foucauldian analysis in a manner similar to David Armstrong, mapping the educational 
literature and linking it to important events from the narrative in order to map the changing socio-educational views of the AP.

\section{Significance of the Study}

The study describes a process for the creation of an educational history of a program or institution. These procedures construct a model in which historians of education can critically analyze the origins and progress of other such educational programs to assess their roles in the larger landscape of American education. The study also has added to the literature on Foucauldian analysis, having created a consistent method for using Foucauldian “archaeology” in the creation of educational historical analysis. This method of analysis may also prove useful in other historical realms beyond education.

Educators in America push for nationalized curricular standards. The AP and its tests are one of a handful of programs that fill this curricular void in American education as with the AP, a national curricular standard emerges. An analysis of AP's history can offer clues to policy makers on the processes of nationalization and standardization and the impact of these upon the American educational system. The study is also of value for states that have already implemented, are in the process of implementing or are planning to implement end-of-course examinations. The study gives policy-makers and school administrators an informative glimpse at the process of creating and maintaining a program based upon the concept of end-of-course tests.

The study enriches discussions as to what programs in education succeed, for whom those programs are intended, and their impact in the greater educational landscape. This history has the capacity to inform policy makers and educational specialists of the 
evolutionary progression of American education through the lens of this specific program; accordingly, these individuals can make rational decisions about the character and nature of AP and education (Woodbridge, 1916).

\section{Delimitations}

The conceptual framework created for this study served as a template through which the historical evidence was analyzed and led to the delimitations in this work. Thorough searches of the literature relating to the AP were used to gather data pertaining to this study. If the data were to be analyzed through a different framework, the time frame constraint would remain the same, but the themes for analysis would change and thus, the conclusions would change along with them.

The second delimitation was the themes created from the data coding (Glaser, 1965). Once these themes were in place, they restricted the analytic range of available options and thus delimit the scope of the research. Any additional data sources added after the formation of themes were integrated into the preexisting themes. This was due to theoretical saturation, and thus limited the necessity to go back and recode when presented with new data items (Glaser, 1965; Grove, 1988).

The final delimitation, the choice of sources used, influenced the results of the study. Sources were restricted to academic journals, newspaper articles, and public policy documents in order to limit actors and authors' voices within the data. This delimitation was fundamental otherwise there would have been an overwhelming amount of data (e.g., teachers' websites, teachers' resources, student study guides, etc.) related to the sociocultural knowledge (Foucault’s term savoir) of AP. 


\section{Assumptions}

The study was based upon the underlying belief that the AP is an integral part of the educational process and part of the discourse in American Education and thus made certain assumptions. First, the study was undertaken with the assumption that the discourse on AP reveals something about the nature of the Advanced Placement Program. Second, it was assumed that AP has played a part in the American educational system. Third, it was assumed that this analysis of AP, which is a part of the educational system, can shed greater light upon the overall state of education in America over the past 55 years.

\section{Definition of Terms}

Advanced Placement is an educational program comprised of 34 college equivalence tests created by the College Board. Colleges and universities use test results to determine whether the test taker should be granted advanced standing, where the student is not required to take the introductory course and can proceed directly to a higher level in that subject, college credit, or both. Each of the tests is based upon a curriculum created by the College Board and disseminated to teachers of AP courses through course guides and a program of professional development workshops.

Archaeology is a Foucauldian method for analyzing historical data. The method traces a body of knowledge from its origins to the modern day. In doing so the archaeology places the knowledge within the larger framework of society and its workings (Foucault, 1972).

The College Board was originally founded in 1900 as the College Entrance Examination Board. It simplified the college Application process in Northeastern 
universities, by having created a series of college entrance tests (College Board, 2011d). Today, the College Board is a non-profit organization that produces and administers the AP program, the SAT and CLEP tests.

Critical Discourse Analysis is a subset within the larger field of Discourse Analysis. CDA analyzes communications to determine underlying power relationships within a society (Bloom \& Carter, 2001; Fairclough 1995; Peräkylä, 2003).

Discourse is any form of communication written or spoken that has the capacity to be analyzed (Fairclough 1993; Petrone, 1995).

Discourse Analysis is a method of analysis for written or spoken communication. The method assumes that the written and spoken communications of a culture can inform researchers upon the nature of that culture. Discourse Analysis correlates communications in a language to the culture in which the communication was articulated creating an analysis of a culture through written or spoken words (Harris, 1952).

Michel Foucault (1926-1984) was a philosopher and historian of ideas. Foucault created multiple methodologies to study modernity through the lens of the individual disenfranchised from the power structure of society. Foucault's was one of the leading philosophers whose work led to the formation of critical analysis, structuralism, and post structuralism.

Genealogy is a Foucauldian method for analyzing historical data. The method creates a narrative following the events of the subject matter from its origin to the modern day. In doing so the genealogy identifies truths inherent in the knowledge base of the subject (Shiner, 1982). 
Historiography is defined as the discovery of new ways of thinking and ideas through an inquiry into the past that allows for an interpretation to take place. (Ankersmit, 1989)

Post Structuralism is a system of analysis that critically deconstructs written words to uncover the underlying truths about society inherent in all written works (Sarup, 1993).

\section{Summary}

This dissertation consists of four additional chapters. Chapter 2 is a review of the literature. It includes an overview of critical analysis and Foucauldian analysis, a brief narrative history of the AP and concludes with an overview of the tests, courses and curriculum that comprise the AP program. Chapter 3 describes the methods that were used in the study and reviews the research methodology, data collection and analytical procedures and limitations of the study. Chapter 4 presents the findings of the study. It contains the Foucauldian archaeological and genealogical narrative used to analyze AP. Chapter 5 is comprised of conclusions and recommendations for further research into critical historical analysis relating to the AP program and in the context of American education. 


\section{CHAPTER II}

\section{REVIEW OF LITERATURE}

This chapter reviews literature relevant to the creation of a history of the AP program, and is divided into two main sections. The first section examines the background of the analytic techniques that was used in the study as they relate to Foucauldian theory. The second section gives a brief overview of the history and structure of the AP program in order to explain its phases and place each within the context of the overall field of education. The overview accomplishes this through the creation of an initial narrative framework was used to guide and maintain the structure throughout the study. The review then examines the current scope of the program in order to determine the structure.

\section{Analytical Techniques}

This section includes an examination of Michel Foucault's theory and methodology and a discussion of David Armstrong's work and his adaptation of Foucault.

\section{Foucault}

Michel Foucault played a major role in transforming the way knowledge has been studied. Although he refused to label his style of inquiry, Foucault's work played a major role in what has been referred to as the linguistic turn which gave rise to post modernism, post structuralism, critical theory, feminist theory and many other critical ways of looking at knowledge. The linguistic turn spread through philosophy, history, and the human sciences. The linguistic turn's progeny in these fields spread throughout the academic community where, by the mid-1980s individuals like Apple and Gireaux 
had introduced the work of Foucault into the sphere of education. In education Foucault plays a particular role in qualitative research methodologies in the field. Foucault has become so integrated into qualitative educational research that Baker and Heyning (2004) referred to a "Foucault industry."

The variety of subject matter and the duality and comingling of methodologies have led to numerous versions of Foucauldian, or Foucault inspired, work to have emerged. Scheurich and McKenzie (2008) believed that no representation of Foucault existed or was possible. They argued for numerous possible readings of Foucault and therefore innumerable possible methodologies based upon Foucault. Butin (2008) examined a variety of readings and methods when he reviewed three books in which the authors utilized Foucault to analyze education. Butin (2008) described the act of divorcing of Foucauldian theory from practice and the reworking of Foucault by the authors for their own purposes. The variety in these authors' works has demonstrated Scheurich and McKenzie’s (2008) assertion that there is no "true "Foucauldian theory, other than Foucault's own work. Although numerous iterations of Foucault have existed, all have shared certain basic commonalities. The rest of this section is an examination of Foucault and explores the core elements that comprise the basic ideas in Foucault's work and bind all Foucauldian scholars together.

Foucault (1972) believed that individuals organized their life as a succession of stories. Thus life could be viewed as a narrative. Narratives use language, and language can be deconstructed (Patterson, 1989). Foucault (1972) argued that meaning has been encoded through the language used by the author. The deconstruction of discourse surrounding a topic has led to an understanding of the fundamental truth inherent in the 
topic (Foucault 1975). These truths have taken the shape of new insights into perspectives on power, knowledge, resistance and subjectification of elements of the populace (Foucault, 1972). Foucault's work in studying these themes was exemplified by examinations of psychology through the study of mental institutions and in gender relations through the study of sexuality. His major works included: Madness and Civilization, The Birth of the Clinic, Death and the Labyrinth, The Order of Things, The Archaeology of Knowledge, Discipline and Punishment, and The History of Sexuality Vol. I \& II.

Foucault utilized three analytical phases termed archaeology, genealogy, and care of the self. Foucault described two of the phases, archaeology and genealogy, as methodologies. The third, care of the self, was an analytical term. To understand these methods certain terminology must be defined. Foucault wrote in French where the verb "to know" has two differing forms depending upon the type of knowledge savoir (to be familiar with) and connaissance (to know information). Foucault took advantage of this subtle differentiation of knowledge to describe and use to make a large distinction in sources of knowledge.

In The Archaeology of Knowledge, Foucault described savior as "different bodies of learning, philosophical ideas, everyday opinions, but also institutions, commercial practice and police activities, mores” (Foucault, 1972, p. 261). Gutting (1989), in his analysis of Foucault, described savoir as the "discursive conditions that are necessary for the development of connaissance" (p. 251). Savoir is "what makes possible at a given moment the appearance of a theory, an opinion, a practice” (Foucault, 1972, p. 261). Foucault studied savoir in his archaeologies to better understand the connaissance. 
Connaissance is the formal body of knowledge existing within the broader savoir. Connaissance can be found in "scientific books, philosophical theories, and religious justifications” (Foucault, 1972, p.261). Connaissance are as Gutting described, “particular bodies of knowledge” (1989, p. 251). Savoir precedes the existence of connaissance. However, connaissance, once in existence, encompasses the savoir from which it emerged.

Archaeology. Foucault wrote three archaeologies: Madness and Civilization: A History of Madness in the Age of Reason, The Birth of the Clinic: An Archaeology of Medical Perception and The Order of Things: An Archeology of the Human Sciences. Subsequently he wrote a methodological treatise on archaeology entitled The Archaeology of Knowledge.

According to this schema, archaeology traced a body of knowledge, connaissance, from its origins through to its modern representation. It is necessary to study the broader body of knowledge that allows the connaissance to exist (Foucault, 1972, p. 262). In Madness and Civilization, Foucault (1975) traced the psychological distinction between madness and reason. He began at what he considered the origins of the concept of madness in the classical age and followed the subject through to the medical version held as today's standard (Foucault, 1975). Madness did not demonstrate a linear progression; instead it followed "a complex series of transformations where the evolution of structures of social control gave rise to new forms of consciousness which in turn produce new forms of social control” (Khafla, 1972). Thus, Foucault (1974) placed Madness within the framework of (savoir) society and its workings. Foucault (1972) explained in his methodological work The Archaeology of Knowledge that his analysis 
was a form of narrative. A Foucauldian historical archeology was not about chronology but an analysis of the structures and practices of society viewed through the lens of specific subject matter, which he referred to as a system of thought (Khafla, 1972). The system of thought through changes having taken place over time makes the work a narrative.

Genealogy. The second methodology Foucault termed was genealogy. He wrote two genealogies: Discipline and Punishment: The Birth of the Prison, and The History of Sexuality Vol. I: An Introduction. Like archaeology, genealogy traces the origins of a subject matter to understand the present history. Whereas archaeology ends with the organization of knowledge, genealogy attempts to identify the truth inherent in the knowledge base of a subject matter. This mining for truth results in the recognition of dissenting views placed in the power structure of society (Shiner, 1982). Foucault also examined changes to the power structure that attempted to subvert dissenting views by comparing periods of time and examining the mechanisms of social control. In Discipline and Punishment, the differences between penal styles from one period to another were described (Foucault, 1977). As the severity of physical punishment lessened, a new system of controls emerged which functioned as oppressively as the previous system of physical abuse. Those new systems included the medical field, religion, psychology/psychiatry, and education (Foucault, 1975).

The care of self. Foucault's third analytic tool was care of the self. The individual uses the truths discovered through the process of genealogy and takes a moral stand. To Foucault the individual needed to demonstrate self-mastery and governance independent of the power structure around him/ her (O'Sullivan, 2010). Care of self then 
is how the individual self regulates in light of the knowledge gained from archaeology and genealogy.

\section{David Armstrong}

David Armstrong utilized a Foucauldian view of history. Armstrong (1984, 1987, \& 2002) employed Foucauldian Archeology to analyze cultural changes in perception in relation to and through an examination of the medical field. In particular he analyzed the discourse on death in medical texts to mine views on death held by the culture (1987). Armstrong (1987) examined themes related to death and concluded that changes in the representation of death within those themes represented changes in the wider culture.

Armstrong's view of Foucault was not singular; Petrone (2000) used a

Foucauldian methodology in a similar manner. In her work, "Life has Become more Joyous Comrades: Celebration in the Time of Stalin,” Petrone used themes to analyze a specific form of discourse, celebrations in the Stalinist Soviet Union. These themes represented categories of discourse that allowed Petrone to include and exclude any information she felt irrelevant to the individual themes. Her themes included gender, nationality, history, culture, and heroes (Petrone, 2000). Petrone asserted that this form of categorization was in line with the work of Foucault to allow for limits on the materials used in the discourse so that only what was fundamentally necessary was chosen (Petrone, 2000).

A post-structuralist history as proposed by Foucault and later Armstrong has not followed the traditional path of historical narrative. Traditionally, historical methodology has provided an account of the past. This changed in 1961 with Carr's book "What is 
History?” In it he argued the truths about the past found in history reveal a greater knowledge of the present (Carr, 1961).

Post-modern and post-structuralist theorists such as Foucault have combined the ideas of Carr with a subjectivist view of the world. Based upon this theory, history was invented not discovered (Foucault, 1972). The argument purported that no universal truth has existed (Foucault, 1972). Each individual has interpreted the events that occur and construct their own truth. These particular truths have tended to be similar within a society increasing in variation between cultures and over time. Ideas, taken as truth in one time frame or culture, may have been looked upon as false in another. The geocentric world gave way to the heliocentric one. Therefore to create history, the best prospect historians have is to organize select events into a pattern based upon the individuals own interpretive framework. Armstrong described his history of medicine in these subjectivist terms. "This story is only one that could emerge from these texts but its meaning is based on the final goal” (Armstrong, 2002, p.188).

Given that there are no universal truths, it is incumbent upon the author to ground an argument in a series of facts that defended the author's interpretation. These facts came in a variety of forms, to Foucault and Armstrong. The most revealing facts came from discourse within texts for their ability to be analyzed. The interpretive framework was then used to evaluate the discourse. Two things were important in Armstrong's poststructuralist analysis of the texts: the source of the text and the author's relationship to the text. The correlation of each to the historical narrative must be understood to have validated the author's interpretation. 
In historical writing this hierarchy has conventionally divided texts into primary and secondary sources. Armstrong (2002) only used primary sources, he described the secondary source as "either devised by someone removed from the original events, or another historian could then be used, in their turn, as the basis for further historical account.” (Armstrong, 2002, p. 189) Secondary sources have problematized the reading of an account because of the ability to criticize the source. This criticism related the material to the history the author has tried to create. The secondary source has been divorced from the author, and thus the author's perception cannot be criticized. The primary source has assessed the genuineness and proper significance of the event it describes (Elton, 2002). Howell and Prevenier (2001) referred to this assessment as determining the reliability of the source. The criticism of a source included seven elements of import: (a) the genealogy of the document (is the document the original or a copy?), (b) the genesis (where the document was produced), (c) the originality (the cultural ramifications surrounding the document), (d) the interpretation of the document (the subjective role of the document), (e) authorial authority, (f) competence of the observer, and (g) trustworthiness of the observer (Howell \& Prevenier, 2001). These seven elements led to a better understanding of the necessity for the use of primary over secondary sources.

Armstrong (2002) preferred the use of the primary source. The secondary source was not trustworthy. From the post-structuralist view, the secondary source guarantees that an interpretation has already been made. According to Armstrong (2002) "The primary source or original text represents the immutable bedrock that can always be visited again and again, retaining its constancy while yielding different subjective 
interpretations.” (p. 189). Too much interpretation on the part of the author has clouded the secondary source. A prime example from antiquity was the work of Tacitus. His Annals have been considered one of the best written histories of the origins of Rome, yet the reader must contend with Tacitus's motives for writing. Tacitus most embodied the seven elements of Howell and Prevenier. The majority of events chronicled by Tacitus, were not witnessed by him, making his work a secondary source. Tacitus’s sources have been inaccessible to the reader leaving him or her reliant upon Tacitus's interpretation of events (Miller, 1977; Overbeck, 1969; Stuart, 1940).

The use of primary sources eliminated certain aspects of author bias, yet this does not suggest that bias does not remain. History has necessitated the examination of the significance of the source material to ensure the reliability of the source. In the primary source, there has been a removal of interpretation of events. The primary source has separated the interpretation of the evidence from the evidence itself (Armstrong, 2002).

Armstrong (2002) argued that in order for the text to be brought to life the reader plays an important role in the interpretation of the text. "The act of reading in the present produces three possible histories: one is history as a story about the past; another is a story as constructed by a historian in the historian's present; and the third is an immediate history constructed at the moment of the reading” (p. 190). An analysis of primary sources is needed to keep each of these histories in mind. The secondary source falls prey to each of these histories twice making the secondary source less reliable. The primary source possesses the elements that make it intrinsically valuable. The primary source exists as the first distillation of the pre-textual world into the written word. Foucault (1973) claimed to juxtapose the present world with the events he was writing about, and 
thus created a history of modernity and its reactions to the past, not of actual past events. The primary source as discourse does not explain the "then" it describes, instead it has described the "then" in which it was written. This way of viewing source material makes all sources (even those most historians have considered a secondary source) to be viewed as primary sources. Armstrong agreed with this Foucauldian interpretation stating, "a text can be read in two ways: as a description of the past it professes to record... or as a refraction of the time it was written/published" (2002, p. 191). This second reading of a text Armstrong used when creating a historical analysis. Other authors inspired by Foucault have used this same definition. Harwood and Rasmussen (2007) used documents such as the third and fourth editions of the Diagnostic and Static Manual of the American Psychological Associations as their sources of data to describe attitudes towards sexuality and psychopathology at the time of their publications. Heller (2003) also supported this in his examination of historical research in music education. He suggested that researchers, in order to better understand the discipline, needed to use as data sources method books and music education textbooks as they contained the necessary discourse (Heller, 2003).

Armstrong's other major issue was the relationship between the author and the text. Because of the interpretive nature of the texts, there has been an immediate rectification with many of the issues related to text validity. By having read each text as a source of information on the time frame in which the source has been written, we can assume some truth in all texts (Armstrong, 2002).

Since the import of the text has been contingent upon the time frame in which the work was written, the organization of texts plays a central role in the understanding of the 
data. Conventional classification, such as by author or subject, as seen in a library, has limited the understanding of the temporal relationship of the works. Instead of a hierarchical layering, a non-hierarchical organization that has reordered all texts into a linear temporal formation has allowed for a reading of texts that was analogous to the fossil layer in sedimentary rocks (Armstrong, 2002). These layers have allowed for a comparison between time spans as the emergent patterns can be related to larger swaths of the historical record.

With this view of historical record, no agent has existed (Armstrong, 2002). No individual or group of individuals has driven the events of history. Instead truth, which Armstrong (2002) defined as the story of history, has been driven by the texts produced at that time. The texts have formed a prism through which events can be examined. This prism has revealed truth in the form of changing attitudes and opinions and can be compared to the truths of earlier and later texts. Man or woman no longer played the role of the actor; instead it was humankind that was constructed through the analysis of the written word. Because of this, Armstrong (2002) posited, the individual author was unimportant. The specific author has become peripheral. What the author says is unimportant; the interpretation made today about that written work, the subject matter, has become important. Thus technical writing became the center of Armstrong's historical endeavor. It reduces the person to the periphery and describes the nature and the changes in nature of humankind itself (Armstrong, 2002). This view was given credence by Robinson (1958), who stated that names, and thus can be extrapolated, individuals, obfuscate meaning, rather than add to it. 
The nature of a Foucauldian examination by way of Armstrong, of a subject, has mandated a narrative structure. How a narrative has been defined must be scrutinized in a post-structuralist framework. Therefore the rest of the review of literature will proceed with a narrative history of the Advanced Placement program to compliment the analysis to take place later.

\section{Overview of Advanced Placement}

The second section consists of a brief narrative history of AP and an overview of the current scope and structure of AP. Figure 1 gives a time line of important events in the history of AP to accompany the narrative.

\section{History of Advanced Placement}

AP began as a result of a number of educational experiments funded by the Ford Foundation. The first was a 1951 study sponsored by the Ford Foundation's Fund for the Achievement of Education. This study was conducted by three preparatory schools: Phillips Exeter Academy, Andover Academy, and The Lawrenceville School in conjunction with the universities into which students from these preparatory schools matriculated: Harvard, Yale, and Princeton. The study found replication in coursework between the preparatory schools and the freshman year curriculum for the universities (Rothschild, 1999). The General Education in Schools and Colleges Report to the foundation followed the study in 1953.

It recommended achievement examinations be given to high school seniors; success in these examinations would give either advanced standing or credit due to work completed in high school (Riccards, 2010). The study and follow-up report led to further 
funding by the Ford Foundation that created incentives and programs that would eliminate overlap in the high school and college curricula (Bowles, 1967).

Gordon Keith Chalmers, the President of Kenyon College received funding from the Ford Foundation in 1952 to study secondary education (Maier, 1957). Chalmers, with the assistance of the faculty at Kenyon College, began the School and College Study of Admissions with Advanced Standing under what became known as the Kenyon Plan. This goal of the plan was to improve secondary education locally in Ohio (Kenyon College, 2011). Under the plan eleven courses were to be taught in secondary schools by high school faculty and advanced standing at the collegiate level would be granted in those courses when an end-of-course test was passed. The Committee on Admission with Advanced Standing was created consisting of headmasters, principals, and school superintendents from 12 colleges and 12 high schools, including those involved in the 1951 study, to oversee the program (Riccards, 2010). Seven small secondary schools initially participated (College Board, 2011e). The first tests were administered at the end of the 1953-54 school year administered by Educational Testing Services (ETS), a private subsidiary of the non-profit College Entrance Examination Board (CEEB). 


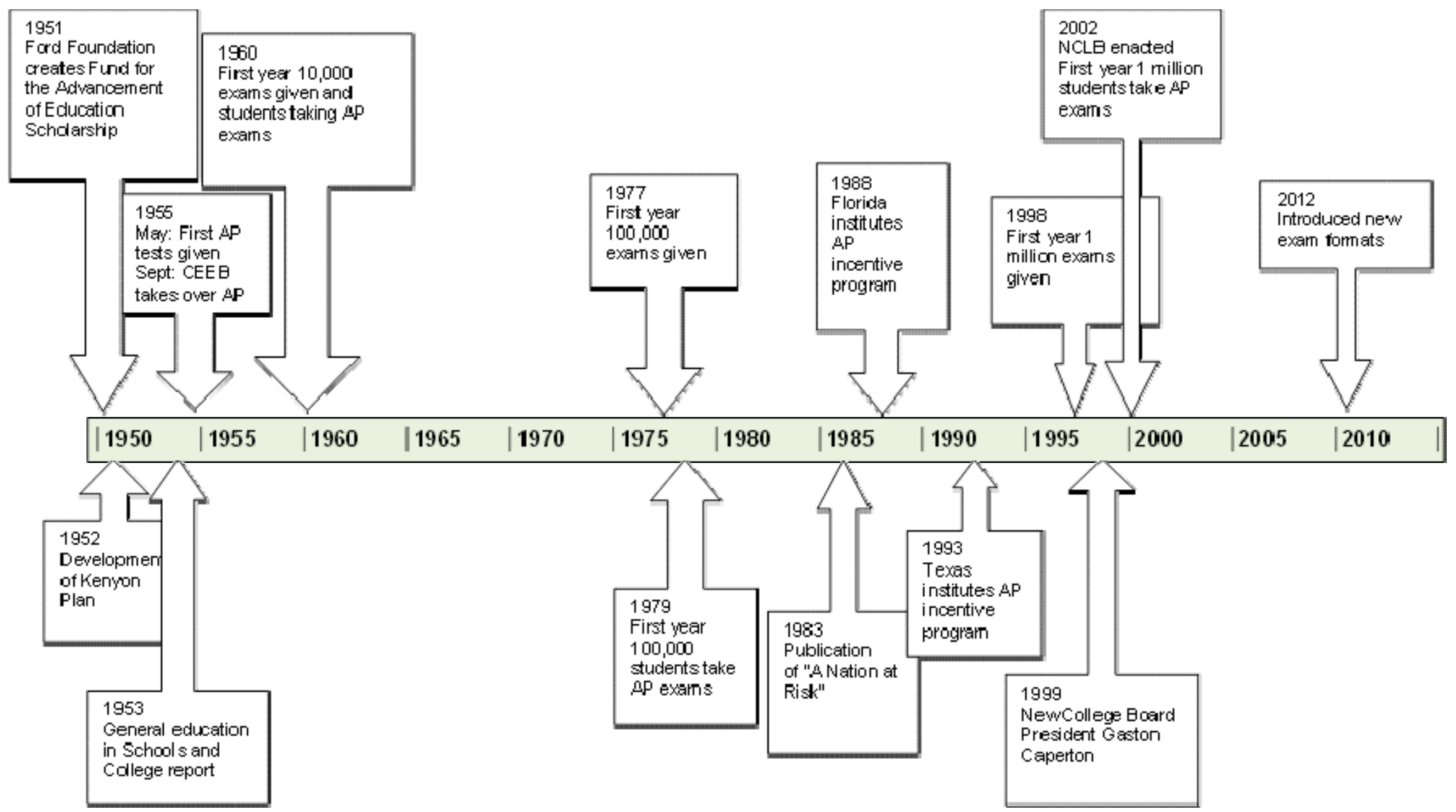

Figure 1. Advanced Placement timeline showing key historical program events. 
In September 1957, at the urging of the Ford Foundation, the CEEB took over administration of the program, newly termed Advanced Placement. ETS continued to create the tests for the program. The first exams with the official AP designation were administered at the end of the 1955-56 school year. That year 1,220 students took 2,129 tests at 104 participating schools (Federman \& Pachon, 2005). Tests were offered in 11 subjects: American History, Biology, Chemistry, English, French, German, Latin IV (Vergil), Latin V (prose, comedy, lyric), mathematics, physics, and Spanish. The following year an test in European History was added (Mollison, 2006).

Another experiment helped with the early adoption of the program. In 1951, the Ford Foundation's Fund for the Advancement of Education subsidized a scholarship program. The program granted talented high school sophomores from Midwestern public schools entry into the University of Chicago, Columbia University, the University of Wisconsin, or Yale University. This ensured two years of college before the students became eligible for the Korean War draft (Riccards, 2010). However, secondary school principals balked at the loss of their best and brightest students and the program was ended (Rothschild, 1999). This left school districts and universities throughout the Midwest looking for ways to implement accelerated courses in secondary schools. AP filled this void, helping to expand the program from New England to the Midwest.

Throughout the 1950s, AP continued as an experimental program and experienced immense growth. By 1958, participation had expanded to 356 schools with 3,800 students taking 6,800 examinations (CCCC, 1959). More importantly by 1958, 280 colleges and universities accepted AP scores for college credit. 
Despite this success the AP program was still small in the number of participating schools and colleges that accepted scores with little uniformity in acceptance standards. It was also still not profitable.

Throughout the 1960s the number of high schools that participated in the program as well as the number of colleges that accepted AP increased rapidly due to the work of the CEEB. In 1960, 890 secondary schools participated in the program and 567 Colleges accepted AP (College Board, 2013). By 1970 the number of secondary schools participating had increased to 3,186 and the number of colleges accepting AP increased to 1,386 . The initial assumption was that professional bodies would set the standards in which AP would test (Bowles, 1967). This did not occur. Professional organizations were indifferent to AP; therefore, the CEEB created its own standards (Riccards, 2010). For each test, the CEEB created a committee composed of both college professors and high school teachers to create standards.

The social climate of the late 60s and early 70s caused a near collapse of AP. The program was accused of excluding Black students and institutionalizing racism (Hochman, 1970). In 1973, the first positive proof of cheating occurred, and Free Response Question (FRQ) readers accused the program of inconsistency and leniency in grading (Vopat, 1981). Additionally, 1976 saw a drop in the number of exams given, and the number of students taking tests for the first time (Rothschild, 1999).

By the 1970s the program was well-established. It was no longer running deficits, and in some years made a profit. This new economic viability soon became one of the major sources for income for the CEEB. Success bred respect and expansion. The number of colleges and universities accepting AP and the number of secondary schools 
offering AP courses increased dramatically. The initial AP tests given in 1955 took place in 104 schools. In 1970, 3,186 secondary schools participated in AP. By 1980 an additional 1,764 high schools were participating (College Board, 2011f). The growth of acceptance at colleges and universities was as significant. By 1970, the number of colleges and universities accepting AP credits grew to 1,368. By 1980, 1,868 of the 3,231 degree-granting institutions in America were granting credits for passed AP tests (US Department of Education, National Center for Educational Statistics, 2011). These numbers provide proof of the program's reach and establishment in the American educational system. Growth of this sort continued through the 1980s, 90s and continues unabated today (College Board, 2011g).

The program's entrenchment in the national debate over education in politics began in 1983 with the publication of the Nation at Risk (NAR) report. The Report delivered to the Education Secretary gave a dismal account of American education. One of the NAR key findings was a need for more rigor in the American classroom (Gardener, Larsen, \& Baker, 1983). At the secondary level the only program in wide-spread use was the AP. As an established program, politicians and school boards turned to AP as a way to inject increased rigor into the curriculum. Numerous states incorporated AP into their educational plans leading to more rapid growth.

Legislation incorporating AP included funding to subsidize student costs for taking the tests and teacher training. Other programs enacted by legislatures included monetary incentives to pass AP tests for both teachers and students (Jackson, 2008). In 2002, the federal government passed "No Child Left Behind.” As part of the bill, the federal government began funding fee waivers for students receiving free and reduced 
lunch. The CB gives a \$22 fee waiver for all students on the federal free and reduced lunch fee program (College Board, 2011h). The federal government pays the remainder of the fee through the Advanced Placement Test Fee Reimbursement Program.

The turn of the century coincided with the appointment of new CB president Gaston Caperton who espoused a new program of equity for all. This shift in philosophy changed AP from a program of exclusion to one of inclusion. The CB reached out to low income and minority students in order to improve these groups' participation in the program. The number of schools offering AP increased as the students taking the courses swelled. The AP matched its growth rates of 5-7\% per year and has continued to do so even though over 1 million are taking AP tests in excess of 2 million tests per year since 2006. Putting these growth numbers in perspective, in 2008, 25\% of all high school graduates in America took an AP course (College Board, 2011i). This is up from 19\% in 2003, with growth predicted to continue.

Corresponding to the enormous gains in the number of students, scores on AP tests have declined. The percentage of tests receiving a 3 or higher decreased from $62 \%$ to 58\% between 2003 and 2008 (Finn \& Winkler, 2009). This corresponds to a drop in mean score from 2.96 to 2.85 (Finn \& Winkler, 2009).

Recent studies, along with a number of universities, have questioned the rigor of the program. Starting in 2012 the CB began rolling out a series of fundamental changes to the tests. These changes were designed to better align the courses with the demands of the modern college courses to which they equate (College Board, 2011j). The first changes took place with the World History and Biology courses, and will continue in every subject over the course of the next decade. 


\section{Current Advanced Placement Scope and Structure}

AP as courses and AP as a series of tests consist of different entities interrelated and necessitating each other for existence. The courses would not exist without the tests. Simultaneously, the tests would not have reached the size that they have today without the introduction of the AP course.

The AP Tests. As of 2011, the College Board offered 34 tests which cover a variety of subject areas corresponding to the potential courses a college freshman could take. These tests include Art History, Biology, Calculus AB and BC, Chemistry, Chinese Language and Culture, Comparative Government \& Politics, Computer Science A \& AB, English Language and Composition, English Literature \& Composition, Environmental Science, European History, French Language, German Language, Human Geography, Italian Language and Culture, Japanese Language and Culture, Latin: Vergil, Macroeconomics, Microeconomics, Music Theory, Physics B, Physics C: Mechanics, Physics C Electricity and Magnetism, Psychology, Russian Language and Culture, Spanish Language, Spanish Literature, Statistics, Studio Art (2-D, 3-D, \& Drawing), U.S. History, U.S. Government \& Politics, and World History (College Board, 2011k). Tests were previously offered in French Literature, Latin Literature, Computer Science A and Physics A.

The tests consist of a variety of components designed to gauge the college readiness of the students taking the test. The majority of the tests consist of a multiplechoice section and a FRQ. The exceptions are the three Studio Art tests in which the score is based solely upon a portfolio created by the students (College Board, 2011l). Certain tests also contain additional elements. The world language tests, AP's name for 
foreign languages, include a spoken component and the Music Theory test includes a sight reading section (College Board, 2011m).

Tests are administered during the first two weeks of May and are graded within the first two weeks of June each year. The creation and grading of the tests are done by ETS. The CB then releases student scores in the first week of July. The scores range from 1 through 5 , where 5 is the highest. The CB defines the grades as:

5 Extremely well qualified*

4 Well qualified*

3 Qualified*

2 Possibly qualified*

1 No recommendation**

*Qualified to receive college credit or advanced placement

**No recommendation to receive college credit or advanced placement

(College Board, 2011g)

The CB has also described their scoring as being the equivalent of letter grades in the corresponding college courses. "The composite score for each AP Exam is converted to a grade of 5, 4, 3, 2 or 1 . An AP Exam grade of 5 is equivalent to an A in the corresponding college course; a grade of 4 is equivalent to grades of A-, B+ and B; and a grade of 3 is equivalent to grades of B-, C+ and C.” (College Board, 2010g) Scores do not guarantee the test taker will earn college credit as individual colleges and universities determine how credit or placement will be awarded.

Performance on the test, not the course, earns students either college credit, exemption from an equivocal introductory course, or both. The decision is incumbent 
upon the institution as to what to award. The standard put forth by the CB is that $3 \mathrm{~s}, 4 \mathrm{~s}$, and 5s are considered passing and should receive college credit. Since this decision is left to the institutions this standard is not universally applied. Some schools will accept a 2 while others will accept no less than a 4. Other schools differentiate scores based upon the individual test and how it relates to the curriculum of the individual school. Harvard University, for example, has a complex system for the acceptance of Advanced Placement scores for credit. It distinguishes advanced standing from placement in courses. Scores of a 4 will result in the students being placed in a more advanced course than the usual introductory course. A score of 5 will count towards advanced standings and earn the student credit at the university if it is combined with enough other AP tests, all earning a 5, for the student to obtain sophomore standing (The President and Fellows of Harvard College, 2010).

Each test is created by a committee thus each test has unique characteristics. The tests vary in length with the shortest being the two Physics $C$ tests at 90 minutes and the longest being Calculus AB \& BC, Chemistry, English Language, and English Literature at 3 hours and 15 minutes. The number of questions varies within tests as well. The shortest multiple-choice test is Physics C with 35 questions and the longest is Art History with 115 . The FRQ vary greatly in number, length and expectations in answers. The Psychology test has two short responses directly to the questions being asked, the European History Exam has three full-length essays with specific formats based upon a separate rubric for each. The language tests such as Japanese Language and Culture have 13 responses that are in a variety of formats including short response questions and a variety of tasks the students perform (See Figure 2, AP Test Chart). 
A development committee consisting of high school and college faculty creates each test. The committees are composed of a chair from the university level and five additional members from either the university system or secondary schools.

Representation appears approximately equal between college and high schools with some committees having three university and two high school members while others have two university and three high school members. This equitable breakdown spans all 34 tests. In addition, each committee also has a chief reader charged with the grading of the FRQ sections.

The College Board's website describes the committee thusly: These dedicated educators play a critical role in the preparation of the Course Description and test. They represent diverse points of view and areas of expertise. As a group, they are the authority in their fields when it comes to making subjectmatter decisions in the exam-construction process. The AP Development Committees represent a unique collaboration between high school and college educators. (College Board, 2011n)

The committee members ensure the material on the test is representative of the curricula of an introductory college level course. Similarities between groups arise and the tests can be divided into five curricular groupings: arts, sciences, social sciences, language and mathematics. Each of these broad groups have similarities either in material, test construction or both material and test construction.

The arts. The arts consist of three Studio art tests: 2-D, 3-D, and Drawing, along with Art History, and Music Theory. The first three do not have a test component but instead have a portfolio that is judged to award credit. Art History and Music theory 
relate materially but do not use a portfolio. Instead, they have a test that is similar in nature to the Language tests. Both tests rely on the identification of sensory stimuli. In the art test students are asked questions about a picture they are presented with, while during the music test presents “aural stimulus test a student’s listening skill and knowledge about theory largely in the context of examples from actual literature.” (College Board, 20110)

The FRQs for the music test are in two forms. In one the student listens to a piece of music and is then asked to complete a task, such as writing the notation on a staff. The other is a sight-reading portion where the student is given a piece of music and asked to sing the proper notes into a recording device. This is similar to the language tests where the student is asked to record their spoken response to a question.

The FRQs for music are similar to the cultural questions on the language tests. “The questions are designed to address significant art historical problems, including contextual, stylistic, chronological, and patronage issues. Students must select and fully identify specific works of art as evidence in their essays.” (College Board 2010p). 


\begin{tabular}{|c|c|c|c|c|c|c|c|}
\hline Course & MC & MC time & MC Weighting & FRQ & FRQ time & \begin{tabular}{|l|} 
FRQ \\
weighting \\
\end{tabular} & Total time \\
\hline Art History & 115 & $60 \mathrm{~min}$ & $40 \%$ & 9 & $\begin{array}{ll}-2 & 30 \mathrm{~min}, \\
3-9 & 5-10 \mathrm{~min} \text { each } \\
\end{array}$ & $\begin{array}{l}1-2 \quad 25 \% \\
3-9 \\
\end{array}$ & \\
\hline Biology & 100 & $80 \mathrm{~min}$ & $60 \%$ & 4 & $\begin{array}{l}10 \text { min reading, } \\
90 \text { min writing } \\
\end{array}$ & $40 \%$ & $3 \mathrm{hrs}$ \\
\hline Calculus AB & 45 & $105 \min$ & $50 \%$ & 6 problems & $90 \mathrm{~min}$ & $50 \%$ & $3 \mathrm{hrs} 15 \mathrm{~min}$ \\
\hline Calculus BC & 45 & $105 \mathrm{~min}$ & $50 \%$ & 6 problems & $90 \mathrm{~min}$ & $50 \%$ & $3 \mathrm{hrs} 15 \mathrm{~min}$ \\
\hline Chemistry & 75 & 90 & $50 \%$ & 6 & $95 \min$ & $50 \%$ & $3 \mathrm{hrs} 5 \mathrm{~min}$ \\
\hline $\begin{array}{l}\text { Chinese Langauge and } \\
\text { Culture }\end{array}$ & 70 & $90 \mathrm{~min}$ & $50 \%$ & $\begin{array}{l}4 \text { tasks, } 9 \\
\text { questions }\end{array}$ & $45 \min$ & $50 \%$ & $\begin{array}{l}2 \mathrm{hrs} 15 \\
\min \end{array}$ \\
\hline Computer Science A & 40 & $75 \min$ & $50 \%$ & 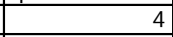 & $105 \mathrm{~min}$ & $50 \%$ & $3 \mathrm{hrs}$ \\
\hline $\begin{array}{l}\text { English langauge and } \\
\text { Composition }\end{array}$ & varies & $60 \mathrm{~min}$ & $45 \%$ & 5 & $\begin{array}{l}15 \text { min reading, } \\
120 \text { min writing }\end{array}$ & $55 \%$ & 3hrs $15 \mathrm{~min}$ \\
\hline $\begin{array}{l}\text { English Literature and } \\
\text { Composition }\end{array}$ & varies & $60 \min$ & $45 \%$ & 5 & $\begin{array}{l}15 \text { min reading, } \\
120 \text { min writing }\end{array}$ & $55 \%$ & $3 \mathrm{hrs} 15 \mathrm{~min}$ \\
\hline Environemntal Science & 100 & $90 \min$ & $60 \%$ & 4 & $90 \min$ & $40 \%$ & $3 \mathrm{hrs}$ \\
\hline European History & 80 & $55 \min$ & $50 \%$ & 3 & 130 & $50 \%$ & $3 \mathrm{hrs} 5 \mathrm{~min}$ \\
\hline French langauge & & & & & & & $2 \mathrm{hrs} 30 \mathrm{~min}$ \\
\hline German language & 60 & $\begin{array}{l}80 \text { min } \\
\text { approx }\end{array}$ & $45 \%$ & 33 & $70 \min$ & $55 \%$ & $2 \mathrm{hrs} 30 \mathrm{~min}$ \\
\hline $\begin{array}{l}\text { Government and politics: } \\
\text { Comparative }\end{array}$ & 55 & $45 \min$ & $50 \%$ & 5 & $100 \mathrm{~min}$ & $50 \%$ & $2 \mathrm{hrs} 25 \mathrm{~min}$ \\
\hline $\begin{array}{l}\text { Government and politics: } \\
\text { United States }\end{array}$ & 60 & $45 \mathrm{~min}$ & $50 \%$ & 4 & $100 \mathrm{~min}$ & $50 \%$ & $2 \mathrm{hrs} 25 \mathrm{~min}$ \\
\hline Human Geography & 75 & $60 \mathrm{~min}$ & $50 \%$ & 3 & $75 \mathrm{~min}$ & $50 \%$ & $2 \mathrm{hrs} 15 \mathrm{~min}$ \\
\hline $\begin{array}{l}\text { Japanese langauge and } \\
\text { Culture }\end{array}$ & 70 & $90 \min$ & $50 \%$ & $\begin{array}{l}4 \text { tasks, } 13 \\
\text { questions } \\
\end{array}$ & $45 \min$ & $50 \%$ & $2 \mathrm{hrs} 15 \mathrm{~min}$ \\
\hline Latin: Vergil & 50 & $60 \min$ & & 5 & $120 \mathrm{~min}$ & & $3 \mathrm{hrs}$ \\
\hline Macroeconomics & 60 & $70 \mathrm{~min}$ & $66 \%$ & 3 & \begin{tabular}{|l}
10 min reading, \\
50 min writing \\
\end{tabular} & $33 \%$ & $2 \mathrm{hrs} 10 \mathrm{~min}$ \\
\hline Microeconomics & 60 & $70 \min$ & $66 \%$ & 3 & $\begin{array}{l}10 \text { min reading, } \\
50 \text { min writing } \\
\end{array}$ & $33 \%$ & $2 \mathrm{hrs} 10 \mathrm{~min}$ \\
\hline Music Theory & 75 & & $45 \%$ & 7 & varies & $45 \%$ & \\
\hline Physics: B & 70 & $90 \min$ & $50 \%$ & 6 to 7 & $90 \min$ & $50 \%$ & $3 \mathrm{hrs}$ \\
\hline Physics: C Mechanics & 35 & $45 \mathrm{~min}$ & $50 \%$ & 3 & $45 \mathrm{~min}$ & $50 \%$ & $1 \mathrm{hr} 30 \mathrm{~min}$ \\
\hline $\begin{array}{l}\text { Physics: C electricity and } \\
\text { Magnetism }\end{array}$ & 35 & $45 \min$ & $50 \%$ & 3 & $45 \mathrm{~min}$ & $50 \%$ & $1 \mathrm{hr} 30 \mathrm{~min}$ \\
\hline Psychology & 100 & $70 \min$ & $66 \%$ & 2 & $50 \mathrm{~min}$ & $33 \%$ & $2 \mathrm{hrs}$ \\
\hline Spanish Language & 70 & $80 \mathrm{~min}$ & $50 \%$ & 8 to 9 & $85 \min$ & $50 \%$ & $\begin{array}{l}2 \mathrm{hrs} 45 \\
\min \end{array}$ \\
\hline Spanish Literature & 65 & $80 \min$ & $40 \%$ & 3 & $110 \mathrm{~min}$ & $60 \%$ & $3 \mathrm{hrs} 10 \mathrm{~min}$ \\
\hline Statistics & & $90 \min$ & $50 \%$ & 5 & $90 \min$ & $50 \%$ & $3 \mathrm{hrs}$ \\
\hline U.S. History & 80 & $55 \mathrm{~min}$ & $50 \%$ & 3 & $\begin{array}{l}15 \text { min reading, } \\
115 \text { min writing }\end{array}$ & $50 \%$ & $3 \mathrm{hrs} 5 \mathrm{~min}$ \\
\hline World history & 70 & $55 \mathrm{~min}$ & $50 \%$ & 3 & $\begin{array}{l}10 \text { min reading, } \\
120 \text { min writing }\end{array}$ & $50 \%$ & 3hrs $5 \mathrm{~min}$ \\
\hline Art 2D & Portfolio & Only & & & & & \\
\hline Art 3D & Portfolio & Only & & & & & \\
\hline Art Drawing & Portfolio & Only & & & & & \\
\hline
\end{tabular}

Figure 2. Overview of Advanced Placement tests and their construction.

The sciences. The sciences consist of Biology, Chemistry, Environmental

science, and the three physics tests. Each has a similar format emphasizing the individual

subject and the importance and use of the scientific method of investigation. Therefore

an important part of each of the science tests is the understanding of how a laboratory 
experiment is conducted. The course description of the Chemistry test's FRQs describes the laboratory component as follows:

Every Section II of the test will contain one quantitative question that is based on chemical equilibrium and one question that is based on laboratory. The laboratory question may Appear in Part A and be quantitative, or it may Appear in Part B and require little or no calculation. (College Board, 2010q)

The science tests consist of the longest and the shortest test available. With the exception of the two physics $C$ tests, the science tests are all greater than three hours in length. The lengths of the two Physics $\mathrm{C}$ tests are 90 minutes so that students can take them concurrently making them together 3 hours.

The social sciences. The Social Sciences tests are composed of World History, U.S. History, European History, Human Geography, Macro Economics, Micro Economics, Comparative Government and Politics, U.S. Government and Politics, and Psychology.

The Social Science tests tend to have the longer times and a large number of questions on the test's multiple-choice section. The FRQs tend to be essays that are highly stylized and reminiscent of those written in a history course in college. The tests are characterized by their usage of a historical method of inquiry. They also have a distinct order in which a student is expected to take the tests. This system of organization progressively moves the student though the historical process of inquiry. Recent changes to the World History test have been made to help achieve this organization. The World History test as originally intended was to be taken in the senior year as an alternative to the European History test. As time progressed statistics showed the majority of students 
taking World History were not seniors but instead sophomores. The new revisions change the FRQs so they are more in line with the skills learned before the US history test. The first test in the FRQ progression is Human Geography. The answers are not necessarily in essay form; instead, they are constructed in such a way that the students demonstrate necessary skills in historical analysis. The course guide describes the FRQs: In the free-response section of the AP Human Geography Exam, students are asked to answer three constructed-response questions. The questions may require students to synthesize different topical areas and to analyze and evaluate geographical concepts. Questions may be based on stimulus material such as verbal descriptions, maps, graphs, photographs, and diagrams. Students are expected to use their analytical and organizational skills to formulate answers in writing their responses. (College Board, 2011r)

Currently the World History test has three essays that address differing skills. The Document Based Question (DBQ) asks the student to address, analyze and synthesize into an argument between four and 10 primary source documents. The comparative essay asks the students to analyze reasons for similarities and differences between two cultures. Lastly the Continuity and Change Over Time (CCOT) essay asks the students to analyze and explain how time has altered a culture over a large span of time (College Board, 2011s). As noted before, US History is traditionally taken in the junior year. The DBQ is expanded. It tends to have more documents than the World History test and also asks the student to have an outside understanding of chronological periodization in American history. The second and third essays are referred to as standard 
essays. Unlike the World History essays where the task of the essay is known in advance, the standard essays of the U.S. History test require students to relate developments in different areas (e .g ., the political implications of an economic issue), to analyze common themes in different time periods (e .g ., the concept of national interest in U .S . foreign policy), or to compare individual or group experiences that reflect socioeconomic, ethnic, racial, or gender differences (e .g ., social mobility and cultural pluralism). (College Board, 2011t)

The European History test has the greatest number of documents to use between 10 and 12 . The subsequent essays are called thematic. The students are allowed to choose between alternative essays related to a certain theme or topic in history. Similar in nature to the essays in the U.S. History test, the students are expected to have knowledge of all possible thematic elements and then write on only those elements asked for in the question.

World languages. The World Languages tests consist of French, German, Spanish Language and Spanish Literature, Latin: Virgil, Japanese Language and Culture, Chinese Language and Culture, English Language and English Literature. The World Language tests, with the exception of the two English tests are composed of a variety of FRQs. They tend to consist of translations, responses to passages and spoken sections that are recorded for later analysis.

Mathematics. The mathematics grouping is the smallest composed of three tests, Calculus $\mathrm{AB}$ and $\mathrm{BC}$, Computer Science $\mathrm{A}$, and statistics. The tests are unique in that 
they are problem based. Yet the tests do not focus solely upon math problems. The College Board describes the Calculus test as follows:

Broad concepts and widely applicable methods are emphasized. The focus of the courses is neither manipulation nor memorization of an extensive taxonomy of functions, curves, theorems or problem types. Thus, although facility with manipulation and computational competence are important outcomes, they are not the core of these courses. (College Board, 2010a)

This includes the FRQ section where the students are asked to identify multiple answers and show all of their work on specific word problem.

To be eligible for partial credit, methods, reasoning and conclusions should be presented clearly. Answers without supporting work will usually not receive credit. Students should use complete sentences in responses that include explanations or justifications. (College Board, 2010a)

The AP Course. The CB governs the AP courses less stringently than the tests. The CB creates the curriculum outline and develops the course content by a committee of course developers composed of college faculty and AP teachers. These same individuals create the test; so that theoretically the course and test are aligned. An AP Course Description Guide accompanies each course so the classroom teacher can know the expected content of the test, and can plan the curriculum accordingly. Members of the course development committee create the guides. "The Course Description for each discipline outlines the course content, describes the curricular goals of the subject, and provides sample examination questions.” (College Board, 2011u) The College Board describes the AP classrooms as a place where "the focus is not on memorizing facts and 
figures. Instead you'll engage in intense discussions, solve problems collaboratively, and learn to write clearly and persuasively”. (College Board, 2010b) Beyond this description the management of how the material is presented is left up to the classroom teachers.

Although the teacher is given much latitude in the creation the course, the College Board mandates that all AP teachers and schools offering courses with the AP designation submit to a course audit. The audit is composed of two parts, the submission of a course syllabus by the course teacher and a course audit form.

The goal of the submission of the syllabus is to ensure the courses meet the rigor and cover the curriculum expected by the CB. The syllabi are submitted for inspection by a college professor associated with the CB. These individuals determine whether the syllabus meets the criteria for the course as determined by the course guide. If the course does not meet the criteria the syllabus is returned to the submitter for revision. Each returned syllabus contains a commentary that elucidates the deficiencies that led to the rejection. These deficiencies are linked to specific criteria to help the teacher revise the course and syllabus. Teachers are allowed two revisions for acceptance before the audit is rejected and the course is denied the AP label.

The audit form is designed to afford the AP teacher some of the academic freedoms of a college professor.

AP teachers are encouraged to develop or maintain their own curriculum that either includes or exceeds each of these expectations; such courses will be authorized to use the "AP" designation. Credit for the success of AP courses belongs to the individual schools and teachers that create powerful, locally designed AP curricula. (College Board, 2011v) 
The school district and the school assert through the audit form that courses with the AP designation have to adhere to the standards of the $\mathrm{CB}$ while creating a curriculum that is individualized to the needs of the individual schools.

The AP Program unequivocally supports the principle that each individual school must develop its own curriculum for courses labeled “AP.” Rather than mandating any one curriculum for AP courses, the AP Course Audit instead provides each AP teacher with a set of expectations that college and secondary school faculty nationwide have established for college-level courses. (College Board, 2011u)

\section{Summary}

This chapter provided the theoretical and conceptual background of historiography. In addition the chapter included background information on the AP Program that was necessary to conduct the study. The next chapter discusses the research method, design, and procedures for data collection and analysis. Results are presented in Chapter 4, and interpretation of findings and their implications are discussed in Chapter 5. 


\section{CHAPTER III}

\section{METHODS}

This chapter describes the data collection and analysis methodology utilized in this study. The study explored the history of the AP created by the CB. It used a historical methodology to investigate the origins, evolution and current state of the program. The historical methodology of the dissertation was guided by a Foucauldian post-structuralist model of exploration based upon a methodology created by David Armstrong. This chapter includes the study's research question, design, and procedures for data collection and analysis.

\section{Research Question}

This study addressed the research question:

What have been the changing conceptions of the Advanced Placement Program from its inception in1956 through 2012?

\section{Methodological Framework}

The methodology of the dissertation was based upon a theoretical progression. Each piece of the progression supported and built upon the other parts of the framework, to create a holistic historical methodology. The overarching theory was based upon a theory of educational history created by Wiersma (1969). A theoretical framework based upon the work of Michel Foucault then supported it (Foucault, 1975, 1977). The study uses what Foucault referred to as archaeology (Foucault, 1972) that Foucault considered as a method of inquiry. Because Foucault's descriptions of the methodology were vague, the study used as its methodology the work of David Armstrong (1984, 1987, 2002). Armstrong's interpretation of the archaeological process was the theoretical basis for the 
data gathering and analysis techniques in this study. Specific data gathering techniques as proposed by Black and Ubbes (2009) were used to support Armstrong's method of data gathering. The work of Braun and Clark (2006) was then used to create the analytical themes used in the analytical process created by Armstrong (2002). See Figure 3 for diagrams of the methodological framework.

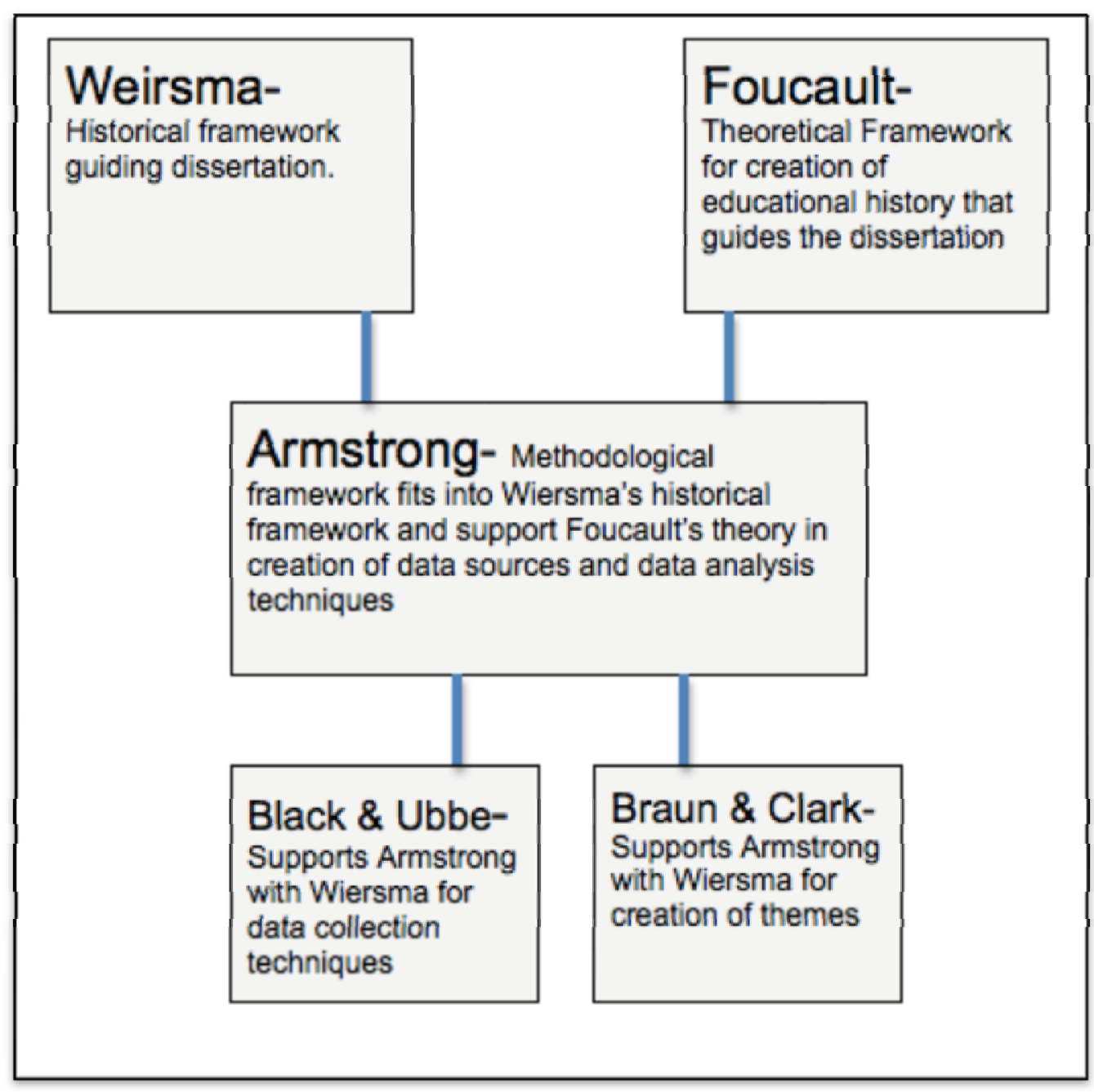

Figure 3. Methodological framework flow chart. 


\section{Research Design}

This study used a qualitative, descriptive analytic historical methodology to create an in-depth critical analysis and understanding of the origins and current state of the AP Program, placing it within the framework of the American education system. The study accomplished this through the examination of the constituent parts of the program, the tests, courses and professional development. Additionally the study examined the role of AP in the college application process. As with the work of Armstrong, the study used the archaeology method and focused upon the discourse related to the topic of choice. This study focused on the analysis of literature created in the study of the AP Program. In part through the analysis of the research that has been conducted on the AP program, this study created a history of the program that sought to define the role of the AP program within the educational landscape. Because of the use of Foucauldian archaeology, the scope of the study was not limited to academic writing. The nature of education as a social and political phenomenon also dictated the use of related texts (and thus placement) within said context (Foucault, 1966). The study used newspapers and government documents to broaden the scope of the study to ensure it fully encompassed the framework of American education.

The study used a historical framework to situate the AP Program within the larger landscape of American education. An historical approach was chosen because the goal of historical research is to give perspective (Black \& Abbess, 2009). Both Wiersma (1969) and Good (1966) in their definitions of historical research ascribed critical inquiry to the process of describing past events to create a perspective. 
(Kaestle, 1988) stated that there is no singular methodology that is history. Instead, it is a field of inquiry with an array of techniques. Within the field, certain common procedures exist that allow history to be a subject These common procedures can then be applied to any field of study when analyzing that field's, "origins, growth, theories, personalities, and crises” (Black \& Ubbes, 2009, p. 33). This historical inquiry can be applied to the field of education; therefore the procedures for creating an educational history as created by Wiersma (1969) were used as the guide for the inquiry.

Wiersma (1969) described historical research in education as being comprised of four interrelated steps: (a) collection of source material, (b) subjecting the material to critical evaluation, (c) synthesis of source material information, and (d) analysis and synthesis that draw final conclusions.

The remainder of this chapter describes the specific methodological steps that were taken in order to meet these four criteria for historical research.

This study emulated the historical methodology of David Armstrong with regards to how the data was handled and analyzed. Armstrong (2002) used a version of Foucault's archaeology. He used as data sources discourse related to the academic writing (connaissance) and the literature for the everyday individual (savoir). Armstrong (2002) was vague in regards to the nature of the data collection techniques. In order to strengthen the argument additional methodologies related to historical inquiry were used to augment Armstrong's methodology.

Armstrong's (2002) methodology required certain assumptions. First was that the analysis was undertaken through a narrative structure. Second, that the narrative required the creation of a history without actors or agents. Third, text and textual 
analysis were emphasized over authorship. Fourth, primary source materials were deliberately and exclusively used. Armstrong’s (2002) method aligned not only with Foucauldian philosophy, but also, with Wiersma's method of historical inquiry in education. The narrative process allowed for the synthesis and analysis of source material. The emphasis on primary source text over agency allowed for the collection and subjugation of source material to critical evaluation.

The narrative drew a vivid picture of "Mankind" and his attitudes (Armstrong, 2002) ${ }^{1}$. Armstrong explored humans though a historical account of subject matters closely associated with humankind and his social development including medicine and the perception of death. Armstrong looked at changes within his fields of exploration to find changes in perception in humankind. The changes he catalogued lead to themes to be explored

.This study used education as its narrative focus to explore education through the creation of a narrative of the AP program. The changes in perception that took place within the field of education were explored through the singular curricular lens of the AP program In this study, changes in perception of, and attitudes toward, education, led to the emergence of themes in the overall field. These themes present the prism though which to view particular times in history.

The analysis conducted by Armstrong (2002) compared texts from differing time frames. The differences were central to the narrative. They formed the narrative, thus

${ }^{1}$ The usage of the term Mankind has been retained to maintain consistency with the vocabulary specifically used by Armstrong in his work. It is believed by the author that Armstrong referred to humanity in general when using these terms and was not specifying only men. 
leading to Armstrong's second assumption that the individual was pushed to the periphery. The prism, instead, was the central actor. The author of the text was important only in the fact that he or she delivers the prism, the author being a reflection of the thoughts and ideas of the time of the writing; the author was merely an agent reflecting the prism and thus relatively unimportant. This led to Armstrong's third assumption; analysis of text leads to the central themes and creates the central figure in the narrative.

The fourth assumption related to the texts that were analyzed. For Armstrong's paradigm to be viable only primary sources were to be used. To Armstrong (2002), all texts could be viewed as primary sources and allows for a wider variety of textual sources to be examined. Each text gave the reader an understanding of the world as it existed at the time of publication. Hence, all texts spoke about the time frame in which the text was written. Although factual inaccuracies may have existed, the truth lies within the texts ability to reflect the time in which it was written.

The only exception to this way of viewing was a text from the present. Current writing could not be looked upon as a reflection since the prism has yet to be formed. An era must no longer occur in order for the prism to be created, as the prism has been our current way of looking at the era in question. The prisms through which the past was viewed can be compared to works from the present to construct a view of a subject matter as it transitions and changes through time (Gothill \& Armstrong, 1999). This last assumption was why Armstrong used a Foucauldian framework. Multiple current views may have led to a variety of prisms though which an infinite number of reflections may have taken place in which a comparison to the present can take place; thus necessitating the strict focus on narrative and a subject matter over an individual in the analysis. 
Armstrong's paradigm for historical research met the definition set forth by Wiersma (1969) as historical educational research. However, his specific methodology for data collection and data analysis lacked description to allow for exact replication. Because of the limited account of methodological procedures in data gathering and thematic coding in Armstrong's work, this study used additional works to supplement the missing methodological specificity. The first phase of data collection used Black and Ubbes (2009). The second and third phases were based upon a system of coding themes for analysis based upon Braun and Clarke (2006). The fourth phase of synthesis, analysis and final interpretation returned to Armstrong's work.

\section{Data Collection Procedures}

Data for this study came from three sources: academic journals, newspapers and government documents. All data was sourced using search engines. For academic journals these were ERIC, PsychINFO, Wilson Web, JSTOR and ISI Web of Knowledge. where abstracts were queried using the keywords "Advanced Placement" and “College Board.” Searches of American newspaper articles used Google News Archive, LexisNexis, News, and Proquest Newspapers. For government documents, the search engines used were LexisNexis, Government Documents, and Proquest, Congressional. Key word queries for "Advanced Placement” and "College Board” were used for both the newspaper and government document searches. The searches for all document types were limited to articles published in the English language from the founding of the AP program in 1957 to the present.

Data for this study was gathered based upon the method used by Black and Ubbes (2009) in their study of conference themes related to professional health education 
associations. The creation of themes was integral to Armstrong's procedures, yet he provided no description of his methods. Thus Bald and Ubbes' method of management of data for later use with thematic analysis was chosen. All data was presented in tables, and organized within chronologically. The tables were used to organize the data for analysis and formation of themes, which conformed to the Wiersma's first step of historical research. An example of a table with sample data chronologically organized is shown in Figure 4.

\section{Data Analysis}

Wiersma's second and third phases of historical research procedures were centered on the thematic analysis of data. In this study, analytic procedures were based upon the methodology used by Braun and Clarke. Thematic analysis has often been considered to be a method of research itself (Boyatzis, 1998; Glaser, 1965; Glaser \& Strauss, 1967; Grove, 1988; Lincoln \& Guba, 1985; Ryan \& Bernard, 2000). Braun and Clarke (2006) agreed that it can be viewed as a methodology, and also that it could be a tool used within another methodology. They noted in their study that discourse analysis, in which the critical discourse analysis of Foucault is a subset, was a form of thematic analysis that looked for themes and patterns across a data set (Braun and Clarke's methodology was viable for this study). 


\begin{tabular}{|c|c|c|c|}
\hline Title & Author & Type & Year \\
\hline $\begin{array}{c}\text { A Successful Advanced Placement } \\
\text { Program in Mathematics }\end{array}$ & $\begin{array}{c}\text { Frank R. Peters \& } \\
\text { Leslie H. Miller }\end{array}$ & journal & 1959 \\
\hline $\begin{array}{c}\text { Implications of the Advanced } \\
\text { Placement Program }\end{array}$ & No Author & journal & 1959 \\
\hline $\begin{array}{c}\text { German Advanced Placement under } \\
\text { the College Board: Promising Signs }\end{array}$ & Reichard, Joseph. R. & journal & 1960 \\
\hline $\begin{array}{c}\text { The Advanced Placement Program: } \\
\text { Advantages and Cautions }\end{array}$ & Saur, Edwin H. & journal & 1960 \\
\hline $\begin{array}{c}\text { English Composition in the Advanced } \\
\text { Placement program }\end{array}$ & Smith, Eugene H. & journal & 1965 \\
\hline $\begin{array}{c}\text { Advanced Placement and the } \\
\text { Secondary School Curriculum }\end{array}$ & Stephens, Wade C. & journal & 1965 \\
\hline $\begin{array}{c}\text { An Unanswered Question about the } \\
\text { Advanced Placement Program: Do } \\
\text { the Examination Questions Predict } \\
\text { Grades? }\end{array}$ & Bergeson, John B & journal & 1968 \\
\hline $\begin{array}{c}\text { An Advanced Placement Student } \\
\text { Explicates "Fleas" }\end{array}$ & Steensma, Robert C. & journal & 1968 \\
\hline $\begin{array}{c}\text { Advanced Placement: Can it Change } \\
\text { with the Times? }\end{array}$ & Hochman, William & Journal & 1970 \\
\hline
\end{tabular}

Figure 4. Sample Data Table used to organize data chronologically

Braun and Clarke (2006) used four terms (data corpus, data set, data item, and data extract) to describe data. Braun and Clark’s definitions of data descriptors were necessary to understand their methodology. The data corpus encompassed all of the data collected for a research project. A data set contained all of the data from the corpus that was used for a particular analysis (Braun \& Clarke, 2006). The data analysis could have been within a research project or an overall research project. A data item consisted of the individual piece of data collected. All of the data together made up the data set or data corpus. The data extract was a specific chunk of coded data taken from a data item (Braun \& Clarke, 2006, see figure 5). 


\section{Step 1: familiarization with data}

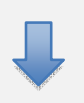

Step 2: generating initial codes

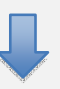

Step 3: searching for themes

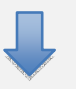

Step 4: reviewing themes

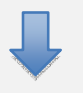

Step 5: defining and naming themes

\section{Step 6: producing a report}

Figure 5. Braun \& Clark’s Six Phase Process for Thematic Analysis

The thematic analysis of data was conducted using the six-phase process of thematic analysis created by Braun and Clarke (2006). Phase one consisted of becoming familiar with the data, $\mathrm{r}$ the reading and rereading of data and the creation of initial notes to facilitate coding in subsequent phases. The successive readings and creation of meaning based upon continual reading was supported by Heyman (1983) who stated, "the 
relationship between meaning and context is indexical and reflexive” (p.430). Meaning was created through the successive reading and assignment to categories and aligned with other documents creating a view of the past. Additionally, a post-modern reading was a “distinctive mode of reading and interpretation of textual data” (Opie, 1992, p.59). According to Leonardo (2004) the successive rereading also allowed the researcher, through focusing on nonconventional interpretations of the text, to question, deconstruct and then reconstruct the data into a form consistent with the goals of the research and the theoretical framework.

The second phase consisted of generating initial codes, and the creation of preliminary thematic codes. Grove (1988) stated that this process tends to be done with tacit understanding of the material. This study did not begin with a priori assumptions. The research examined the data for themes relating to a postiori assumptions related to the theoretical framework of Foucauldian discourse analysis. All data was worked through systematically and chronologically, identifying aspects related to underlying repeated patterns across the data set related to power/knowledge issues. Data items were explored for themes and Foucauldian ideology guided the creation of broad themes that emerged from the data set. This process conformed to a Foucauldian historical analytic method used by numerous researchers including Petrone (2000) and Armstrong (2002). As themes emerged, data extracts were coded and collated with similar codes. Consequently themes were created through the conjunction of data and background (Black \& Ubbes, 2009; Ryan \& Bernard, 2000).

The third phase required searching and identifying themes through a broad analysis of the complete collated data This was accomplished through the creation of 
thematic maps. Any data that did not seem to fit into emerging themes were placed into a miscellaneous category for further examination or placement in later phases (Braun \& Clarke, 2009; Grove, 1988).

The fourth phase consisted of reviewing themes, reducing candidate themes, rejecting those themes with not enough data, merging similar themes or separating broad themes into separate themes so that data within the themes coheres meaningfully. This took place at two levels. The first level was at that of the data extract to enable coherence in the pattern. The second was at the level of the data set so that the themes reflect the meaning related to the entire data set and are relevant to the theoretical framework (Braun \& Clarke, 2009).

The fifth phase defined and named the themes, and finalized the theme creation process. Once the data was mapped, each individual theme was refined and defined. At the end of this process each theme had to be capable of telling an individual story that fell within the narrative of the research question (Braun \& Clarke, 2009). Additionally each data extract and item was checked against the definitions of the theme for ambiguity, overlap and relationship (Grove, 1988).

The sixth phase produced a report, telling the story of the data through the final analysis. This integrated with the fourth step of Wiersma (1969) and was where the study returned to Armstrong's analytical methodology for guidelines. The final analysis of data was based upon thematic association. Those associations were explored based upon time frames to maintain the narrative structure. Thus themes were analyzed in relationship to major shifts in perception around specific historical points (Armstrong, 1984, p. 743). 
Braun and Clark’s process for thematic analysis has been used by a variety of researchers in multiple fields of study since its inception. Yardley, McDermont, Pisarski, Duchaine, and Nakayama (2008) used Braun and Clark’s thematic analysis process to analyze data from semi-structured telephone interviews. From their coding of the interview material, Yardley et al. created two topical themes for analysis on the perspective of individuals with prosopagnosia, an inability to recognize faces (see Appendix A). Sridawruang, Ryding, and Pfeil (2010) used Braun and Clark’s method to assess attitudes towards premarital sex in rural Thailand. Their methodology describes the first five phases of analysis as applied to data gathered from focus groups (see Appendix B). Day, Thorn and Kapoor (2011) use Braun and Clark’s method to analyze the efficacy of pain management programs in rural Alabama. Their work describes the phases and gives samples of a data mapping (see Appendix C).

The data analysis procedures described above are what Peräkylä (2003) referred to as the "informal approach." "By reading and rereading their empirical materials, they [the researchers] try to pin down their key themes and thereby, to draw a picture of the presuppositions and meanings that constitute the cultural world of which the textual material is a specimen” (p. 353). Though informal, the methodology consisted of mechanisms to guide and give direction to the research. The research had to "contrive strategies that balance technical refinement with theoretical subtlety, always tempered by recognition of the serviceability of even approximate answers” (Anderson, 1961, p.1). In this way Armstrong's analysis can be viewed as an attempted to emulate the methodologies for comparative educational analysis as stated by Anderson. 
Armstrong achieved his analysis through strict control mechanisms of his methodology. The first was chronology. This allowed for text to be examined as a reflection of the time in which the text was written (Armstrong, 1987). The adherence to chronology also allowed for the researcher to interrogate texts for differences that show major shifts in perception (Armstrong, 1984). These shifts in perception allowed for Foucauldian themes to emerge (Gotthill \& Armstrong, 1999). Through rereading of the texts, the themes guided the analysis to an understanding of origins, nature and context of the research subject in relation to society and the broader field in which it is entrenched (Armstrong, 1989).

The other control mechanism Armstrong used was a restriction in source material. Armstrong's interest lay in medical history; therefore he restricted his source material to the general practice materials of the medical field. With this limitation, the texts and practices of medicine could have been seen as inseparable (Peräkylä, 2003, p. 355). The link between text and practice played an important role in reading a text as part of the discourse. When text and practice were united the author's relationship became muted. Instead of looking at the text as the work of an author recording events, the text was looked at as a part of the discourse reflecting the attitudes of the time in which it was written (Armstrong, 2002). This freed the research from concerns over whether the original materials conclusions were correct or not. Instead, the text created the prism through which individuals can view a previous time frame. Even the Foucauldian framework in which this work was based is a modern equivalent that reflects current concerns through a lens that was meant to shed light on the intellectual movement of the 1960s. It allowed for the deviations from Foucault made by Armstrong. Butin (2006) 
agreed with Armstrong for the need to rework Foucault. Through the divorcing of theory from practice, authors have been able to embrace Foucault for his theoretical insight while having integrated it into their own purpose and thus distinct from Foucauldian methodology.

\section{Summary}

In this chapter the methodological framework was explained. The theoretical progression of the literature review was integrated into specific steps based upon the work of Armstrong, Black and Ubbes (2009), and Braun and Clark (2006). Data collection, management and analytical procedures were described. Chapter 4 presents the findings, and Chapter 5 concludes with discussion, implications, and suggestions for further research. 


\section{CHAPTER IV}

\section{FINDINGS}

This chapter presents the findings of the Foucauldian critical analysis. These findings answer the question: What have been the changing conceptions of the Advanced Placement Program from its inception in1956 through 2012? Discourse related to the subject of the AP program was the data analyzed for themes. The data consisted of academic journal articles, newspaper articles, and public policy documents. The data was analyzed inductively using a hybrid method based upon Black and Ubbes’ (2009) data gathering method and Braun and Clark’s (2006) thematic analysis. The data corpus consisted of 1135 documents with 641 documents derived from journal articles, 412 documents derived from newspaper articles and 82 documents derived from government documents. The data was organized into data tables, a sample of which is presented in Appendix D. This led to a final data set of 312 items that yielded 417 data extracts. The data was then coded and analyzed using Foucauldian methodology which revealed three major themes. Once the themes were revealed the data content was reviewed and the themes were named and organized.

Foucault can be interpreted in a variety of different ways. Yet methodologically there are similarities that run throughout all works ascribed as Foucauldian. These arise from Foucault’s ill-defined methods of critical analysis termed archeology and genealogy. In both cases the analytical method focuses on the power relationships stemming from the control of knowledge in society. This is achieved through an analysis of the various forms of discourse created within that society. Foucault (1969) believed that a society's discourse was not an exact replication of the society, but instead became a 
culturally constructed replication of the society. Because the discourse is a cultural construct, it reproduces the power and knowledge dynamics that exist within any given society.

Foucauldian methodology entails the analysis of the discourse within a time period. Discourse changes over time. Foucault's methods analyze these changes. The methods utilize historically significant events termed "ruptures.” These ruptures constitute a change in the institutional relationships in society (Miewski, 2010). Foucault (1969) himself used ruptures to examine changes in the discourse that would account for changes in societal ideology. Thus Foucauldian analysis examines the social beliefs of the time. The analysis of ideology of an era defined by a rupture occurred when Foucault compared the discourse of that time to the discourse from previous and subsequent eras. These social beliefs are infused with the power and knowledge dynamics of the time in which the analysis attempts to discover. The ruptures sparked different ways of thinking which are demonstrable through a comparative analysis of the change in discourse.

Three historical events sparked ruptures in discourse related to the AP program. The historical events were: (a) the launch of Sputnik in 1957 (82 item data set); (b) the publication of “A Nation at Risk: The Imperative for Educational Reform” (NAR) in 1983 (88 item data set); and, (c) the passage of the No Child Left Behind Act of 2001 (NCLB: 172 item data set). Three themes emerged: (a) AP as an educational reform for the elite student (84 data extracts); (b) the shift from a placement test to the preparatory course (92 data extracts); and, (c) a widening of access to AP (241 data extracts). Each theme manifested itself after the occurrence of each rupture and yielded subthemes. In addition to the analysis of themes and subthemes that emerged from the discourse shown 
in Figure 6, this chapter will include historical contextualization of each rupture and analysis of the discourse of the timeframe following each rupture.

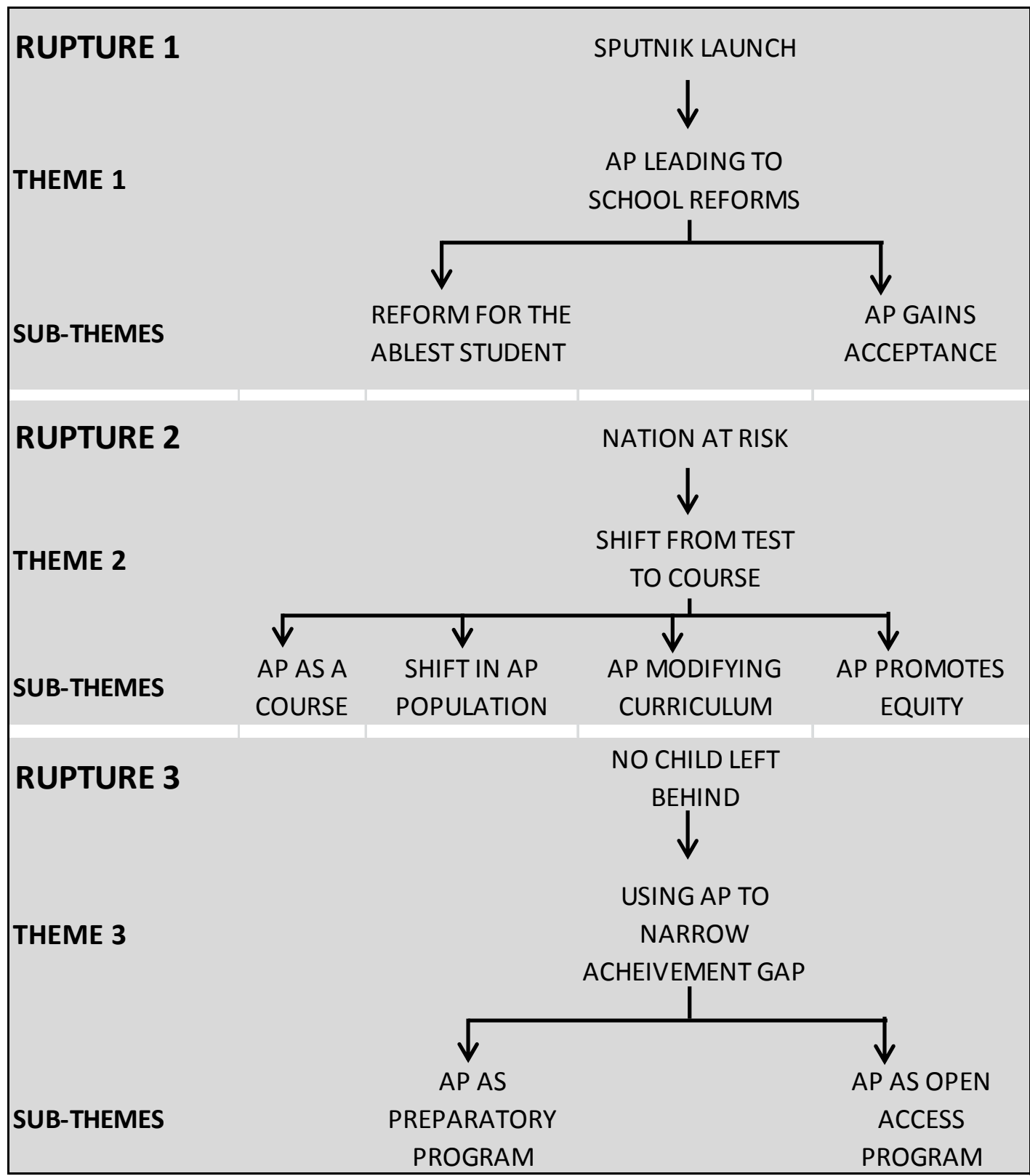

Figure 6. Ruptures and Themes in AP discourse

\section{Rupture 1: The Sputnik Launch}

During the 40s and 50s, the burden of knowledge and the power that accompanied such knowledge lay in the hands of a group of educated elites who had attended 
America’s premier colleges and universities. However the Soviet Union’s successful launch of the Sputnik satellite in 1957 changed the focus of American education (Powell, 2007) and led to the enactment of the National Defense of Education Act (NDEA) of 1958 which funded and shaped the educational system.

The late 40s and early 50s had seen a large boom in the college-going population. Before World War II, fewer than 2 in 10 high school graduates attended college (Kinzie et.al., 2004). By the early 1950s, when AP was in its experimental phase that number had swelled to 1 in 2 high school graduates attending college (Kinzie et.al, 2004). The Servicemen's Readjustment Act of 1944, known as the GI Bill, began to open up the university system of the nation, and changed the national perception of the value of a college education (Clark, 1998); In addition, the results of the Brown v Board of Education decision in 1956 increased college access for African Americans. Before the Brown decision, $90 \%$ of all African Americans who attended college went to “Historically Black Institutions” (Rochback \& Murty, 1993) After Brown, formerly segregated White universities became an option for Black students (Kinzie et.al, 2004).

The Soviet Union’s successful launch of the Sputnik satellite in 1957 symbolized a turning point in the overall American consciousness, not just education. "For the public, it symbolized a threat to American security, to our superiority in science and technology, and to our progress and political freedom” (Bybee, 1997, p. 1). The reaction to Sputnik was a criticism of (and a desire to reform) education that until that rupture largely remained pedagogical. The NDEA was the first comprehensive federal legislation directed at education (U.S. Department of Education, 2012). The act called for the improvement of elementary and secondary science, mathematics, and modern foreign 
language curricula, yet its greatest impact was at the collegiate level where the act supported student loans for college and graduate fellowships. The AP program, having been created by educational reformers just before the launch of Sputnik, benefitted by the ensuing societal emphasis on education for the elite..

\section{Theme 1: Role of AP Leading to School Reform}

The theme that emerged from the discourse published around the Sputnik launch was that of using the AP program to lead to school reform. Within this theme two subthemes emerged. The first subtheme related to the target population of the AP program, it being a reform program created for what the discourse referred to as the elite or "ablest" of student. The second subtheme to emerge was the push for acceptance of the AP reform program generally into the existing educational landscape, and so facilitating acceptance in the form of growth and continuance of the AP program in general.

According to the discourse, AP was viewed as beneficial to both the "ablest" student and as a whole school reform.

The Central Committee took the position that American education could be substantially improved by strengthening the secondary schools and that this could best be done by offering the schools an opportunity to qualify their ablest graduates for advanced placement in college. (Cornog, 1957, p. 50)

Jean Fair from Evanston Township high school stated "the work with the gifted has probably stimulated interest in providing better for low-ability students.” (Fair, 1958, p. 46). Wade Stephens suggested:

Perhaps the greatest benefit of A.P. is the electrifying influence it has on the teachers and schools entering the program. A little leaven is a dangerous thing; 
one or two A.P. courses may shake a department or a school into rethinking much of what they do, not only with the seniors, but with the lower grades as well. (Stephens, 1965, p. 134)

Edwin Douglas in his description of the program claimed that the AP mathematics "unquestionably led to a move to re-examine our secondary school mathematics curriculum" (1959, p. 95). Keller described the program as having "affected curricular thinking, course planning, articulation, of work done in school and college communication between schools and colleges particularly at the teacher level, and the intellectual tone in schools and colleges” (1958, p. 7). This idea of wholesale school reform due to the presence of the AP program would be touted again in the following decades. In 1975, Jones used almost identical wording when describing the intellectual tonality the AP program catalyzes in a school. "Not only are teachers and students directly enrolled in the Program affected, but the intellectual tone carries over to the rest of the school as well.” (1975, p. 66) In a more physical nature, Jones argued, the AP program also improved the school by adding to the school library more mature and difficult work that can be accessed by the entire populace. He also argued for a change in teaching method that accompanies AP spreading to the rest of the faculty (1975).

\section{Subtheme 1.1: AP as Reform for the Ablest Student}

In the context of the Cold War and within it the launch of Sputnik, the nation needed to focus on improving education. The most talented and gifted students became of the highest political importance. Even prior to the launch of Sputnik some of these ideas were coming into focus. Clarence Faust (1957), the vice president of the Ford Foundation and President of the Fund for the Advancement of Education wrote: 
There are two major sources of our newly aroused interest in adequate educational provisions for the gifted. One of these is an awareness of certain urgent needs of our society in these troubled times. The other is a clearer sense of meaning and responsibility of democratic education with respect to the development of individual capacity. (Faust, 1957, p. 12)

Sputnik then acted as a catalyst for change. Engelstein and Miller (1958) echoed Faust. “America’s security and future rests, to a great extent, upon the best development of the potentials of scholarship, creativity, and leadership in our young people.” (p.32). Austin (1958) added to the discourse that AP was instituted to increase college entrance rates, one of the goals of the NDEA. The AP program challenged students with the curriculum they and the nation needed for college while still in attendance in secondary schools.

In 1958, the National Association of Secondary School Principals published a special edition of their journal dedicated to the nascent AP program. The discourse derived from this issue highlights the initial view of AP as a program for elite students. On the very first page of the journal, a description of the AP by College Board's AP Director David A. Dudley noted that the program was created with the philosophical underpinning "that all students are not created equal” (Dudley, 1958, p.1). Dudley went on to say that advanced students need special accommodations in the same way that slow students do. Opportunity needs to be accorded based upon capability and ambition. The most elite and capable students need to be given the knowledge commensurate with their intellectual advantages. This view is repeated throughout the journal issue. Fair (1958) describes Evanston Township High School, one of the original AP pilot schools, in terms 
of the parents of the student body. "The parents of most of our students have had almost two years of college. A large percentage holds degrees and a good number have done advanced work.” (p. 39) Another public school early to adopt AP, Senn High School in Atlanta Georgia, had $80 \%$ of its students attend colleges before the advent of AP (Engelstein \& Miller, 1958). This was in a time when less than $10 \%$ of America's high school students graduated from college. These descriptions were indicative of the students at most of the early adopting schools, both public and private.

The issue also published a list of the colleges that accepted AP credits for placement, credit or both. Most of the approximately 375 schools were small private institutions. While the list showed AP trying to gain a foothold of acceptance in the American university system, the list also demonstrates the elite nature of the schools that first accepted AP credits. In a time when few students were attending private colleges, small private liberal arts colleges were the majority of the schools accepting AP test scores.

The first three schools in Florida to accept AP credits were Stetson University, named after hat manufacturer John B. Stetson, Barry College (now University), a small Catholic college in Miami and Rollins College, a small liberal arts school modeled after those in the Northeastern United States. All of the students who took an AP test and received credit in the 1958-1959 school year in the state of Florida attended small selective institutions. Generally the articles in the journal issue described the selection of the most able and ambitious students who were selected because of their high scores on tests, grades in classes and sometimes interviews with school personnel (Austin, 1958; Engelstein \& Miller, 1958; Fair, 1958; Keller, 1958). 
The discourse created by the College Board in these early years mirrored exceptionalist beliefs tied to the AP course and test. The College Board published its journal The College Board Review to promote the idea that the student who takes AP was an exceptional student. Casserly (1968b) interviewed former AP students. She states "Selection procedures into AP courses, even for pupils on the fast track, seemed unnecessarily stringent and therefore tended to deny access to AP classes to many students who my respondents felt qualified to enter them." She continues "across the board tracking had led in some cases... to the establishment of a social as well as intellectual elite” (p. 21).

This was exhibited through the requirements for admission into many public schools’ AP programs. Monroe High School in New York state required, "high rating on tests of intellectual aptitude and of reading comprehension, superior achievement in each of the basic academic subjects, the expressed desire of the student, and the approval of his parents” (Burnside, 1958, p. 27).

Senn High School in Chicago utilized teacher interviews of prospective students along with teacher recommendations. The school also examined pupils' "past records, particularly in the language arts, and scores on psychological and reading tests” (Engelstein and Miller, 1958, p. 34) Memorial High School in Pelham, NY began tracking students in middle school based on IQ scores, aptitude tests and teacher recommendations. Students were then placed in special classes in preparation for the AP courses and monitored for progress (Whipple, 1958). Only the demonstrably exceptional students gained access to the AP program at these public institutions. The AP program 
served as a way to differentiate even more these already privileged students from their peers.

Education in the 1950s was by ability grouping. The belief was that each group needed separate curricula in order to reach their full potential. Bish (1958) states this belief, "The crux of the matter is that there is nothing so unequal as the equal treatment of unequals.” (p. 16). Burnside (1958) reaffirms the idea stating his school "operates under a democratic ideal of equal, though not identical, educational opportunity for all” (p. 27). The division was not just between exceptional and average. The able students were divided as well. “The exceptionally bright pupils are divided into two groups-those whose major potential capacity fall within the area of mathematics and science and those whose major potential capacity and interest fall within the area of language-arts” (Bernstein, 1958, p. 22).

William Cornog led The Committee on Admission with Advanced Standing that led to the AP Program. Cornog's writing demonstrated for whom the AP reform was intended.

The study was designed to revise the content and teachings in secondary schools in order to make more adequate provision for the education of very able boys and girls than even the best schools had, even in their 'honors' courses, devised. (Cornog, 1957, p.49)

The discourse he produced included three basic assumptions in which the program was founded upon,

(1) that for the able student the American system wastes time, (2) that the best place for a school-age boy or girl is school, and (3) that the best teachers of 
adolescent boys and girls are to be found in the secondary schools. (Cornog, 1957, p. 50)

Cornog's ideas predated the launch of Sputnik and matched the prevailing attitude of a post Sputnik America and can be seen in an excerpt from the writing of Faust. "Adequate provision for the education of exceptional talents is important, quite apart from its value in producing creative leadership in society, in that it provides for the fullest flowering of the individuals who compose the society” (1957, p. 13).

The discourse exhibited a necessity for educational programs aimed at the exceptional talent in order to maintain unequal status quo. The AP program was a reform aimed at what society deemed the upper echelon student. The General Education in School and College committee report stated "we have been particularly concerned about the superior student” (quoted in Rothschild, 1999, p.177).

In the discourse the privileged students at elite schools were referred to as the ablest student or other similar terms. Evanston Township High School in Evanston, IL, became an AP pilot school to provide "for its very able students" (Fair, 1958, p. 39). Bernstein (1958) described the AP program at Midwood High School, in Brooklyn, NY, as being for "the exceptionally bright pupils" (p. 22). Memorial High school in Pelham, NY, instituted AP for "stimulation of superior students in order to induce them to use their talents to the utmost.” (Whipple, 1958, p.24). Senn High School in Chicago, IL, instituted the AP program for the "maximum development of the able students" (Engelstein and Miller, 1958, p. 32). Central High School in Philadelphia, PA, instituted AP and created special classes for its "students of high mental ability" (Angermann, Field, \& Angermann, 1958, p. 48). Rock Island High School in Rock Island, IL, began 
offering AP courses to increase college entrance rate "with special emphasis on courses for the gifted.” (Austin, 1958, p. 54) Monroe High School, in Rochester, NY, established "honor classes for its intellectually gifted" that included AP (Burnside, 1958, p. 27).

These terms described the top performing students at the most elite schools in society, the population that the early AP program aimed to reform their education.

Cornog (1957) justified the expense of curricula for the able students such as AP. He believed courses for the able student were of equal value as the education of the slow or handicapped student (Cornog, 1957). The added expense of a program for the able was as valuable as the added expense for slow or handicapped students. The discourse of the time revealed a belief that the curriculum for the able students was not adequate. There was a call for a reform to help the able student.

\section{Subtheme 1.2: AP Gaining Acceptance as a Reform for Secondary Schools and}

\section{Higher Education}

An initial 12 colleges and universities participated in the program that would become AP. The schools agreed to accept the courses completed by these students as college equivalents. Once the program and courses were established the committee members realized that, if the program were to expand students taking these courses would have to attend more than these 12 colleges and universities. A test was created to ensure quality so that the program could grow. The Ford Foundation tasked ETS with the creation of the annual tests while the CB was tasked with the administration of the program. The courses were not standardized in colleges throughout the country. In order to get colleges and universities to buy into the program, the College Board needed to 
demonstrate equality between the two. To bring schools on board the College Board was proactive. Dudley stated in the introduction in the NASSP Bulletin,

E.T.S. sends to the college to which the student has been admitted the following materials for each subject: a student's examination grade, an interpretation of the grade, the examination questions, the students course outline as submitted by the school, the school recommendation concerning the student, and the examination paper itself for the instructors at the college to re-read if they wish to do so.

(Dudley, 1958, p. 2)

These early efforts were made to maximize the possibility that the students would receive placement for their participation and test score. The efforts demonstrated the rigor and knowledge equivalence of the students to universities unfamiliar with AP.

Discourse during the program's second decade demonstrated a continued need to validate the tests and offer correct placement for students. The discourse notes there was still some reluctance on the part of college and university faculty to accept AP (Hochman, 1970). An issue of The Biology Teacher from 1974 published the multiplechoice section of the 1970 AP Biology test (Kastrinos and Erk, 1974). While the FRQ section had been published annually, the multiple-choice section was not published so that questions could be reused. The article that accompanies the test describes the construction, and grading procedures. This demonstrates to higher educational institutions the rigor and relevance of the test as compared to a college introductory biology class.

Other ways the discourse validated the AP program was through the comparison of achievement between AP and non-AP students. Burnham and Hewitt (1971) 
compared the AP students who received placement and those who had taken an introductory course at Yale in their performance on the next level course. Ruch (1968) compared the performance of students from the same high school, Evanston Township, once in college. Chaimberlaine, Pugh, and Schellhammer (1978) looked at the achievement of AP students not just in the tested courses, but also over the course of their college experience. Each study demonstrated some benefit received by the student because of their AP experience.

One piece of discourse from this time described the benefits of college placement programs. Darrell White (1974) penned an article for The College Board Review describing a placement program in Utah. He began with a defense of the need for such a placement program. He stated:

For many capable, college bound students, meaningful education ends long before high school graduation. Some have completed minimum high school requirements and are anxious to begin work on college programs...In short these students have out grown the typical high school curriculum and require a program to meet their unique needs (White, 1974, p. 7).

The NASSP Bulletin on AP published in 1958 was split into two sections. The first section includes an introduction to the program by individuals involved early on and describes early adopting schools and how their programs were built. One of the introductory pieces by Charles Keller (1958) describes Harvard's acceptance of AP. "The college specifically endorses the Advanced Placement Program, it gives credit and advanced placement” (p. 10). Another is a short piece of discourse that lists all of the 
colleges and universities that accept AP scores for placement or credit. The section begins

A substantial number of colleges... permit qualified entering freshmen who have received college-level instruction in secondary-school course to begin their college studies in those subjects at the regular sophomore level. Many of these colleges also grant college credit for this advanced school work (Advanced Placement in the Member Colleges, 1958-1959, 1958, p. 77).

The section then lists 377 schools by state that had accepted AP scores.

Context can be found in the discourse as well, that was aimed at secondary schools as well as at colleges and universities. Secondary schools should adopt the program and colleges and universities were given reasons why they should accept AP scores for placement. The subtext could be read as; universities who offered AP would obtain students proven exceptional by their test scores.

The second section is dedicated to model syllabi for an AP course. Its introduction states

Each subject area is presented in two sections. First in each subject area selections of the syllabus prepared by a special independent committee and included in the College Entrance Examination Board's Advanced Program syllabus...The second section...presents adaptations of the CEEB's syllabuses as made by selected schools. (Course Description, 1958, p. 89)

Each of the 11 AP courses received an introduction and two syllabi. The first was the College Board's model syllabus created by a committee of collegiate instructors and high school teachers and the second was an actual syllabus from one of the high schools 
in the AP program. The syllabi for each course created by the CB include statements consistent with the discourse above. The American history syllabus states "An advanced course in American History should make demands on students equivalent to those of an introductory college course” (American History, 1958, p. 90). It continues, “There is no desire to standardize advanced school courses in American History; American History courses vary from college to college, and teachers in schools should feel free to show initiative and to experiment in planning their courses.” (p. 90). In European History, “ the committee has not attempted to outline a particular course for the schools but rather to define the level of approach, coverage, and kind of materials which any course proposing to qualify students for college credit should comprehend” (European History, 1958, p. 96). Biology, "should provide a more mature presentation of content and more extensive laboratory experience than is usual in a secondary school course” (Biology, 1958, p. 101). Chemistry begins with, "The advanced chemistry course should be planned to meet the objective of a general chemistry course on the college level. The following are representative of the college view” (Chemistry, 1958, p. 112). Physics states “The students who deserve advanced placement and credit in college should be able to" and then lists six criteria (Physics, 1958, p. 124). The syllabus for mathematics states a revised program for the last three years of secondary school, culminating in a course that will be acceptable for advanced placement in college was worked out in detail by the Mathematics Committee of the School and College Study of Admission with Advanced Standing. (Mathematics, 1958, p. 133) The syllabus in literature does not mention the college course but reassures the reader that "Advanced work in literature is more concerned with the quality than with the 
quantity of a student's reading...It rather tries to develop in the student those skills which characterize a mature reader” (Literature and English Composition, 1958, p. 142). It continues by expounding upon what those skills are. The French syllabus states Since colleges and universities vary widely in the emphasis given in different courses to the different objectives of language study, the advanced examination is designed to provide information about the quality of a student's attainment in each of these respects. Colleges generally will expect some competence both in knowledge of the literature and culture, and an outstanding and mature performance in one. (French, 1958, p. 155)

German takes a direct approach addressing previous candidates, stating that "Most students who demonstrated competence at this level were granted advanced placement and credit, or credit alone” (German, 1958, p. 160). Latin stated

Although the course contents are rather specifically stated as an aid to teachers planning such courses, it should be emphasized that the primary aim is to develop the advanced student's ability to a level of proficiency comparable with that of the college freshman (Latin, 1958, p. 163).

In the Spanish syllabus it is stated

As a candidate for advanced placement in college, he will be expected to have the ability to understand spoken Spanish in connected discourse, to express himself with reasonable ease and fluency in conversational Spanish, and to write freely and accurately on subjects that fall within the range of his experience. (Spanish, 1958, p. 166) 
These syllabi served two functions. The first demonstrated to schools that were thinking of adopting the program of what the tests and courses entail (Dudley, 1958). Secondly, it demonstrated to the universities accepting the credit/placement that the course would be without a doubt the equivalent of a freshman course in college. The syllabi demonstrate the rigor and coverage of material that would convince a college or university that the course was worthy of offering placement.

Other discourse from the time that affirmed the need for acceptance of the program is revealed in the issue of the NASSP Bulletin. Reichard (1960) wrote about the AP German program:

What is Advanced Placement? It is a relatively new and steadily expanding national educational program which seeks to enrich the curriculum of the able and ambitious student in the secondary school by challenging his mind with subject matter of college level and quality. Insofar as an increasing number of gifted secondary school students take advantage of this program, Advanced Placement represents a strengthening of both secondary and college education in this country. (Reichard, 1960, p. 153) and Encouraging reports are also coming from the colleges. As they gain confidence in the high standards set by the College Board Examiners and Educational Testing Service Readers, they are in growing numbers granting not only placement but frequently graduation credit as well (Reichard, 1960, p. 154) In 1974, The American Biology Teacher published an entire AP test, including the multiple-choice questions. The accompanying article by Kastrinos \& Erk (1974) 
described the program and how the test is graded. Their work exhibited the CB's desire for acceptance, by releasing a test that was not usually released.

Continued growth of the AP program signaled greater access and less selectivity for the program. Despite its elitist stance through the 60s, 70s, and early 80s, the AP, program also made an appearance in the discussion on race issues especially in education, As a program for the most advanced and able students, AP perpetuated racial divides in education. Articles in The New York Times from the early 1980s attest to the institutionalization of racial and socioeconomic differentiation that was inherent in the AP program. An article from 1981 addresses the array of AP courses available in the Greenwich school district (Kleinman, 1981). While the article only addressed the Greenwich schools, the article mentioned the fact that lower income communities surround the town and insinuated that these districts' lack of ability to provide courses such as AP helped the program to be exclusive. An article from the same paper two years later is more direct contrasting the educational opportunities afforded students in neighboring towns. One town, Lawrenceville, is upper middle class and predominantly white, and offers AP in any academic discipline (Winerip, 1983). The other Hempstead, was predominantly Black and Hispanic and because of monetary constraints was unable to offer a single AP course (Winerip, 1983). These examples point to the fact that the exclusivity followed the patterns of American society with AP and were and continued to be racially exclusive as well.

\section{Rupture 2: A Nation at Risk}

Secretary of Education T.H. Bell created the National Commission on Excellence in Education in 1981 and in 1983, the commission presented to President Reagan $A$ 
Nation at Risk: The Imperative for Educational Reform. The NAR report made sweeping claims regarding the state of education that brought education once again to the forefront of the nation's public policy discussion. The publication of the report brought into the public consciousness the claim of a public school system with problems and put those problems in terms of national security in a manner similar to the launch of the Sputnik satellite. The NAR report was a historical rupture that brought about changes in the power and knowledge structure of the type of education students received. In the intervening years numerous challenges to the validity of the report have been published (Berliner\& Biddle, 1995; Hayes, 2004). Valid or not, the NAR report struck a chord with the public and led to large changes in the way Americans viewed education.

\section{Theme 2: A Shift in Emphasis from the AP test to the AP Course}

The theme to emerge from the discourse following the NAR report was a shift in emphasis in the AP program from the test to a series of course that culminated in a test. During the Sputnik era the CEEB focused upon the test. The shift in discourse after the NAR report emphasizes the College Board course culminating in a test. Three subthemes emerged from the discourse. The first subtheme is AP as a course. The second subtheme is the shift in population stemming from the emphasis to the course. The third subtheme is how the AP course contributed to a modification of the secondary and higher education curriculum.

\section{Subtheme 2.1: AP as a Course}

Early discourse on AP shows that the initial goal was receipt of placement beyond the introductory course in a college or university. Classes were not coded as AP; there was no actual AP class and nothing about the class showed on the transcript to show that 
the course was AP. The tests were given at the end of rigorous college equivalent classes and only once admission to the college took place did the student and College Board intervene in the process to give the student advanced standing in the college. When the student was accepted to a college the College Board and ETS transmitted the student's score, an explanation of the score, a copy of the test, the student's answers, and the teacher's syllabus so that the university could make its decision regarding the student's standing. Today, with the Course Audit, AP is an official designation that can be given or retracted by the College Board that can be listed on a student's transcripts regardless of how well the student did on the test. Colleges and universities are making choices on student admission based upon the fact that a student takes a course.

Hill (1999) begins his article on AP European history by stating, “AP courses stand as practical and real measures of quality” (p. 269). The change in discourse that followed the publication of the NAR report supports Hills assertion. The course became more important than the test. Edwin Dickey (1986) compared AP Calculus BC students to college calculus students to determine whether the AP students were learning on the same level as their college counterparts. Dickey (1986) took a different approach than his predecessors in the Sputnik era. He compared students and not the outcome or test results. How the students performed in the course not on the AP test, or how those who passed AP tests performed on college tests became important (Austin, 1975; Bergeson, 1968; Burnham \& Hewitt, 1971; Chamberlain, Pugh, \& Schellhammer, 1978).

Bodenhausen (1989) examined the performance differences between private and public schools and used AP scores as a measurement of learning and achievement. The actual difference between the two groups is inconsequential. It is the fact that her work 
only looked at test performance as a measure of achievement. We must deconstruct learning in preparation for the test was considered a sign of college preparedness in addition to readiness to omit introductory classes from a student's college coursework.

An article in The Journal of Economic Education introduced the new AP Economics courses and spent the majority of its argument discussing on the course and not the test (Highsmith, 1989). The author begins the article by calling the examination "the core of every AP program" something that , "is the part of most interest to students, teachers, and university professors” (p. 115). Yet the remainder of the article is spent having described the course and the research basis for the course and not the test. The article included a sample course outline (Highsmith, 1989). This is in contrast to the discourse from the Sputnik era where the discourse focused on the test and its outline; and only described the course with sample syllabi in relation to the tests (NASSP Bulletin, 1958). Thus Highsmith while maintaining the importance of the test has changed the order of importance emphasizing through his description the course.

In 1999, The History Teacher published a special issue on AP history courses. The issue introduced the new AP World History program. Five articles were dedicated to the new World History examination. Stearns (1999) examined the themes and structure of the course curriculum. Lillich (1999) examined the historical skills developed in the course. She stated "If they (students) master the skills and habits of mind identified by the Task Force, they will not only succeed in AP World History, but they will also be well prepared to begin their college history courses” (Lillich, 1999, p. 294)

Burstein (1999) compared the curriculum of the course to that of a college course. His discourse mentioned the course but never referred to the test. He began the discourse 
by stating that ETS was incorporating "a world history course to its list of courses" (Burstein, 1999, p. 283). Andrea (1999) described the curriculum of the proposed "course of study” (p. 297). Black (1999) added to the discourse by writing about how schools can set up the course and whether schools have students ready for the course. Her only mention of the test was to state that the test was "the type of format used in traditional advanced placement history tests.” (Black, 1999, p. 291). All five centered on the curriculum of the world history course over the test.

The rest of the issue included discourse on the other social studies AP courses American history American government and politics and European History . DiLorenzo, (1999); Ennis, (1999); Hill, (1999); Neutuch, (1999); Reichard \& Keirn, (1999) analyzed the course. The discourse created by Ennis (1999) also examined resources for the course. She stated "AP students should also learn how to do historical research. Therefore, I require my students to produce a full formal research paper” (Ennis, 1999, p. 240). Also, "after the AP exam in early May I ask my students to complete a genealogy project” (Ennis, 1999, p. 243). Her writing revealed assignments not pertinent to the test. Her preference for the course over the test is also exhibited in a statement on the DBQ, "They provide excellent practice for the AP exam, but, more importantly, they are great teaching tools” (Ennis, 1999, p. 239).

Blagaich (1999), Hyser (1999), and Oberjuerge (1999) analyzed the test. Even the discourse on the test referred to the classroom in a way that was different than in the previous discourse. Oberjuerge (1999) began his discussion by referring to AP as courses and not tests. While discussing the test-driven nature of AP American Government and Politics he stated, "It is important to realize that our students can benefit from AP 
instruction not simply to receive college credit... but also because the curriculum challenges them to acquire intellectual skills that will prepare them for college.” (Obejuerge, 1999, pp. 263-264). Hyser (1999) stated that the test and the classroom experience are to mirror the college course. These descriptions further emphasized the difference between the discourse before the publishing of the NAR report and the subsequent emphasis on the course.

Music Educators Journal added to the discourse with two articles on the AP Music courses. The title of the first article is Advanced Placement: More than a Test (Colwell, 1989) and the second is AP Music Theory in Your School (Lucia, 1993). The articles were about the course; the test was only mentioned once in each articles. Colwell (1989) described the course and its advantages. He stated, "The two AP music courses ... are also valuable for the student not headed to college or for the nonmusic major who is interested” (p. 27). He continued

College credit need not be the primary objective in offering AP courses; credit and status are only the frosting on the cake. The educational objective is to enable students to apply what they have experienced in ensembles, to understand music at a deeper level and to discover those inner secrets of music that excite you and me. (p. 27)

Lucia (1993) described the course, its content, and how to start the course in a new school. He mentioned the examination in describing the course, and use two released tests as guides to the creation of individualized curricula. Yet he described the reasoning for offering the course: "it offers student musicians an excellent opportunity to gain new insight into melody, harmony, and structure” (p. 38). He stated finally that "AP music 
theory deserves to be a part of any strong school music program. Although it takes planning and preparation, AP theory rewards both the teacher and the student with a heightened awareness of music's sublime engineering and architecture” (p. 59).

Colwell's (1989) only mention of the examination was somewhat dismissive as shown in the statement "no negative values accrue when the student does not attain a high grade. The two music courses can be invaluable endeavors in which the students attain their personal goals without either taking the examination or obtaining a high grade on it” (p. 28).

Neither article treated the examination as the most important outcome of the course. Instead the curriculum and the knowledge gained were in the authors' opinion more important.

The concern for the course over the test was similarly demonstrated in the research on other AP courses. Michael Henry (1991) explored the curriculum taught in an AP US History class after the examination. Pushkin (1995) in AP Physics stated "it is very common for students to take their introductory physics at the university, regardless of their AP exam performance” (p. 532). He claimed the course and curriculum overtake the test and the accrual of the resulting knowledge as the most important outcome of the course. Neutuch (1999) added the student's perspective to the discourse on the distinction between the course and test. Neutuch, along with 27 of his 28 classmates took and passed the test, yet he felt that his teacher "failed to substantially develop valuable skills and capacities in the vast majority of enrolled students” (p. 246). Neutuch held a belief that the course should not only prepare him for taking the AP test, but also help to develop the skills necessary in college. In a similar vein James Hill (1999) stated that his 
AP European History course "is much more a matter of learning disciplined study skills than getting credit for courses in college” (p. 269). In both articles reflecting the student experience, emphasis is placed upon the course. These examples demonstrate also the change of focus from test to course.

\section{Subtheme 2.2: A Shift in the Target AP Population}

NAR moved education to the forefront of the national agenda and its impact was noticeable in the discourse surrounding education. There was a shift in focus from providing requirements of resources and allocation for education to the judgment of student achievement. This shift to focusing on achievement catalyzed a push for college education for a greater percentage of the nation. AP was one of the few college preparatory programs in the nation at the time and it was also the largest. This helped to bring AP into the public consciousness and led to an introduction of AP into public policy. These changes widened the scope of students for whom AP was available. The CB supported this shift as was revealed in the discourse.

One catalyst which helped perpetrate this shift was a 1982 news story published nationally about AP Calculus teacher Jaime Escalante (Mathews, 1982). AP was taught in mostly white and upper class schools of the suburbs and Escalante brought AP to Garfield High School which served middle and lower income Hispanic families in Los Angeles. The success of Escalante's students garnered national attention, particularly as these students were not traditional AP students and at a time when the federal government was publishing a report on the poor quality of education in the nation. 
Escalante's students represented the first part of AP’s journey from elitism to open access. This change was fueled by a changing societal belief that American schools in general were failing their students.

Small changes in the discourse that pertain to this shift of broadening the AP target population began to take place in the years after NAR. AP moved from a program in America's most elite private and public schools to a program for academically advanced students in the majority of schools. In 1983, the year NAR was published, 5,827 high schools offered at least one AP course in their school. This represented one quarter of the approximately 22,000 secondary schools in America at that time (National Center for Educational Statistics, 2012). The growth of AP in schools over the rest of the decade is indicative of the changing focus in America after the publication of NAR towards a college preparatory education. In the decade before 1983, the AP program never added more than 400 schools with most years adding between 100 and 300. From 1983 until 1991, the program added at least 400 schools every year. Most years, the program added closer to 500 schools. By the 19080s, AP was in a substantial enough number of high schools to be considered a mainstream curriculum with national appeal

Even as late as 1983, an article in The New York Times still referred to the AP student as intellectually superior and emotionally mature (Carlan, 1983). By 1990, the description of the AP student had changed. No longer were the students portrayed as exceptional or most able. A description of the AP studio Art program in School Arts (1990) describes the AP student as "highly motivated" and " seriously committed." (p. 44) No mention is made of the exceptional intelligence or giftedness of the student. An article in the Physics Teacher from 1995 compares the AP to the college curriculum 
(Pushkin, 1995). Not once did the author mention the class status of the motivation level of the students in the article. This change in discourse can also be seen in the writing on public policy. A Delaware report on the AP program from 1989 refers to the AP student not as exceptional or more able than other but simply as academically able (White, 1989).

Another shift in the discourse after the NRA in relation to the target population is the connection between Honors and the AP curriculum. AP no longer stands alone as a curriculum for a few exceptional students who are perceived as being so different from the rest of the student body. Instead, AP begins to be treated in the discourse as the next step in the educational progression of students. AP no longer maintains a differentiated place but instead is simply a part of the curriculum for students who advance beyond the traditional coursework. The titles of two of Norman Herr's (1992 \& 1993) articles reflect this. "A Comparative Analysis of the Perceived Influence of Advanced Placement and Honors Programs Upon Science Programs” and “The Relationship between Advanced Placement and Honors Science Courses.” Both articles equated the AP and Honors curriculum as equal parts of the advanced curriculum in the nation.

The first hints of opening access to the program coincided with the release of NAR. This is not to suggest NAR caused the beginnings of open access. Instead, there more access to the AP program for students (especially students in economically advantaged areas) at the same time as the publication of NAR. The early studies of open access along with the message of needing improved school performance in NAR led to an educational shift. 


\section{Subtheme 2.3: AP Courses used to Promote Equity}

The NAR report ushered in a shift in the way American viewed equity in schools. In 1974 the federal government passed the Equal Educational Opportunity Act. The government used education to be the agent of change in society. Congress attempted to give minority and low-income students greater social equality through an equal education. This did not occur and it was the NAR report and educational crusaders of the early 80s that forced the tying of equity to excellence (Viteritti, 2004). The discourse on equity in education changed after the NAR rupture. This is reflected in the discourse on AP at the time. James Hill (1999) described the role of AP European history, AP courses stand as practical and real measures of quality, using university standards as opposed to politically determined standards of expectation and content. Universities therefore must support AP European history if they want to strengthen the intellectual level of high school teaching. (p. 269)

AP was viewed as a model of excellence in education. It could be used as a reform similar to the programs usage after the launch of Sputnik. After the NAR report the reason for the reform changed. AP was a reform to aid minority and low-income students who traditionally performed poorer on measurements of educational success. At the beginning of the NAR era the program was dominated by White middle and upper class students. More inclusion of minority and low-income students would bolster numbers in advanced classes and improve the educational opportunities for these underserved groups. This came from the belief that by simply having more minority students in AP and other rigorous classrooms would lead to greater educational equity. The ideas were reflected in both the newspapers and public policy of the time. A 1985 
article in The New York Times discussed how states wanted to implement a system to compare schools and state school systems. One of the indicators of success would be "the extent of Advanced Placement courses” (Associated Press, 1985, p. A22).

Reports from school districts and state Departments of Education revealed a new interest in AP data and research in who was taking AP tests followed. Data analysis led to the ability to quantify numerical differences in gender and minority participation in AP classes. Bridgeman and Lewis (1991) examined gender differences in performance on AP tests. They found that males were better at the Multiple-choice section while females performed better on the FRQ section of the test (Bridgeman \& Lewis, 1991). Following up on their work, Stanley and Heinrich (1997) found similar, stable differences between genders and in addition their research noted gender differences in the number of tests taken as well as scores. They noted low female enrollment in AP physics, mathematics, and computer science courses (Stanley \& Heinrich, 1997). Their results demonstrated gender inequality occurring through a lack of participation by half of the population in courses that were considered a priority in the NAR report. It also pointed to a systematic difference in the power and knowledge relationships in education between the genders, where women through a lack of rigorous education in these fields face subjectification in these societally important fields. The results reflected a societal inequity where women were tracked out of rigorous science and math courses at the secondary level. This connects to the lack of enrollment of women in math and science related fields in colleges and universities and thus women not embarking in careers in these societally necessary and lucrative and professions. 
Rodriguez (1997) explored gender and socioeconomic status within ethnic groups while looking at AP among a variety of tests. Rodriguez’s (1997) findings confirmed that fewer minorities took and passed AP tests. By dividing the groups by gender he discovered African American females outperformed their male counterparts and that the trend was increasing (Rodriguez, 1997). Steller \& Lambert (1996) offered AP as the reform that could meet the higher standards and make up for the educational differences found among minority groups. Thus AP reform leads to educational equity. There also exists an unspoken desire for societal equity born of educational equity.

Stellar and Lambert (1996) described AP as having given urban students college preparatory environment and rigor. Their article described how an AP program was implemented in Oklahoma City schools and how they would implement AP in Boston. These large cities undertook the use of AP as an educational reform in an attempt to alleviate the societal inequity within the city's populace through attempts at eliminating educational inequality. This use of AP, as a reform, led to a reconfiguration of the purpose of AP that will be explored in greater detail in subsequent themes.

The disaggregation of AP data took place across the country so as to understand who was taking AP tests and how well different groups performed in these tests. Many of the reports compared local trends in AP data to national performance. The reports also addressed the issue of increasing AP participation as a way of bolstering the performance of the states' top students. The recommendations section of a 1999 Delaware report exemplified the focus in much of this discourse. "It is essential that school officials, especially guidance staff encourage minority and economically disadvantaged students to 
enroll in college preparatory, honors, and Advanced Placement courses” (Delaware State Department of Education, 1999, p. 8).

Casserly (1986) in a follow up to her 1968 report on AP described an AP program in the 1980s as familiar and respected by colleges and their faculty. With NAR, the AP program was used as a reform to addressing the lack of rigor and coherence in American schools as noted in the categories related to course content and standards and expectations. The report described the country's educational standards as “an often incoherent, outdated patchwork quilt” (A Nation at Risk, 1983, p. 9). AP for 29 years was coherent, nationally recognized, rigorous, and college focused. Thus, AP was used as a vehicle for reform. This use changed the view of AP from a program of exclusivity to a program of opportunity (Colwell, 1990; Rothschild, 1999). Students could use AP for the experience and deeper level of understanding not just for the college standing (Colwell, 1989). Politically AP was easy to insert into public policy and with ETS constructing tests and keeping demographic data, the AP was straight forward for school boards to quantify and justify.

\section{Subtheme 2.4: AP Courses Modifying Curricula}

In the 80s and 90s AP and its curriculum expanded and changed significantly leading to curricular changes at both the high school and college levels. When AP was initially introduced in 1956 there were 11 tests. A 12th test European History was introduced in shortly thereafter, in 1958. Between that year and 1980 two additional AP tests were introduced, Art and Music. Physics and Calculus were split into two separate tests in 1969. This brought the total in 1980 to 16 tests. From 1980 until 1999 eighteen tests were introduced bringing the total to 32. A variety of new AP courses were 
introduced in the 80s and 90s rounding out the curriculum. The two music courses introduced in 1972 and 1978 were combined into one course. Art was expanded to include studio art and Art History. In 1980, a second English test in language and rhetoric was added to the literature course. In 1984, the College Board introduced the Computer Science test. In 1987 two political science tests, U.S. Government and Comparative Government were introduced. In May 1989 the two Economics tests- Microeconomics and Macroeconomics- were introduced. The Psychology test was introduced in 1992. In 1997, statistics was added as an additional math option. In 1998, environmental science was introduced. Since 2000 only two tests have been introduced, human geography in 2001 and world history in 2002. The addition of these courses, as revealed by the discourse, helped to modify both the high school and university curriculum. This expansion in AP courses caused an expansion in secondary school curricula and a reevaluation of what material is taught in these courses in colleges and universities.

Discourse on AP after the NAR rupture revealed AP as having an effect on the modification of curricula at both the secondary and collegiate levels. AP music theory introduced into the high school curricula "insights into melody, harmony and structure" not previously available (Lucia, 1993, p. 38). Lucia (1993) also recommended the introduction of a new basic musicianship course into the high school curriculum as a prerequisite to the AP course. Colwell (1990) supported the institution of prerequisite courses stating, "The AP theory course should be restricted to those students who can read music. Dictation, part writing, and score analysis...all require facility with notation.” (p. 28). The introduction of AP music reformed what it meant to have a music program 
at the secondary level. Oklahoma City high schools followed a similar trajectory. After AP courses were introduced a pre-AP program was created.

Recognizing that success in an Advanced Placement course was really the result of the preparation that occurred in earlier grades, the district established pre-AP courses in ninth and tenth grade English, tenth grade world history, ninth grade biology, tenth grade chemistry, and tenth and eleventh grade math” (Steller \& Lambert, 1996, p. 101)

Lukhele, Thissen, \& Wainer (1993) used AP tests in chemistry and US History to better understand the relationship between multiple choice and constructed response questions in a large scale test. Though interested in testing in general, they chose AP because of its high quality high school tests. Meckna (1999) at Polytechnic High School in Long Beach California stated the, "modern world history course has gradually withered away while more and more students have taken the European one” (p. 257). AP European history changed the curriculum in his school. Hill (1999) argued that AP European history improved teaching and was above the political squabbling over what should be in education in California. He believed, "Universities therefore must support AP European history if they want to strengthen the intellectual level of high school teaching.” (p. 269). Hearn (1998) studied the AP physics curriculum. After his examination he suggested the British system model the curricular changes of the A-level tests after the AP Physics tests (Hearn, 1998). Herr (1992) found "the amount of time spent on testing and evaluation was independent of the type of program used ... there was virtually no difference between AP and honors class” (p. 524). These works revealed the potential and real effects of AP upon the high school curriculum. 
The introduction of the World History test affected both the secondary and higher educational curriculum (Burstein, 1999). Stearns stated similarly the AP course "will benefit world history teaching at both high school and college levels” (p. 281). As a course, world history is traditionally taught only at the secondary level. Colleges and universities traditionally teach a course or series of courses on western civilizations. Political pressure on the College Board demanded the new course fit with the traditional secondary curriculum and world history was chosen over a western humanities course. Burstein (1999) asked, “As the new AP world history course becomes generally accepted at the secondary school level, will it serve as a catalyst for the transformation of college and university world history courses?” (p. 287). His answers demonstrate that he believed the AP course in world history would reform secondary curriculum through greater uniformity (Burstein, 1999). He continues that acceptance of the World History secondary course along with the existence of a college course on western civilizations from a more globalized view of American history might pressure higher education to transform their world history course to line up with the secondary and AP course (Burstein, 1999). Peter Stearns (1999) stated there was a "need to develop more sophisticated sequences in world history teaching, to embrace at the college level the students who will have experienced and benefit from this new AP program” (p. 281). The World History course would change the collegiate western civilization format already in place in colleges into a more globalized view of history. "As indicated in the college/university survey, more and more colleges are beginning to offer world history courses as well as the traditional western civilization course” (Black, 1999, p. 291). 
Harvard has moved to a world history model and George Mason now offers the option of either world history or western civilizations.

Reicharard and Keirn (1999) wrote about AP “as a catalyst for better university instruction and higher post-secondary standards” (p. 171). Edwin Dickey (1986) compared the differences in skill sets between the students in second year calculus. The two groups compared were those having taken the college calculus course or the AP test for first year calculus credit. Dickey found that his university had to differentiate for these students and recommended a new mathematics pathway at his university depending upon how the introductory calculus credit was earned thus modifying the college curriculum. Black (1999) suggested "undergraduate and graduate students need to participate in activities in history classes that require written analysis of historical source material, especially those activities that include the type of format used in the traditional advanced placement history exam” (p. 291).

\section{Rupture 3: No Child Left Behind}

This federal law enacted a system of accountability based upon testing. The goals of NCLB are the increasing of student achievement and decreasing what is commonly referred to as the achievement gap. The law holds states, school districts, and schools accountable for student achievement in standardized tests of reading and mathematical skills. The extent to which NCLB has altered education is still being determined. In comparison to the two previous ruptures NCLB is relatively new and its effects are still being assessed.

NCLB was the culmination of a variety of educational legislation begun in 1965 with the Elementary and Secondary Education Act (ESEA). NCLB is a reauthorization of 
the ESEA - an element of Lyndon B. Johnson's war on poverty. The goal of ESEA was to reduce inequality by providing funds for school districts that served lower income students. The act's 1994 reauthorization, entitled the Improving America's Schools Act of 1994, restructured ESEA and put into place key elements of NCLB. It incorporated standards and accountability elements along with paths for school choice to be initiated by parents.

The movement for educational accountability had been growing for a number of years. In 1991, President George H.W. Bush outlined the America 2000 goals that included voluntary testing tied to standards. In 1994, President Bill Clinton signed into law Goals 2000, which provided grants to help states develop standards. Various states implemented content and performance standards and began the process of large scale high stakes assessment and data gathering. NCLB pushed this trend into federal legislation and into the national consciousness in regards to education.

\section{Theme 3: AP as a Means to Narrow the Achievement Gap}

The theme to emerge from the discourse following the NCLB rupture was widening of student access to AP courses as a means to narrow the achievement gap. Two subthemes emerge from the discourse. The first was the shift in the program from a placement program to a preparatory program. The second subtheme was a shift in the population of the students taking AP course in that it became accessible to a wider group of students.

Under NCLB, AP has been used in an attempt to narrow what is commonly referred to as the achievement gap between Whites and Asians as one group and the other group of culturally diverse minority students (Black, Hispanic, and Native American). 
This gap was quantified during the NAR era, but the quantitative focus of NCLB led to greater public attention. It was known that fewer minority students were offered rigorous course work (Klopfenstein, 2004). The discourse revealed a belief AP could be used as rigorous course work in which all disadvantaged students would enroll and receive supplementary academic support to help ensure success. The University of Virginia created the AP Challenge Program to provide local minority students and teachers with academic and developmental support (Nguyen, Callahan, \& Stevenson, 2010). A similar program was instituted in southern Texas, along the Mexico border, where college faculty for the Texas A \& M University System worked with high school faculty to improve AP scores and increase participation of Hispanic students (Blackwell, Pisani, \& Pisani, 2007). Central High School in Omaha Nebraska created a voluntary program entitled Minority Scholar which created a support system for minority students to overcome the isolation and stigmatization of advanced classes and offered tutoring and time management help, as well as career and college planning (Saunders \& Maloney, 2004). In Arlington Virginia, Wakefield High School used a cohort system to improve the rate of male minority student enrollment and passing of AP tests. Suncoast High School teacher David Hale (2007) taught AP English Literature to students in the school's lowest academic quartile. He used the AP curriculum to improve underperforming students overall school achievement. Broward County Public schools in Florida used AP as an intervention strategy to decrease the achievement gap in the school district (Leonard, Blasik, Dilgen, \& Till, 2003).

Mark Oberjuerge taught AP American Government and Politics course at Jordan High School in Longbeach California. He tried to narrow the achievement gap by aiming 
his program at minority and immigrant students. He described his students as "benefit[ing] from being exposed to an advanced curriculum and higher standards; they can and do perform well with the college level material.” (Oberjuerge, 1999, p. 264) The idea behind these reforms was that exposure to and participation in the higher-level courses, regardless of the outcome on the AP tests would benefit the students. The CB has published the same sentiment, having touted AP as not just a test for placement courses, but for teaching the skills needed for college (Caperton, 2006).

The discourse described an attempt to increase the participation of Hispanic and Black students who are underrepresented in AP courses nationwide and whose pass rates are significantly lower than their white counterparts. The intent of these programs is to use them for rigor and not for the student's placement.

This led to numerous public policy reforms to be instituted around the AP program. States created laws that used AP as part of a reform for servicing disenfranchised students. The specter of fees was lessened or in the case of some states, removed entirely for students who could not afford the $\$ 89$ fee for each AP test. Beyond the test, subsidy states have linked AP performance to scholarships and cash bonuses for teachers and students (Dounay, 2000; Dounay, 2007). One program in Dallas pays students $\$ 100$ per test for each passing score of 3 on an AP (Vega, 2010). Florida has an incentive program that pays teachers $\$ 50$ for each passing student with a $\$ 2,000$ maximum (Gupta, N.D.). There is a bonus of $\$ 500$ for teachers in underperforming schools for just having a student pass. As a reform, Florida has also included AP participation and pass rate of all AP test takers in a school as part of the evaluation process for schools. 


\section{Subtheme 3.1: AP as a College Preparatory Program}

Gaston Caperton (2006) wrote an open letter celebrating the $50^{\text {th }}$ anniversary of AP. The letter was published in a special issue of the College Board Review dedicated to the AP program. At no point did he mention AP as a way to get college credit and fulfill placement requirements early. Instead he wrote of the students who will "aim for college” and the "training they will receive in AP courses" to help in earning their bachelor degrees (Caperton, 2006, p.1). The article praised the advantages AP provided as a preparatory program. Another article in the College Board Review, AP student Maria Chicuen never mentioned placement or of her early graduation from college due to the credits earned from her AP classes. Chicuen’s (2006) article described the hard work that went into the course and the learning that took place in AP classes. Her article implied that because of her AP classes "her teachers have encouraged her to apply to Ivy League schools” (Chicuen, 2006, p. 5). AP was seen as the challenge and preparation Chicuen needed in order to reach the top schools in the country while originally AP was intended to release the academically advanced from the tedium of the first year course at these schools. Now in the NCLB era, applying and acceptance to these schools was the purpose of AP. Renee H. Shea (2006) examined the AP program at two schools - one in rural New Mexico and one in Chicago. She described how many students took AP classes and how many went to college. When AP was used as placement program, it was almost a given that the students in the course would go on to college. In the discourse, published after NCLB, AP was used to get students ready and interested in college. Only once was there mention of the potential for college credit; when the school was using outreach to 
get parents to enroll the students in the program. Otherwise, the article focused on the preparatory nature and hard work of AP.

In another article, from the same issue, Veronica Chambers (2006) interviewed past AP students who had gone on to great success. The interview excerpts addressed the preparatory nature of the AP courses. Each of the individuals interviewed discussed what they learned within the confines of the AP program and how this learning had made them better prepared. In the article, only two of the nine individuals mentioned AP as a vehicle for avoiding introductory courses. Each was brief and one suggested that his placement was tinged with regret. Eric Cornell stated he could have used one of the English classes he placed out of (Chambers, 2006).

The change from a placement to a preparatory program was also evident in discourse found in publications other than those published by the CB. William Casement (2003) in his article on the decline of the AP program discussed how the change took place. Originally the AP program was a placement program only available at select schools and for those students intending to attend elite colleges. Because the secondary schools worked with the universities these students attended, AP was a viable means for placing the students in upper division courses. Charges of elitism forced the program to expand and take on a more open access policy (Casement, 2003). The most selective colleges took note and as more students took the test, these institutions tightened their credit acceptance policy. However as acceptance of test scores for placement became harder, another shift occurred; elite colleges and universities now looked at AP as an integral part of transcripts for acceptance. Even as the credit they were supposed to grant was not enough to satisfy advanced placement, the AP course became the preparation the 
schools were looking for as a criterion for entrance within the same institution. Casement stated that one elite college required 4 to 6 AP courses on a student's transcript for admission (Casement 2003).

This view of AP as preparatory over placement could also be seen in the annual ranking of the Nation's High Schools by Jay Matthews (2012) published in Newsweek. This ranking of school quality was based upon AP participation as a stand in for college preparation. Matthews (2012) did not use college acceptance rates or high school graduation; he saw AP as a function of a school's ability to prepare students for college.

This is not to suggest the change from placement to preparatory was necessarily negative for the program. The shift took place due to the charges of elitism within the program. As the College Board moved to shift the program from restricted to open access, the focus of the program shifted as well. This shift in purpose helped to open the program to many culturally diverse groups who had been underserved by their education prior to the introduction of AP. Through AP, disadvantaged students were able to attain the rigorous education needed for a college entrance when previously it served as a placement program for students at elite schools.

The change from placement to preparatory was also evident in discourse from newspapers. Lewin (2006) writing for The New York Times wrote, “The AP program started... as a way to introduce a few high school students at top schools to college level work. But in recent years it has expanded drastically...helping students impress colleges” (Lewin, 2006, p. A19). This perpetuated the narrative of the program as preparatory. The story, although about pass rates, portrayed the program as a way to prepare students for college by exposure to a college curriculum and not a college placement program. The 
test had not changed; therefore, the outcome could not have changed. The courses and tests were preparatory.

Some institutions took a double stand on the issue of AP as preparation or placement. Harvard used AP courses for admission yet only gave credit for the scores of a 5 on the test. The 5's did not give credit, only placement in the higher-level course. The school only granted advanced standing if students receive four 5's. The reasoning given proved the subtle shift in perception. Students entering having taken and passed AP tests were not prepared for the higher-level course. The news article by Lewin (2002) quoted a representative from MIT who stated, “We don’t discourage kids from taking AP courses, but we are not going to give credit” (p. A20). The implication was for students to take the test to prepare for the curriculum in college but that the curriculum offered in preparation of the test was not sufficient to exempt the students from college courses. Ronald M. Latanision was also quoted in the article describing when students were placed out of entry-level courses as saying “they were clearly not prepared.” This demonstrated that the Ivy League universities were not as interested in the placement as they were in the preparation factor in the role of AP testing.

Howard Everson, the CB's chief research scientist was interviewed for an article in The New York Times about the growing number of students taking AP courses and the grade inflation that comes with AP and this increase. He stated "It shows that there is a growing cohort of those who aspire to attend a competitive college” (Honan, 1998, p. B1). This demonstrated the change in the CB's narrative began in the late 1990s.

AP has recently become the grade booster that leads to the higher-weighted GPA, and for colleges demonstrates student preparation for college. In a newspaper article on 
college acceptance in The New York Times, the only mention of AP is in how it weighted averages and made students work harder. There was no mention of how AP was used to place students out of the normal entrance course sequence (Rubenstein, 2005). This suggested that to the students, AP was not seen as a way of more rapid advancement to higher-level collegiate courses; rather AP was viewed as a grade inflator that tells the universities that students are prepared for entrance.

NCLB's impact on education has been far-ranging. It was the first piece of comprehensive educational legislation in the nation to specifically mention the AP program as a part of an overall national curriculum. The validation through financial support of AP as a part of a national curriculum helped with the transition from a placement program to a college preparatory one. AP's codification in public policy gives financial assistance, in the form of fee waivers provided by both federal and state governments along with supplemental budgetary support provided by states, to increase significantly the number of schools that offer AP and the number of students taking AP. NCLB financed partial fee waivers for low-income students taking AP classes. The legislation paid $\$ 45$ of the test’s $\$ 85$ fee. Many states followed the federal government’s lead and offered fee discounts to students and funding to districts to set up AP programs in their schools.

The AP courses that accompanied the test was part of the student transcript and thus becomes another criteria for college admittance. While NCLB only addressed the test, the connection between the course and the test became clearer. The shift in the discourse saw a favoring of research related not to the test or the passing of the test but 
instead to the course and its outcomes. The research focused on topics such as classroom resources, course format, and what to do in the class after the test is over (Ennis, 1999). Another way this shift from placement to preparatory was shown can be seen in the discourse on the connection between the AP test and actual student performance once in college. Some of the research questioned a students' abilities to perform in higher-level college courses regardless of their performance on the AP test (Hansen et.al., 2006; Menson, Patelis, \& Doyle, 2009). Even though the AP courses prepare the students for entrance into college the discourse shows a belief that the course may not prepare students for the placement that the tests offer. Despite the creation of new courses, the discourse depicted the program being as much about college preparation as it is about placement. Andrea (1999) writing just before the World History course was offered, said a "curriculum in global history [that] promises to offer instruction in skills and perspectives that will produce students who are better able to deal with the often daunting challenges of studying world history at the post-secondary level.” (p. 297)

It was in the interest of the CB to maintain the dual purpose of placement and preparation. By keeping an emphasis on the testing, the CB maintained the public policy incentives in the form of fee waivers for students which were paid directly to the CB by federal and state dollars, and has contributed significantly to the phenomenal growth of the AP and the $\mathrm{CB}$ in the past decade. The tests validate the courses as a standard assessment that guarantees a standard curriculum in the AP courses across the nation (Jeong, 2009). Many States have adopted the idea of AP as a rigorous, systematized curriculum and have linked AP results to a variety of incentives for both students and teachers in an attempt to use AP as a preparatory program (Dounay, 2000, 2007). While 
the CB has warned that AP should not be used for these purposes, it has also encouraged them at the same time (College Board, 2011i). Thus, the College Board has maintained its power and hold on defining rigorous knowledge at the secondary level.

\section{Subtheme 3.2: Shift of AP to an Open Access Program}

The advent of NCLB and the financial windfall that ensued for the CB caused a change in AP's target population and in particular that the program was no longer only for the elite student. Financial waivers and government sponsorships allowed less financially-advantaged students the opportunity to take the tests and legislation in many states also gave schools and districts financial incentives to set up AP programs in their schools. With financial constraints no longer a barrier, the program flourished in schools where they may not otherwise have occurred. This change is reflected in the substantial growth of the program. Between 2002 and 2012 over 4,000 new schools began offering AP courses (College Board, 2011f). Texas alone, with its push to increase participation, has seen a 122\% increase in AP participation since 2002 (Texas Education Agency, 2013).

NCLB changed the educational landscape in America with the resultant greater testing and accountability in schools. NCLB mandated the disaggregation of data ostensibly to help eliminate educational disadvantages of low-income and minority students. Many school districts that believed they already offered a high quality education reevaluated the curriculum and rigor in light of NCLB and its data collection requirements (Swanson, 2007). Because AP was already in place, this disaggregation of data from state reports on AP data was some of the first to be used in research. 
Data analysis in the years following NCLB showed that disadvantaged students, both racially and ethnically were underrepresented in AP programs and scored lower than their white peers (Venkateswaran, 2004). Research from districts around the country supported the findings that culturally diverse students whether black or Hispanic were less likely to participate in the AP program, were underrepresented in AP classes and scored worse on AP tests (Klopfenstein, 2004; Ndura, Robinson, \& Ochoa, 2003; Solorzano \& Orenales, 2002; Solorzano \& Orenales, 2004). The data also showed a large differential in gender participation in the sciences and mathematics (Strumpf \& Stanley, 1996; Strumpf \& Stanley, 1997; Zohar \& Sela, 2003)

Work has recently focused upon AP as a way to close the disparity between student performances in these groups. The disparities still play a role in the changing belief in access to the program. Even though higher enrollment should increase the overall number of minority students who pass the AP test, it still does not guarantee a closing of the performance gap. Leonard, Blasik, Dilgen, \& Till (2003) examined a program in Broward County, Florida that used AP coursework as an intervention strategy. They found that "AP coursework can be extended to a wider range of students than previously thought, including minority students” (Leonard, et al., 2003). The opening of access to an even greater number of students clearly has served to widen the AP audience. Venkateswaran (2004) examined race and gender based upon performance and within the AP US History test. He found that the performance of females and minority groups were generally lower than average and specifically lower on the multiple-choice section. Analysis of the essay question showed that when given a choice in essay questions female and minority test takers had preferences for different questions 
than White males (Venkateswaran, 2004). The offering of a FRQ option with topics of interest to these students led to an improvement in performance. The choice in questions demonstrated a transformation in the test, which led to a transformation of the course to create curricula that may have drawn more female and minority students into taking the course.

There have been other ways as well that the CB has attempted to expand access to AP for more minority students. AP Spanish Language courses have been used to try to draw Hispanic students who are already native speakers of the language into courses that are more rigorous, and through that rigor, increase their self-efficacy and academic aspirations (Kettler, Shiu, \& Johnson, 2006). Schools have also tried to expand access to AP. Wakefield High School in Arlington Virginia created cohorts that used an approach based upon teamwork in sports to get more black and Hispanic males into AP classes (Beitler, Bushong, \& Reid, 2004). The program resulted in greater college participation. A similar program was launched at Central High School in Omaha, Nebraska aimed at increasing the enrollment of all minority students through cohorts receiving a variety of support services (Saunders \& Maloney, 2004). The program led to an increase in minority performance and AP enrollment. In each of these examples, increased access is viewed as connecting to increased rigor and academic achievement.

In facilitating open access each of the levels of government, federal, state, and local have contributed to the expansion of AP. NCLB infused the states with money specifically for AP. Each state then passed laws that helped facilitate the expansion of the program within the state. As a result, there is a patchwork of statutes with each state 
having laws to facilitate the expansion of the AP program by name or as part of a larger push for advanced courses.

Florida was one of the first states to offer AP assistance to increase the number of students taking the test. Florida enacted legislation that pays the fees for AP tests as long as the student was enrolled in the AP course (Florida Department of Education, 2013). This legislation opened enrollment to all students regardless of socioeconomic status. Florida also has and continues to encourage districts and schools to increase AP participation by offering extra funding based upon student pass rates.

California increased access through increasing the availability of AP courses in schools. The increase took place due to Daniel v. California that then led to legislation (Oakes, Muir, \& Joseph, 2000). The suit charged that student’s civil rights were being violated because they were denied equal access to AP courses in lower income schools which had a disproportionately fewer number of AP courses than their middle and upper class income counterparts and so denied the students equal educational opportunities. The subsequent legislation led to the provision for AP challenge grants that increased AP access not only in California but also in other states across the nation.

Arkansas and Mississippi now mandate at least four AP courses in each high school (Education Commission of the States [ECS] State Policy Database, 2013). This mandate took effect in the 2007-2008 school year in Mississippi. The only exception is if the school offered the International Baccalaureate program instead of AP. In Arkansas, beginning with the 2008-2009 school year, each high school must have at least one AP course in each of the four core subject areas (ECS State Policy Database, 2013). To encourage more AP courses in individual schools, one-time grants for equipment and 
books are available to establish AP programs. Depending upon state funding, schools may be awarded $\$ 50$ for each score of a three or higher on an AP test. These funds must be used on the school AP program. While this legislation encourages AP expansion and thus increases access, Arkansas also wants to increase its pass rate for AP tests. This is demonstrated by its extra funding for schools that generate passing scores and an additional mandate that all school districts implement pre-AP courses from sixth grade though 10th grade and aligned with the 4 core courses mandated in each school (Education Commission of the States (ECS) State Policy Database, 2013). Minnesota offers $\$ 1,000$ reimbursement to a school for the cost of starting a new AP program (Education Commission of the States (ECS) State Policy Database, 2013). In addition, the state has competitive grants available for districts to apply for that are directly tied to AP.

The enormous growth and the financial resources generated from the continuous growth of the AP program through its position of open access have enabled the AP program to wield considerable power in the field of education. AP is recognized as the de facto advanced curriculum in the country. Gifted programs rely on AP for supplying curricula in secondary schools. Much of the discourse over the past 20 years on secondary gifted education programs and AP revolves around whether or not it is the best program for students labeled as gifted (Geddes, 2010; Kim, 2010; Olszewski-Kubilius \& Lee, 2004; Winkler \& Jolly, 2011). Yet the undercurrent of much of the literature is that AP is the curriculum used and that alternative approaches will not be coming soon. All indicators in the public school point to greater growth of the program than ever. 


\section{Summary}

This chapter contained the analysis of the critical analysis of the College Board's AP program. It integrated the information gathered in the literature review to inform the data gathering and analysis. The analysis utilized based a method based upon the work of Foucault, Armstrong, Black and Ubbes (2009), and Braun and Clark (2006). This method of analysis led to the revelation of three themes connected to three chronological ruptures, which led to changes in the discourse. Each theme contained two to four subthemes. Chapter 5 concludes the dissertation with a discussion on the implication of the findings along with suggestions for further research based upon the analysis. 


\section{CHAPTER V}

\section{DISCUSSION AND RECOMMENDATIONS}

The chapter is divided into five sections. The first section reviews the study and the research question. The second section discusses the findings in relation to the research question and frames the implications of the changing conceptions of the AP program as related to American education. The third section discusses the limitations of the research. The fourth section discusses implications for future research and practice created by the narrative. The fifth section discusses the implications for the use of the method of research and practice. The chapter closes with concluding thoughts and a summary of the chapter.

\section{Review of the Study and Research Question}

Many in America believe that the educational system is broken (Brandenburg, 2013). This belief pervades news opinion pieces, blogs and political speeches (New York Times, 2005; Washington Times, 2012). Despite this belief, according to these sources, the one element of the educational landscape that appears to be succeeding is the AP program. This study examined the perception of this success in an historical context. The changing role of the AP program was examined through critical theory to determine the elements of a continual view of its success since its inception 57 years ago.

Critical theory involves the application of a broad array of techniques. A review of the relevant literature on critical theory revealed the importance of the work of Michel Foucault whose ideas became the lens through which an analytical framework was constructed. Though Foucault's interpretation of critical analysis is influential it is also open to interpretation (Scheurich and McKenzie, 2008). Research into the variations of 
Foucauldian critical analysis led to the work of David Armstrong (2002). His view of Foucault was chosen as the analytical framework because of the researcher's ability to relate Armstrong's work on medicine to the present subject of education. Because Armstrong did not specifically address the gathering of the data or thematic creation in his methodology, Black and Ubbes’ (2009) data gathering techniques and Braun and Clark’s (2006) data analysis for thematic formation were utilized for their synthesis with Armstrong's version of Foucault as well as their methodological validity.

The review of the literature provided the researcher with the deeper understanding of the AP program and its history, needed to facilitate the analysis. A chronology of events was created to stand alongside an in-depth review of the current AP program which involved an examination of both the tests and curricula. Published first-hand accounts and CB publications were used to accomplish this task.

Research journals, newspaper articles, and public policy documents served as the discourse, forming the data to be critically analyzed. The data was gathered through key term searches of ERIC, PsychINFO, Wilson Web, JSTOR and ISI Web of Knowledge for the academic journals, Google News Archive, LexisNexis, News, and Proquest Newspapers, for newspapers, and LexisNexis, Government Documents, and Proquest, Congressional for government documents. This yielded a data corpus of 1135 documents (641 journal articles; 412 mews paper articles; 82 government documents). The documents were read and organized (see Appendix D) to yield a working data set of 312 items. The data set was then read, reread, and then 417 data extracts were culled from the documents (see Appendix D). These extracts were grouped based upon similarity in both timeframe and content. The groupings were explored to detect themes and chronological 
divergences in the discourse that Foucault termed "ruptures.” These ruptures encompassed a larger sociological dimension and were not limited to the field of education. They can be viewed in the discourse through a pattern of changes in the discourse over time.

The data revealed three historical ruptures: the launch of the Sputnik satellite in 1958 (84 data extracts), the publication of the NAR report in 1983 (92 data extracts), and the passage of NCLB in 2001 (241 data extracts). These ruptures correlated to three emergent themes. Each of these themes offered one or more subthemes specific to each of the ruptures.

The first theme emerged from the discourse published after the launch of the Sputnik satellite and explored the increasing role of the AP program in education and how the program led to so-called school reform. This led to two subthemes: (a) AP as an educational reform for the ablest of students; and (b) the gaining in acceptance of the AP program by secondary schools and colleges and universities. According to the discourse, AP as a reform for the "ablest" students required education reform to meet the demands of society (Cornog, 1957). The discourse revealed a belief held by educational reformers that education needed to be differentiated by ability groups (Fair, 1958). The rationale given in the discourse was that the ablest students needed a more rigorous education to better serve society, and the prediction was that these reforms for able students would lead to better education for all ability groups (Keller, 1958). However the program needed to expand from the few schools that initially sponsored the program if it were to serve the needs of the reformers. This led to the other subtheme, the need for AP to gain 
wider acceptance as a reform particularly in secondary schools and colleges and universities.

The second theme that emerged from the discourse was the transition of the AP from a test-based program to a course-based program, which was associated with the historical rupture of the publication of the NAR report in 1983. This theme had four subthemes: (a) AP as a course; (b) a shift in the population taking AP courses; (c) the use of AP courses to promote equity; and, (d) AP courses as defining and modifying secondary and collegiate curricula. An analysis of the discourse after the NAR rupture revealed firstly that a shift in the discourse that focused on the AP course and its benefits to students above and beyond the benefits of the AP test. This shift in emphasis from test to course led to a shift and expansion in the population taking the course. This shift in population could be viewed in the discourse which showed that AP program was no longer for the student at the elite schools; it was for any student with designs of attending college who wanted to take a rigorous course and take advantage of the AP program. In turn the growth in the number of students taking AP courses led to discourse in the reformulation of the curricula leading up to the AP course and the college courses that the AP program purportedly replicated. The emphasis on the course led to the use of AP as a way to promote educational equity at the secondary level.

The third theme explored the evolution of discourse on the AP program after the third historical rupture, the passage of NCLB. The theme explored the opening up of access to the AP program. The discourse offered two subthemes: (a) AP as a college preparatory program; and (b) AP as an open access program. At this time the discourse showed that colleges and universities began to look for AP courses on student transcripts 
as part of the admissions process. Secondary schools, cognizant of this began to counsel their college going populace of this fact, and these students began taking more AP courses for their benefit as a way of preparing for and getting into college. This focus on courses and de-emphasizing of the test results led to another shift in the population participating in the AP program. Secondary schools began to look at AP as a preparatory program and opened the programs to populations that had never been exposed to the program before. The discourse revealed a shift in the program itself so that it was no longer a gatekeeper differentiating the college-going populace from the rest of the school populace. Instead any student regardless of previous academic performance was encouraged by the CB to take AP courses.

\section{Discussion of the Research Question}

The study asked the following research question: What have been the changing conceptions of the Advanced Placement program from its inception in1956 through $2012 ?$

Over the past 57 years the AP program has become an integral part of the educational landscape. The program has been assimilated into the American educational system as a layer of the curriculum and represents to many the apex of academic rigor in the U.S.. To remain consistent with Armstrong's version of a Foucauldian analysis, the findings address the relationship between themes and subthemes herein and the ramifications of the changing conception of the program. The findings are also discussed both in terms of the AP program's role in the broader field of education and in relation to education's role itself as relative to the political structures of society. 
Three major ramifications that were uncovered in the course of the study related to the integration of the AP program. The first ramification related to the finding that the present day AP program has become a dichotomous program consisting of a test and a course. The AP test has increased inequality between groups but, at the same time, the AP course has become a tool used to expand equality. The second ramification relates to the finding that the AP program has become an economic juggernaut. Revenue derived from the AP program makes up over half of the CB’s $\$ 720.65$ million in revenues, over \$60 million of which was profit, in 2011 alone. As a result, this revenue gives the CB significant political capital. The ability of the AP program to generate a large income serves as a model to encourage the entrance of other institutions, both non- and forprofit, into education. The third ramification is the AP program acts as a successful agent of privatization in the public schools. The findings showed the privately-owned program began in elite public schools but quickly expanded to public schools. It has since been institutionalized by legislation using public funds, yet the privatization aspect of this is not challenged or even referred to in the discourse on the AP program.

\section{The AP dichotomy}

The findings revealed AP as a program with two elements, the test and the course. Each effects education in a diametrically opposed manner. This dichotomy is an example of the diverse roles of the Foucauldian concepts of power and knowledge. As the AP program expanded and changed over time, these two elements have taken divergent paths in relation to equity. The test is an agent of those already in possession of power and knowledge. The test has maintained its traditional role as an agent of inequity while becoming the less important of the two elements. The course has gained in significance 
as politicians and educational reformers have used this tool as a means of reducing inequity and redistributing societal power though the acquisition of knowledge.

As opposed to other histories of the early program that have only attended to the test, the findings here have revealed that the AP program gave an additional curricular advantage to the students already receiving the best curricula in the nation. Curricular advantages came in differing forms such as students receiving a college level curriculum at the secondary level and access to the school's best teachers. For many of the private schools that initially adopted the program, these advantages were already present. For the early adopting public schools these advantages were created as new curricula were created to meet the demands of the AP program’s tests (Burnside, 1958; Engelstein \& Miller, 1958; Keller, 1958; Whipple, 1958; Douglas, 1959; Jones, 1975). The discourse from early adopting schools describes the extensive and intensive nature of the work done by the students needed to make the course curriculum match the college equivalents and maximize student participation on the test. These early versions of AP courses were so selective in which students took the courses that the majority of students earned a passing score on the test.

The early adopting public high schools were generally in affluent neighborhoods with parents from professional occupations. One of the early adopting public schools, Nicholas Senn High School in Chicago, had $80 \%$ of its students attend college upon graduation (Engelstein \& Miller, 1958). The socioeconomic status of the community can be inferred from such a large collegiate attendance rate in the 1950s. In 1958, Evanston Township high school in Illinois boasted well-educated parents with the majority having some college education (Fair, 1958). 
The reference to the AP program in the NAR report (1983) embedded the AP program in the ongoing national debate and discussion of the American educational system. One of the key findings of the report was the need for more rigor in the American classroom (Gardener, Larsen, \& Baker, 1983). At that time the AP program was the only program in existence that stressed rigor and the only program that was sufficiently large to grain traction. From that time the AP program was considered to be a standard part of the secondary school curriculum, although it could still be found in fewer than half the nation's schools. State and local school boards reacting to the NAR report began incorporating the AP program in schools throughout the nation and the program was incorporated into the fabric of the American educational system.

At the same time a new concept emerged in the literature, centered on a change in emphasis from the program's test to the program's course work (Colwell, 1990; Highsmith, 1989; Lucia, 1993; Lillich, 1999; Stearns; 1999). Earlier in the program AP classes did not have a special designation or were designated as honors classes and students could simply decide to take the AP test at the end of the school year. By the mideighties, courses were designated as AP and the test was an expected outcome. The CB began publishing course descriptions that included the course content and curricular goals and sample test questions (College Board, 2011u). The findings in this study revealed that this change in emphasis of prioritizing the course over the test led to inequity in two ways. First, as a course, the AP program incorporated into the curriculum a third layer of educational differentiation (regular, honors and AP courses) further widening the gap between the advantaged and disadvantaged students (Herr, 1991; Herr 1992). Second, the creation of the AP course allowed for a differentiation in the credit granting system that 
articulated grade point average (GPA). Schools addressed the difference in difficulty levels between AP and other courses through course name and through the awarding of bonus points to the student's GPA for the taking of the AP course. Both of these advantages were reflected on the student's transcripts and gave the individual an advantage in the college application process. The literature shows the CB helped to ensure the quality of the bonus points on transcripts by having schools certify their courses as AP (College Board, 2011v). This added to the advantages afforded by the AP program in regards to higher education. In the earlier period of the AP program students felt the advantage of the AP program after their acceptance to the university; now with the certification of the course, there was also an advantage in the application process.

The AP program tests give an additional curricular advantage in college to those who traditionally held power through the additional knowledge afforded by college attendance. One of the features of the test that helps to maintain the inequality is the cost of the tests for students. The CB charges $\$ 89$ for each test. Students from a more affluent socioeconomic status may have the ability to take more AP tests and thus have the possibility to gain a greater curricular advantage at the collegiate level. For the economically disadvantaged student even with the reduction (both federal and state) afforded students participating in the free and reduced lunch program, the reduced fees (often $\$ 19$ per test) may still be cost prohibitive. In addition students of a higher socioeconomic status tend to have greater access to more experienced teachers, tutoring, and practice materials in preparation for the test.

Another example of Foucault's power/knowledge relationship is exemplified in the increased focus on AP courses in the AP program and role of the course in the reform 
to increase equality in education. After the release of the NAR report the AP program was viewed as a model of excellence in education which could be used to address the issues of equity in secondary schools. Educational reformers attempted through various means to expose disadvantaged students to the rigorous AP program curriculum in order to narrow the general achievement gap. This made the AP program more accessible to a greater number of students than ever before, although it still acted as a barrier to many. Local and state governments have used research on the AP program results to disaggregate data on participation by subgroups of the population (Bridgeman \& Lewis, 1991; Rodriguez, 1997; Stanley \& Heinrich, 1997). The AP program was used to address the inequity within itself and be treated as if this were addressing inequity in education in general (Stellar \& Lambert, 1996; Delaware State Department of Education, 1999). The belief was that by expanding the AP program it would lessen the inequity between White and Asian students and Black and Hispanic students. These changes in access to the AP program helped to promote a rapid and continuing expansion of the program facilitated by governments.

The discourse revealed how the AP program became a vehicle used to quantify equity differences, especially with the advanced students. Equity as it relates to the AP program was tied to state and local reports of student performance. These reports quantified the gaps between different ethnic groups and the genders (Bridgeman \& Lewis, 1991; Delaware State Department of Education, 1999; Rodrigues, 1997; Stanley and Heinrich, 1997). Although the reports were written with the intention of rectifying the ethnic and racial gap, there was little in the discourse to demonstrate that any attempt at rectification was made. 
The shift in the AP program after the publication of the NAR in 1983 from a placement to a preparatory experience began to address issues of equity. As demonstrated in the preexisting literature and reaffirmed by the findings this shift essentially widened the scope of students taking the AP program courses in several aspects. Previously the AP program had been for the secondary school student who was already prepared for the college level curriculum. Students could take college-like courses in their secondary schools. With this shift the course became something in between a college and a secondary offering and a progression in the advanced curriculum that would give added support in preparation for the difficulties of collegiate classes. Colleges and universities admissions bought into this concept that by having taken an AP course students were prepared for the rigors of college and the AP program became a de facto part of the acceptance process.

The findings on the shift to open access also revealed that the AP program was used as a tool for rigorous remediation (Leonard, Blasik, Dilgen, \& Till, 2003; Hale, 2007). These particular programs were not necessarily created with the intention that the students would pass the AP exam. Instead these programs focused on using the AP program to reform local school curricula and reduce inequality within schools, school districts, and states. These reforms often simply used the AP program to expose disadvantaged students to the rigors of a college level curriculum with the belief that they would increase equality through use of the same curriculum (Leonard, Blasik, Dilgen, \& Till, 2003; Oberjuerge, 1999). These reform programs increased disadvantaged student participation in the program but they did not focus on passing the test thus negating any intention of narrowing the achievement gap in testing. The reforms instead expanded the 
gap between racial and ethnic groups passing the exam, and so exerted little to no influence on the disparity as related to the collegiate benefits of the program. The literature supports this showing a decrease in the pass rate from $62 \%$ to $58 \%$ over the 5 year period from 2003 to 2008 (Finn \& Winkler, 2009).

Examples of other programs that attempted to reduce inequality through the course and the test included The AP Challenge Program in Virginia, The University Faculty Fellows Program in Texas and the Minorities Scholars Program in Omaha, Nebraska. These programs focused squarely on narrowing the gap in the AP program pass rates between racial and ethnic groups (Blackwell, Pisani, \& Pisani, 2007; Nguyen, Callahan, \& Stevenson, 2010; Saunders \& Maloney, 2004).

\section{The AP program as an economic juggernaut}

The AP program has moved from a small program, reliant upon grants for sustenance, to an economic powerhouse. Every push for growth of the program by the $\mathrm{CB}$ made the AP program financially stronger. In recent years The $\mathrm{CB}$ has earned over half of its profit from the AP program. "For the period from July 1, 2010 to June 30, 2011, according to its most recent available Form 990, the College Board had \$720.65 million in revenues (96.5 percent of which were program service revenues) and expenses of \$684.98 million, yielding ... a “profit” of 9.9 percent.” (Cohen, 2012). The profits have given the CB Foucauldian power through its control of knowledge in the sphere of education. This financial windfall, which is mostly due to the AP program exam fees, has also encouraged for-profit organizations to enter into the educational sphere in search of profits. 
The literature showed and the findings confirmed that there was a concerted effort to expand the AP program and gain acceptance from secondary schools, colleges and universities nationwide. The findings revealed the AP program's spread from elite private schools, to upper and upper-middle class public schools gaining acceptance based upon the names and reputations of the founding AP schools. The literature showed that CEEB pushed the program relentlessly (Bowles, 1967). The CEEB took every opportunity to proclaim the advantages that the AP program afforded elite students at private schools. The students, parents, and faculty of the nation's elite public institutions desired to emulate the advantages afforded by the private schools and in particular have their children attend exclusive private liberal arts colleges and universities. This could be seen in the list of early adopting public schools, the socioeconomic status of their student bodies, and the list of the universities that initially accepted the AP program scores for credit or placement.

The findings confirmed that the continual growth of the program was important for the program's growth in power and thus continuance. In the early years the AP program was funded through grants and thus apt to lose money. Once under the wing of the $\mathrm{CB}$, the expansion of the AP program brought in greater funding and the program began to break even. The literature showed that though not profitable in the early years the extraordinary growth of the program significantly changed the status and financial standing of the program and the $\mathrm{CB}$. The AP program became financially stable by the 1970s. In 1955 the program was in 104 schools; by 1970 it had expanded to 3,186 (College Board, 2011f). The program expanded in the number of exams taken every year 
from its inception until 1975. There was a single year drop in participation in 1976, before the pattern of continual expansion resumed (Rothschild, 1999).

The literature demonstrated that the AP program gained the ultimate power when it became the de facto curriculum (controlled the knowledge) of rigor in the secondary schools by the 1980s. The literature showed the AP program expanded in the number of courses offered in addition to the number of schools it served (College Board, 2011u). The findings add to the literature the modification of curricula due to the program's change in role. The expansion of the AP program prompted changes in the curricula of secondary schools and in higher education. These changes did not occur because of a conscious desire to reform curricula for the betterment of students. Instead both colleges and schools reformed their curricula in an attempt to conform to the AP program and its standards. Secondary schools instituted pre-AP and preparatory courses to prepare students for the rigor of AP (Colwell, 1990; Lucia, 1993; Steller \& Lambert, 1996). The College Board took advantage of this and began offering ways to promote AP preparations. This then brought more students into the program and facilitated the economic growth of the program.

The findings show that the subsequent significant expansion in the program's participation increased the funding for what was, at the time, a financially-strapped company. The findings confirmed a statement from the literature that Caperton was brought in to increase revenues (Lorin, 2011). The shift to a preparatory program widened the scope of students taking AP courses. With this shift the course became something in between a college and a secondary course and the course became a progression in the advanced curriculum that would give added support in preparation for 
the difficulties of collegiate courses. This change portrayed the program in benevolent terms; the AP program at the behest of the College Board's new president would assist students in college admissions.

One of the findings that added to the literature was revealed in how the financial success for the CB was propelled by an ostensible push for equity using fee waivers provided by federal and state governments. As the CB notes, each state offers fee waivers of between \$26 and \$28 (College Board, 2011h). The federal government gives additional incentives that vary depending upon the socioeconomic status of the parents. The waivers encourage more participation in the program. The waivers are also paid directly to the $\mathrm{CB}$ and thus contribute its profit.

In reality inequality still resulted from the fees charged for the tests. The literature shows the remaining portion of the testing fee even after the waiver of \$26 and \$28 and an additional $\$ 22$ fee waiver given by the CB was approximately $\$ 50$ (College Board, 2011h). Even with fee waivers many students could not afford the portion of the test that remained payable. In certain instances students had to take fewer AP tests or use installment plans to pay for their share (Ceaser, 2012). By not covering all of the fees for impoverished students, the AP program remained a gatekeeper that maintained the institutional apparatus of power through inequality of access to the most rigorous curricula in the educational system.

\section{AP program as an agent of privatization}

The findings revealed a concept previously unexplored by the literature - the spread of the AP program as a private program being instituted in public schools. The CB through its AP program has changed the Foucauldian dynamics of power in the sphere of 
education. The CB is a private entity that is being supported by public funding and the AP program has attained economic power because of the publicly funded nature of the program. In education the AP program was one of the first private institutions to receive public funding. This has influenced educational policy creating an acceptable notion of public funding for private institutions. Today because of the path set by the AP program, numerous private entities have tapped into public educational funds. This has included the charter school revolution and private test making companies such as Pearson that use public funds to make and administer tests for the public school system.

The findings agree with the literature. The original experimental AP program was privately funded. In 1951, the Ford Foundation sponsored a study, the Fund for the Achievement of Education (Rothschild, 1999). The General Education in Schools and Colleges report came from the study and recommended the creation of achievement exams to give advanced standing or credit to high school seniors (Riccards, 2010). The Ford Foundation initiated two experiments for the elite student. The first experiment was a scholarship program subsidized by the Ford Foundation's Fund for the Achievement of Education that sent juniors in high school to college to finish their high school career and simultaneously begin college (Riccards, 2010). The second was the Kenyon Plan that created 11 courses taught in the high school and granted college credit (Maier, 1957).

After the different programs coalesced into the AP program, public schools began to take part in the program and public funds began being used to pay for the private program. Initially the investment was used to create an infrastructure in the school to support the exam takers and thus help student achievement in the program. The findings revealed the expansion of the program further embedded the AP program in public 
education and encouraged the reception of public funds by a private entity. In the late 80s and early 90s states began programs to encourage AP participation. Since 1989, Florida's legislation has paid school districts and teachers for passing scores. Legislation in the state also pays the totality of the exam fee for all students who take the AP course (Florida Department of Education, 2013). Florida also created legislation mandating all public colleges and universities accept AP program scores.

In California, Daniel v. California mandated the AP program in all public schools. The ruling stated public schools were denying equal educational opportunities when they did not offer AP courses (Oakes, Muir, \& Joseph, 2000). Subsequently California has passed laws mandating the AP program in all schools and the acceptance of AP in all public colleges and universities. The findings also revealed other mandated state funds being used for the AP program. Arkansas and Mississippi mandates at least four AP courses in each high school (Education Commission of the States (ECS) State Policy Database, 2013). These states are a few examples of the legislation that has been enacted across the nation. Each example demonstrates the integration of the private program into legislation and thus the interweaving of the private sector into public education.

The findings also revealed that the AP program is no longer alone in receiving public funding. Over time the legislation has added other private programs that now receive public funds. The IB and Cambridge programs, the AP program's main rivals, are among those that have received public funds. Private testing corporations have received public funds for the creation and administration of end-of-course exams in public schools. In addition, legislation has been enacted for the creation of charter schools which are private schools using public funding. 
Initial state reports on advanced program in the 80s and early 90s only used the AP program (Bridgeman \& Morgan, 1994; Bodenhousen, 1988; Creech, 1995; Delaware State Department of Education, 1999). More recent reports have included the AP program's competitors, especially the IB program (Dougherty, 2006; Foust, HertbergDavis, \& Callahan, 2009; Geiser \& Santelices, 2004; Johnstone \& Del Genio, 2001; Massachusetts State Department of Education, 2003; Minnesota Department of Education, 2010).

The CB spends a considerable amount of lobbying for legislation. In 2010 fiscal year the CB spent $\$ 726,000$ on lobbying (Lorin, 2011) and could spend more if desired as that year the CB enjoyed a profit of approximately \$36 million. This ensures a continuation of public funding of the private program.

\section{Limitations}

As with any Foucauldian discourse analysis the study is limited by the interpretation of the data. Ball (1995) in his analysis of the use of Foucault in education noted that the theory of discourse analysis rested upon complexity, uncertainty and doubt. Hume and Bryce (2003) stated, "the search for clarity and simplicity of meaning is seen as illusory because there will always be other perspectives from which to interpret the material under review. To seek a definitive account is, thus, a misguided undertaking” (p. 180). Another author could look at the same data set and have found different themes and come to different conclusions. The reliability of the knowledge claims can be drawn into question. Absolute truths can never be drawn in any historical analysis, yet they can be mitigated. I believe that I have mitigated this limitation as much as possible with the methodological rigor applied to the analysis. 
A second limitation is that the AP program is more than just discourse and thus there is more to draw upon in understanding the AP program than the discourse itself. This limits the scope of the investigation as well as the ultimate level of understanding available. This limitation is present in any discourse analysis of something that is currently extant. Unlike CDA, Foucauldian discourse analysis does not pay close attention to the features of the text. Instead it relies upon the relationship the language used in the discourse and the social processes at work (Taylor, 2004).

A third limitation is related to historiography. The end point of 2012 brings the history into the present. Armstrong (1993) argued that discourse from the current era cannot be fully analyzed because it includes contemporary perspectives that distort the resulting discussion. The comparison of the discourse from previous eras with subsequent eras and the modern perspective is how Foucault was able to analyze discourse. Analysis of older eras takes place in terms of what came after. The modern era cannot be analyzed in these terms. It can only be analyzed in terms of what is happening currently. Thus the analysis of modernity is less reliable than the analysis of past eras.

\section{Recommendations for Practice and Policy}

The AP program is integrated into the educational system of the U.S. sociologically, academically and in the public policy concerning that system. This then leads to numerous political implications for the program. While a withdrawal from the AP program is not likely to take place, a variety of institutions could benefit from the findings and implications of this study.

Politicians charged with the regulation of education in the nation should recognize the growing integration of the private AP program into the educational system and 
determine whether or not the educational system should grow to be dependent upon the AP program to deliver the curricular needs of certain sets of students. Politicians should also be cognizant of the unintended consequences of crafting laws incorporating private programs such as the AP program into law and be willing to change the law if there are deleterious effects.

As we move towards a national curriculum, politicians need to ask whether the AP program, or even other private education institutions competing with the AP program, should be included in the national curriculum. The most recent attempt at a national curriculum is the Common Core. This comprises a set of curricular standards that have been adopted by 44 states, the District of Columbia, four territories, and the Department of Defense Education Activity. The new president of the CB, David Coleman, was one of the architects of the common core (Goldstein, 2012). The CB is selling the new standards and claims that the AP program is aligned with these standards (Hart, Carman, Luisier, \& Vasavada, 2011).

In addition, politicians and governmental entities such as state Departments of Education should examine the issues of equity in relation to statutes that include the AP program. An examination of the manner in which the AP program is used and an analysis of how the usage of the AP program will affect a culturally diverse populace should take place before the statute is made law or if that is not possible before the statute is implemented by departments of education. This is the opposite of the current system where if equity is addressed it is only done after the implementation that may have led to the inequity in the first place. 
Higher education needs to reexamine its policies in regards to the AP program. The dichotomous nature of the program may no longer align with the original intentions that colleges had when they began accepting AP credits. This is especially true if the AP program is being used as both criteria for entrance as well as a means of granting course credit at the institution. This may harm both the validity and reliability of an institution's acceptance and degree-granting procedures. As the AP program is a tool in the admissions process, higher education also needs to examine the current inequity in the program and take inequity into account in the admissions process.

Secondary education needs to evaluate its usage of the AP program along with the populations that are taking AP courses and tests. Departments of Education, school districts and schools should examine their use of the AP course and exams and determine whether their policies are fostering equality or inequality within their student population. Secondary schools may want to examine how they are using the AP program in terms of its tests or courses. The schools must then align with what the perceived benefits of the program are to the school and to the students. Schools need to ask if they are using the AP program as a reform for the benefit of the students or for the incentives the program gives the schools because of state legislation.

Additionally Departments of Education need to look at the transformation of the program that has taken place and apply the lessons learned from the changing conception of the AP program to secondary end-of-course examinations. As more states institute end -of-course exams it is important to examine what institutions will be in competition for the potential economic windfall that could come from the administration of the tests. Departments of Education should also be mindful of the unintended consequences of 
their end-of-course examination program. This mindfulness should set up parameters for reaction for unintended consequences that are not beneficial or desirous.

\section{Recommendations for Research}

The findings of the study suggest several avenues for further study. First, it would be possible to expand upon the themes that were found through exploration of additional data sources. Further research might investigate the changing conception of the AP program through the lens of secondary AP teachers and administrators who have been involved in the program for long periods of time. Additionally research into the program could involve the perception of various groups of students who have taken the AP program over the course of its existence. The student population has evolved with the program and their opinions as to the advantages and disadvantages of participation should be canvassed.

Additional research could be undertaken into the benefits and disadvantages for the AP program institutions, constituents and students have experienced as a result of the changes in perception stemming from the widespread growth of the program. In particular, certain advantages to be researched might include how the growth of the AP program has affected the college attendance rates of various groups of students. This research would look at correlations between college attendance and success rates for socioeconomically disadvantaged students. Research could also be undertaken in a manner similar to Casserly (1968a, 1968b, \& 1986) interviewing socioeconomically disadvantaged students who took part in the AP program and who now attend college. Disadvantages should be investigated also. Further research could be conducted as to the loss of prestige that has accompanied the expansion of the program. One question could 
be whether the change in conception has changed the role of the AP program in the admission process of universities. Second, research could be conducted on the commodification of the program and how its inclusion into the standard high school curricula has changed the program. Third, research could be conducted on the influence of the AP program in privatization of institutions in the American educational system.

\section{Summary and Final Thoughts}

The ubiquitous AP program is synonymous with the buzzwords rigor and relevance. The program has become the advanced secondary curriculum in the U.S.. Although privately held, the AP program has integrated itself into the educational system so fully that the AP program has become the next step for advanced students after honors classes. It does not stand as a separate test as it once did; AP courses are now a part of the curriculum and the program has lost its place as an elite program that distinguished students from their peers. Recent rivals, including the IB program, Cambridge program and dual enrollment, compete with the AP program at the advanced curricular level. Despite these developments the AP program is still the dominant program. The CB has crafted for the AP program a position envied by its rivals. Although the AP program has been losing support from the very base on which it was built, the findings show that the program has evolved so that the AP program and the College Board no longer need the support of the elite private schools that founded the program. The CB has turned the AP program into a moneymaking juggernaut whereby the profits can be channeled back into guaranteeing the program’s continued vitality.

The changing conceptions of the AP program have opened up the program to a wider audience. Students today have greater access to the AP program and have more 
possibility of taking an AP course. After the initial test phase of the program and the uncertainty over whether or not it would succeed, all subsequent uses of the AP program as a reform have been outside of the original scope of the program. The subsequent reforms have been a boon for the program especially in the increased numbers of students now taking AP. Whether or not the reform worked does not seem to matter to educational reformers as the AP program is looked upon in a favorable light, and thus its use as a reform is looked upon positively. If the reform succeeded, it demonstrated the utility of the AP program. If the reform did not, the exposure to rigor and the college level material was viewed as still being beneficial to the students.

The change in the original purpose of the program has also affected the willingness of students to take the courses. The AP program as a curriculum with a broad array of courses that place an emphasis on college preparation has changed the dynamics so that more students are willing to take the classes. AP is no longer just for the students definitely going to college and who need the extra challenge (Colwell, 1990; Lucia, 1993). As a preparatory program, the AP program now makes college more attainable for a broader spectrum of students. The preparatory nature relates to the usage of the AP program as a standard for college admission. Students at less reputable schools have a nationalized curriculum of rigor to demonstrate their worth in the admissions process (Honan, 1998; Sadler, \& Tai, 2007).

The interplay and interrelation between all three of the themes demonstrate a changing dynamic in American schools in general. The availability of a college preparatory program in some form has expanded over 56 years in a large part due to the AP program. Even when schools cannot offer the AP program directly, attempts at access 
have been made through telecommunications and the Internet (Barker \& Brannon, 1992). This shows the changing focus as to which students are interested in attending college in the U.S..

The AP program currently stands at a crossroads. In many circles the AP program is more prestigious than ever. It enjoys broad support from federal, state and local governments. Parents, students, and college admissions officers all view the AP program as a sign of success and as an unqualified boost to student transcripts. Yet cracks in the foundation of the AP program as an elite program are appearing and the College Board is responding to these challenges. The academic departments of colleges and universities have recently begun to question the courses' rigor and compatibility compared with introductory courses. These questions have led the College Board to make sweeping changes. First an audit system was put in place in the 2007-2008 school year ostensibly to improve course rigor though in reality it also guaranteed the AP program brand and the CB's financial interests. The audit addressed the concerns of equality in rigor of AP courses for college admissions officers. It was not enough to appease academics who believed that the tests no longer reflected the college curriculum. To combat compatibility issues, the College Board has begun to roll out a redesign of the courses to better align with current college standards. The changes began in 2012 with the Biology and World History tests, two courses that were seemingly furthest from their collegiate equivalent. The redesigns will progress with the rest of the program's courses through the end of the decade.

Another crack in the foundation stems from the fact that the AP program is now distant from its elite roots and the College Board no longer has the same relationship with 
the elite institutions that founded the program 56 years ago. Some of the prep schools in the original pilot have dropped the program in favor of locally created curricula. Two of the three secondary schools responsible for the General Education in School and College: A Committee Report by Members of the Faculty of Andover, Exeter, Lawrenceville, Harvard, Princeton and Yale which led to the AP program no longer participate. Additionally the elite universities that were originally involved in the program no longer participate or are nominal in their participation. Harvard is a nominal participant. A look at the school's website reveals the school only accepts scores of 5 on select tests and then only for placement. Students must score a 5 on a minimum of five AP tests and only then if they meet these requirements, the student is offered sophomore standing. Both Yale and Princeton now only accept a score of 4 or 5 depending on the test, and only accept scores from a limited number of tests. To combat these losses the College Board has reemphasized its push for broader acceptance of the program by incorporating the program into more secondary schools and gaining its acceptance in more institutions of higher learning. Through political lobbying the College Board has incorporated the AP program into legislation in all 50 states and in the federal government. Some states such as California and Arkansas have mandated the AP program in every public high school in the state, thus offsetting the loss of elite private schools with the volume of sheer numbers. Pushes by the College Board have led to legislation in some states such as California and Florida that mandate all public universities accept AP credits, thus insulating the program from issues faced at elite private institutions with mass acceptance. These cases exemplify the reason for continuous growth of approximately 5-7\% per year (College Board 2006i). 
Another challenge comes from the competition from other rigorous elite programs. The International Baccalaureate, Cambridge and dual enrollment programs all compete for the curriculum of rigor in elite American schools. Where the AP program was once the uncontested measure of quality in schools across the country, this competition has eroded that dominance. Newsweek's original measurement of school quality only included the AP program. Now the measurement has expanded to include both the AP program and IB. As such, the AP program has lost some of its position as the de facto curriculum of rigor in America's secondary schools. The most recent education legislation in many states is no longer AP specific. Instead legislators have incorporated IB, and dual enrollment into the language of public policy. In Florida the legislation has made IB an acceleration program equivalent to the AP program. The state mandates that all Florida's public post-secondary institutions accept the AP program and IB exam scores, that school districts administer equal weighting in quality points for a student's GPA when taking AP, IB and dual enrollment courses, and offers the same teacher financial incentives for both the AP program and IB program (Florida Department of Education, 2013). Texas offers equal financial incentive for passing both the AP and IB exams (Education Commission of the States (ESC) State Policy Database, 2013). In Minnesota, IB was added to AP as an advanced educational option as part of the Education Omnibus Bill in 1992 (Espinosa, 2012). .

Yet even at these crossroads the AP program stands as an integral educational program in America's secondary schools. The CB has created a perception of the AP program as the standard for rigor and a successful educational reform. the AP program and the importance it places on testing coincide with the emphasis on testing in America. 
As the AP program has grown, testing has proliferated and come to dominate American schooling. In addition the AP program has defined what it means to have a rigorous curriculum especially for the advanced and gifted student. In many secondary schools it is the only option for those students labeled as gifted. The AP program also serves as an indicator of quality on student transcripts. College admission officials, unable to determine school quality, still use the AP program to guide their decision making process; this is even true in colleges and universities that no longer accept AP scores.

Even with these cracks in the program's foundation of economic might, the programs dichotomous nature between test and course suggests that there is enough evidence of evolution in the conception of the program that it will continue as the nation's premier academic program of rigor and college preparation. The change and growth in conception of the program over the past 56 years has resulted in a deep integration with the educational fabric of the nation. As such the program will continue to remain and evolve as an intrinsic part of the American education system. 


\section{REFERENCES}

ACT Inc. (2009a). The Advanced Placement program benefits mainly well-prepared students who pass AP exams. National Center for Educational Achievement.

ACT Inc. (2009b). Using PLAN to identify student readiness for rigorous courses in high school. Retrieved from: https://www.act.org/research/policymakers/pdf/Using Plan.pdf

Advanced Placement in the Member Colleges, 1958-1959 (1958). NASSP Bulletin, 42(242), 77-87.

Ailwood, J. \& Lingard, B. (2001). The endgame for national girls' schooling policies in Australia? Australian Journal of Education, 45(1), 9-22.

American History (1958). NASSP Bulletin, 42(242), 90-96.

Ammeraal, B. (1997). Correlation between Students' Placement Scores on Acorn Book Multiple-Choice Tests and Passing Rate on the AP Language Examinations. Chicago, IL: Educational Resource Information Center.

Anderson, R. (2011). Mathematics course-taking in rural high schools. Journal of Research in Rural Education, 26(1), 1-10.

Andrea, A.J. (1999). Some observations on the proposed Advanced Placement curriculum in world history. The History Teacher, 32(2), 297-303.

Andrews, H. (2003). Progress in Advanced Placement and International Baccalaureate in SREB states. Atlanta, GA: Southern Regional Education Board.

Angermann, G., Field, E., \& Angermann, G.O. (1958). The advanced curriculum. NASSP Bulletin, 42, 47-53

Ankersmit, F.R. (1989). Historiography and postmodernism. History and Theory, 28(2), 137-153.

Arbolino, J.N. (1961). What's wrong with the Advanced Placement program. NASSP Bulletin, 45, 28-32

Arendt, U. \& Morgan, R. (1995). Comparing performance of high school and college students on the listening sections of the Advanced Placement German Language examination. Unterrich Tspraxis/ Teaching German, 28(10), 40-45.

Armstrong, D. (1984). The patient's view. Social Science Medicine, 18(9), 737-744.

Armstrong, D. (1987). Silence and truth in death and dying; Social Science Medicine, 24(8), 651-657. 
Armstrong, D. (2002). A new history of identity: A sociology of medical knowledge. New York, NY: Palgrave.

Ashford, E. (2007). AP courses get audited for quality. The Education Digest, 72(7), 2528.

Associated Press. (1985, Nov 19). Ways to compare schools are asked. New York Times, pp. A.22-A.22. Retrieved from http://search.proquest.com/docview/425707447?accountid=10901.

Au, W. (2007). High-stakes testing and curricular control: A qualitative metasynthesis. Educational Researcher, 36(5), 258-267.

Austin, C. O. (1958). Advanced Programs for Able Students. NASSP Bulletin, 42(242), 54-57.

Bailey, A.J. (2000). Industrialization and economic development in Advanced Placement Human Geography. Journal of Geography, 99(3-4), 142-153.

Bailey, T. \& Karp, M.M. (2003). Promoting college access and success: A review of credit-based transition programs. Retrieved from http://ccrc.tc.columbia.edu/publications/access-success-credit-basedtransition.html

Bain, R.B., \& Shreiner, T.L. (2005). Issues and options in creating a national assessment in world history. The History Teacher, 38(2), 241-271.

Baker, J. G. (2008). Can a Merit-Based Scholarship Program Increase Science and Engineering Baccalaureates? Journal for the Education of the Gifted, 31(3), 198213.

Baker, B.M. \& Heyning, K.E. (2004). Dangerous Coagulations? The Uses of Foucault in the study of education (Eruptions, V.19). New York, NY: Peter Lang Publishing Inc.

Ball, S.J. (Ed.). (1990). Foucault and education: disciplines and knowledge. New York, NY: Routledge.

Barker, B. O., \& Bannon, J. (1992). The Hawaii Teleschool: An Evaluation of Distance Learning for Advanced Placement Calculus Instruction in "Paradise.". [S.l.]: Distributed by ERIC Clearinghouse.

Barnett, L.B., \& Durden, W.G. (1993). Education patterns of academically talented youth. Gifted Child Quarterly, 37(4), 161-168.

Barron, B. (2004). Learning ecologies for technological fluency: Gender and experience differences. Journal of Educational Computing Research, 31(1), 1-36. 
Barthes, R. \& Duisit, L. (1975). An introduction to the structural analysis of narrative. New Literary History, 6(2), 237-272.

Becker, C. (1938). What is historiography? The American Historical Review, 44(1), 2028.

Beeken, P. (2011). Atwood's heavy chain. The Physics Teacher, 49, 470-472.

Beitler, A., Bushong, D, \& Reid, A. (2004). Making the team. Principal Leadership(High School Edition), 5(4), 16-21.

Bentley, M. (1999). Modern historiography: An introduction. New York, NY: Routledge.

Bergeson, J. L. (1968). An unanswered question about the Advanced Placement program: Do examination questions predict grades? The Journal of Higher Education, 39 (2), 101-104.

Bernstein, J. L. (1958). Midwood High School's Advanced Placement program. NASSP Bulletin, 42(242), 22-23.

Bindel, T. H. (2007). Discovering the thermodynamics of simultaneous equilibria: An entropy analysis activity involving consecutive equilibria. Journal of Chemical Education, 84(3), 449-452.

Biology (1958). NASSP Bulletin, 42(242), 101-112.

Bischof, D. L. (2005). Validating the AP German Language exam through a curricular survey of third-year college language courses. Teaching German, 38(1), 74-81.

Bischof, D. L, Baum, D. I., Casabianca, J. D., Morgan, R., Rabiteau, K. A. \& Tateneni, K.. (2004). Validating AP modern foreign language examinations through college comparability studies. Foreign Language Annals, 37(4), 616-622.

Bish, C. E. (1958). Can we provide a better program for the able student? NASSPBulletin, 42(242), 13-21.

Black, A. C., Little, C.A., McCoach, D.B., Purcell, J.H., \& Siege, D. (2008). Advancement Via Individual Determination: Method selection in conclusions about program effectiveness. The Journal of Educational Research, 102(2), 111123.

Black, J. M., \& Ubbes, V.A. (2009). Historical Research: A thematic analysis of convention and conference themes for selected professional health education associations from 1975-2009, International Electronic Journal of Health Education, 12, 33-47. 
Black, L. (1999). Advanced Placement World History: A rigorous but manageable course for high school. The History Teacher, 32(2), 289-292.

Black, M.M. (1959). The use of achievement tests in curriculum development. NASSP Bulletin, 43(244), 90-93.

Blackwell, D. L., Pisani, J. S., \& Pisani, M. J. (2007). The challenge of Advanced Placement partnerships in the South Texas border classroom. Teacher Education \& Practice, 20(1), 93-108.

Blagaich, P. (1999). Advanced Placement courses are not for everyone. The History Teacher, 32(2), 259-262.

Bloom, B.S., \& Heyns, I.V. (1956). Development and Application of tests of educational achievement. Review of Educational Research, 26(1), 72-88.

Bloome, D., \& Carter, S. P. (2001). Lists in reading education reform. Theory into Practice, 40(3), 150-157.

Bodenhousen, J. (1988). Does the academic background of teachers affect the performance of their students? Retrieved from: http://files.eric.ed.gov/fulltext/ED293836.pdf.

Bodenhausen, J. (1989). Do public and private schools differ in the performance of their Advanced Placement tests? Paper presented at Annual Meeting of the American Educational Research Association, San Francisco, CA.

Bowles, F. (1967). The refounding of the College Board, 1948-1963: An informal commentary and selected papers. New York, NY: College Entrance Examination Board.

Bramer, G. R. (1970). Like it is: Discourse analysis for a new generation. College Composition and Communication, 24(5), 347-355.

Brandenburg, G. F. (2013, April 14). American public schools are not failing- For example look at Advanced placement tests [Web log comment]. Retrieved from http://gfbrandenburg.wordpress.com/2013/04/14/american-public-schools-arenot-failing-for-example-look-at-advanced-placement-tests/trackback/

Braun, V. \& Clarke, V. (2006). Using thematic analysis in psychology. Qualitative Research in Psychology, 3(2), 77-101.

Brennan, R. L. (2010). Evidence-centered assessment design and the Advanced Placement program: A psychometrician's perspective. Applied Measurement in Education, 23(4), 392-400. 
Bridgeman, B. \& Lewis, C. (1991). Sex differences in the relationship of Advanced Placement essay and multiple-choice scores to grades in college courses. Princeton, NJ: Educational Testing Service.

Bridgeman, B. \& Lewis, C. (1994). The relationship of essay and multiple-choice scores with grade in college courses. Journal of Educational Measurement, 31(1), 37-50.

Bridgeman, B. \& Morgan, R. (1994). Relationships between differential performance on multiple-choice and essay sections of selected AP exams and measures of performance in high school and college. New York, NY: College Entrance Examination Board.

Bridgeman, B., Morgan, R., \& Wang, M. (1996).The reliability of document-based essay questions on Advanced Placement history exams. Retrieved from http://www.ets. org/Media/Research/pdf/RR-96-05.pdf.

Briley, R. (2000). What do you mean you don't do Advanced Placement?: Confessions of an educational heretic. The History Teacher, 33(4), 527-532.

Brinton, L. J. (2003). Historical discourse analysis. In D. Schriffrin, D. Tannen, \& H.E. Hamilton The Handbook of Discourse Analysis. Malden, MA: Wiley-Blackwell.

Brocklesby, J. \& Cummings, S. (1996). Foucault plays Habermas: An alternative philosophical underpinning for critical systems thinking. The Journal of the Operational Research Society, 47(6), 741-754.

Brown, R. S. (2005). Changes in Advanced Placement test taking in California high schools 1998-2003. University of California All Campus Consortium on Research for Diversity. Retrieved from http://escholarship.org/uc/item/6ps2j962.

Bryan, R. R., Glynn, S. M., \& Kittleson, J. M. (2011). Motivation, achievement, and advanced placement intent of high school students learning science. Science Education, 95(6), 1049-1065.

Burdman, P. (2000). Extra credit, extra criticism. Black Issues in Higher Education, 17(18), 28-33.

Burnham, P.S. \& Hewitt, B.A. (1971). Advanced Placement scores: Their predictive validity. Educational and Psychological Measurement, 31, 939-945.

Burnside, L. H. (1958). Honor program of studies including Advanced Placement study. NASSP Bulletin, 42(242), 27-31.

Burstein, S. M. (1999). The new AP World History course: How will it compare with college world history courses? The History Teacher, 32(2), 283-288. 
Burstyn, J. N. (1990). Narrative versus theoretical Approaches: A dilemma for historians of women. History of Education Review, 19(2), 1-7.

Butin, D. W. (2006). Putting Foucault to work in educational research: A review article. Journal of Philosophy in Education, 40(3), 371-380.

Bybee, R.W. (1997). The Sputnik era: Why is this educational reform different from all other reforms? Retrieved from http://www.nas.edu/sputnik/bybee1.htm.

Byrd, S., Ellington, L., Gross, P., Jago, C., \& Stern, S. (2007). Advanced Placement and International Baccalaureate: Do they deserve gold star status? Washington DC: Thomas B. Fordham Institute.

Camara, W., Dorans, N. J., Morgan, R., \& Myford, C. (2000). Advanced Placement: Access not exclusion. Education Policy Analysis Archives, 8(40), 1-11.

Carr, E. H. (1961). What is history? New York, NY: Random House.

Carson, S. (2008). OpenCourseWare resources for advanced high school study. Understanding Our Gifted, 21(1), 3-5.

Casserly, P. L. (1968a). What college students say about Advanced Placement- Part I. The College Board Review, 69, 6-7.

Casserly, P. L. (1968b). What college students say about Advanced Placement- Part II. The College Board Review, 70, 18-22.

Casserly, P. L. (1986). Advanced placement revisited. Retrieved from: http://research. collegeboard.org /sites/default/files/publications/2012/7/researchreport-1986-6advanced-placement-revisited.pdf

Casement, W. (2003). Declining credibility for the AP program. Academic Questions, 16(4), 11-25.

Cavazos, A. G., \& Cavazos Jr., J. (2010). Understanding the experiences of Latina/o students: A qualitative study for change. American Secondary Education, 38(2), 95-109.

Cech, S. J. (2007). Number of schools offering AP falls after first audit of courses. Education Week, 27(12), 1-5.

Cech, S. J. (2008). AP Trends: Tests soar, scores slip; gaps between groups spur equity concerns, Education Week, 27(24), 1-4.

Chajewski, M., Mattern, K. D., \& Shaw, E. J. (2011). Examining the Role of Advanced Placement ${ }^{\circledR}$ Exam Participation in 4 Year College Enrollment. Educational Measurement: Issues and Practice, 30(4), 16-27. 
Chamberlain, P.C., Pugh, R.C., \& Schellhammer, J. (1978). Does Advanced Placement continue throughout the undergraduate years? College and University, 53(2), 195200.

Chemistry (1958). NASSP Bulletin, 42(242), 112-124.

Chu, J. M. (2000). Preparing for the AP exam: The dangers of teaching for the test. The History Teacher, 33(4), 511-520.

Clark, T. (2001). Virtual school: Trends and issues. Phoenix, AZ: WestEd.

Coe, B. (2007). The Heart of the Senior Year. Montessori Life: A Publication of the American Montessori Society, 19(4), 22-25.

Cohen, R. (2012). Is the College Board a NINI (non-profit in name only)? Nonprofit Quarterly Promoting an active and Engaged Democracy. Retrieved from https://nonprofitquarterly.org/policysocial-context/21184-is-the-college-board-anino-nonprofit-in-name-only.html.

College Board (2010a). Calculus: Calculus AB, Calculus BC Course Description [Data File] retrieved from http://apcentral.collegeboard.com/apc/public/repository/apcalculus-course-description.pdf.

College Board. (2010b). Choose AP [Data file]. Retrieved from http://www.collegeboard.com/html/ap/docs/Choose-AP-Brochure.pdf.

College Board (2011a). Program summary report [Data file]. Retrieved from http://professionals.collegeboard.com/profdownload/AP-Program-SummaryReport.pdf.

College Board (2011b) Advanced Placement Program (AP): The value of the AP program to colleges and universities. Accesses (April 15, 2011) Retrieved from http://professionals.collegeboard.com/higher-ed/placement/ap.

College Board (2011c). AP program size and increments 1987-2011 [Data file]. retrieved from http://professionals.collegeboard.com/data-reports-research/ap/data.

College Board (2011d). History. (Accesses August 14, 2011) Retrieved from http://about.collegeboard.org/history.

College Board (2011e). The history of the AP Program. (Accessed July 13, 2011) Retrieved from http://apcentral.collegeboard.com/apc/public/program/history /8019.html.

College Board (2011f). Annual AP program participation 1959-2009 [Data file] Retrieved from http://professionals.collegeboard.com/profdownload/annualparticipation-11.pdf. 
College Board (2011g). AP Examination volume change 1987-2011 [Data file]. Retrieved from http://professionals.collegeboard.com/profdownload/AP-ExamVolume-Change-2011.pdf.

College Board (2011h). Fee reductions for AP exams. (Accessed December 27, 2011) Retrieved from http://professionals.collegeboard.com/profdownload/AP-ExamVolume-Change-2011.pdf.

College Board (2011i). Fifth annual Advanced Placement report to the nation [Data file]. Retrieved from http://professionals.collegeboard.com/profdownload/5th-annualap-report-to-the-nation-2009.pdf.

College Board (2011j). AP world history course home page. (Accessed December 27, 2011) retrieved from http://apcentral.collegeboard.com/apc/public/courses/teachers_corner/4484.html.

College Board (2011k). A brief history of the Advanced Placement program [Data file]. Retrieved from http://www.collegeboard.com/prod_downloads/about/news_info/ap/ap_history_en glish.pdf.

College Board (2011l). Studio art course description [Data file]. Retrieved from htpp://apcentral.collegeboard.com/apc/public/repository/ap-studio-art-coursedescription.pdf.

College Board (2011m). Annual AP program participation 1959-2009 [Data file] Retrieved from http://professionals.collegeboard.com/profdownload/annualparticipation-09.pdf.

College Board (2011g). AP exam scores. (Accessed August 14, 2011) Retrieved from http://professionals.collegeboard.com/highered/placement/ap/exam/grades.

College Board (2011n). Course \& exam development. (Accessed August 14, 2011) Retrieved from http://professionals.collegeboard.com/highered/placement/ap/exam.

College Board (2011o). Art history course description [Data file]. Retrieved from http://www.collegeboard.com/prod_downloads/about/news_info/ap/ap_history_en glish.pdf.

College Board (2011p). Music theory course description [Data file]. Retrieved from http ://apcentral.collegeboard.com/apc/public/repository/ap08_music_coursedesc.pdf.

College Board (2011q). Chemistry course description [Data file]. Retrieved from http://apcentral.collegeboard.com/apc/public/repository/ap08_chemistry_coursede sc.pdf. 
College Board (2011r). Human Geography course description [Data file]. Retrieved from http://apcentral.collegeboard.com/apc/public/repository/ap-human-geographycourse-description.pdf.

College Board (2011s). World History course description [Data file]. Retrieved from http://apcentral.collegeboard.com/apc/public/repository/ap07_worldhist_coursede sc.pdf.

College Board (2011t). United States history course description [Data file]. Retrieved from http://apcentral.collegeboard.com/apc/public/repository/ap-us-historycourse-description.pdf.

College Board (2011u). AP courses and exams. Accessed (August 15, 2011). Retrieved from http://apcentral.collegeboard.com/apc/public/courses/index.html.

College Board (2011v). AP Course Audit. Accessed (August 15, 2011). Retrieved from http://www.collegeboard.com/html/apcourseaudit/courses/chemistry.html.

College Board (2013). Annual AP program participation [Data file]. Retrieved from http://media.collegeboard.com/digitalServices/pdf/research/2013/2013-AnnualParticipation.pdf.

College Board (2014). For Students. Accessed (June 20, 2014). Retrieved from http://student.collegeboard.org

Colwell, R. (1990). Advanced Placement: More than a test. Music Educators Journal, 76 (6) 26-30.

Comber,B. (1997). Managerial discourses: Tracking the local effects on teachers' and students' work in literacy lessons. Discourse: Studies in the Cultural Politics of Education, 18(3), 389-407.

Cornog, W. H. (1957). Initiating an educational program for the able students in the secondary school. The School Review, 65(1), 49-59.

Corson, D. (2000). Emancipatory leadership. International Journal of Leadership in Education, 3(2), 93-120.

Course description (1958). NASSP Bulletin, 42(242), 89.

Creech, J.D. (1995). Challenging students to higher standards through Advanced Placement. Atlanta, GA: Southern Regional Education Board.

Crippen, K. \& Brooks, D. W. (2005). The AP descriptive chemistry question: Student errors. Journal of Computers in Mathematics and Science Teaching, 24(4), 357366. 
Cross, T. L. \& Burney, V. H. (2005). High ability, rural, and poor: Lessons from Project Aspire and implications for school counselors. Journal of Secondary Gifted Education, 16(4), 148-156.

Cunningham, R.J. (1976). Is history past politics?: Herbert Baxter Adams as precursor of the "New History". The History Teacher, 9(2), 244-257.

Daddone, P. (2008). Advanced Placement courses put the squeeze on English electives. The English Journal, 98(2), 76-80.

Day, M.A., Thorn, B. E., \& Kapoor, S. (2011) A qualitative analysis of a randomized controlled trial comparing a cognitive behavioral treatment with education. The Journal of Pain, 12(9), 941-952.

Dee, T. S., \& Jacob, B. A. (2009). Standards and Excellence: Evidence from Advanced Placement (AP) Exams. Evanston IL: Society for Research on Educational Effectiveness.

Delaware State Department of Education. (1999). Delaware's college-bound seniors: 1999 SAT \& AP results for Delaware and the nation. Dover, DE

Dentith, A. (2008). Smart Girls, Hard-Working Girls but Not yet Self-Assured Girls: The Limits of Gender Equity Politics. Canadian Journal of Education, 31(1), 145-166.

Denzin, N. K. \& Lincoln, Y. S. (Ed.). (1998). Collecting and interpreting qualitative materials. Thousand Oaks, CA: Sage Publications.

Dickey, E. M. (1986). A comparison of Advanced Placement and college students on a calculus achievement test. Journal for Research in Mathematics, 17(2), 140-144.

DiLorenzo, R. (1999). Teaching Advanced Placement United States History in the Urban, Minority High School: Successful Strategies. The History Teacher, 32(2), 207221.

DiYanni, R. (2002). The origins and development of the AP, the College Board's Advanced Placement program: Part I, American beginnings and American success. International Schools Journal, 22(1), 31-42.

Advanced Placement Program: Part I, American beginnings and American successes. International Schools Journal, 22, 31-42.

Dong, Y., Guerrero, S., \& Moran, M. A. (2008). Using DNA technology to explore marine bacterial diversity in a coastal Georgia salt marsh. The American Biology Teacher, 70(5), 279-283.

Dougherty, C. (2006). Identifying and Studying High-Performing Schools. NCEA Issue Brief\# 1. National Center for Educational Accountability. 
Dougherty, C., Mellor, L., \& Jian, S. (2006). The Relationship between Advanced Placement and College Graduation. 2005 AP Study Series, Report 1. National Center for Educational Accountability.

Dounay, J. (2000). High-stakes assessments bring out the critics. State Education Leader, 18(1), 4-6.

Dounay, J. (2007). Recent state policies/activities: High school—Advanced Placement. Education Commission of the States Policy Brief, Retrieved from: http://www.ecs.org/ecs/ecscat.nsf/WebTopicView.

Dredger, K. (2008). Incorporating student choice: Reflective practice and the courage to change. The English Journal, 98(1), 29-35.

Dudley, D. A. (1958). The Advanced Placement Program. NASSP Bulletin, 42(242), 1-5.

Dudley, D. A. (1969). College Entrance tests and the disadvantaged student. Journal of the National Association of College Admissions Counselors, 13(4), 13-15.

Dutkowsky, D. H., Evensky, J. M., \& Edmonds, G. S. (2009). Should a high school adopt Advanced Placement or a concurrent enrollment program? An expected benefit Approach. Education Finance and Policy, 4(3), 263-277.

Education Commission of the States (ECS) State Policy Database. (2013). Advanced Placement. Retrieved from http://mb2.ecs.org/reports/Report.aspx?id=922.

Elder, F. L. (1959). A junior high school seminar for talented students. NASSP Bulletin, 43(247), 95-98.

Elton, G.R. (2002). The practice of history, $2^{\text {nd }}$ ed. Oxford, UK: Blackwell Publishers.

Engelstein, S.S. \& Miller, H.H. (1958). Advanced work for gifted students at Senn High School. NASSP Bulletin, 42, 32-38.

Ennis, R. (1999). Resources for AP United States history. The History Teacher, 32(2), 237-243.

Etkina, E., Matilsky, T., \& Lawrence, M. (2003). Pushing to the edge: Rutgers astrophysics institute motivates talented high school students. Journal of Research in Science Teaching, 40(10), 958-985.

ETS. (1983). The College Board Review, 127, 17-19, 29.

European History (1958). NASSP Bulletin, 42(242), 96-101. 
Evans, J. \& Tsatsaroni, A. (1996). Linking the cognitive and affective in educational research: Cognitivist, psychoanalytic, and post-structuralist models. British Educational Research Journal, 22(3), 347-358.

Facts, Q. (2006). BHEF 2006 Issue Brief.

Fain, H. (1990). Some comments on Stern's "Narrative versus description in historiography”. New Literary History, 21(3), 569-574.

Fair, J. (1958). The talented youth program. NASSP Bulletin, 42(242), 39-46.

Fairclough, N. (1993). Critical discourse analysis and the marketization of public discourse: The universities. Discourse \& Society, 4(2), 138-168.

Fairclough, N. (1995). Critical Discourse Analysis: The critical study of language. Boston, MA: Addison Wesley.

Fairclough, N (2001) The dialectics of discourse Textus 14:231-242.

Faust, C. H. (1957). Why the new concern for educating the gifted? The School Review, 65(1), 12-19.

Federman, M. \& Pachon, H. P. (2005). Addressing institutional inequities in education: The case of Advanced Placement courses in California. In J. Petrovich and A. S.Wells (Eds.), Bringing Equity Back: Research for a New Era in American Educational Policy (pp. 136-160). New York: Teachers College Press.

Finn, C. E. and A. M. Winkler (2009). Growing Pains in the Advanced Placement Program: Do Tough Trade-offs Lie Ahead? Washington DC: The Thomas B. Fordham Institute .

Flores, S., \& Gomez, M. O. (2011). Strategies for increasing Advanced Placement participation for underrepresented students: Barriers, practices, and positive outcomes. NASSP Bulletin, 95(10), 65-79.

Florida Department of Education (2013). Comparison of Florida's Articulated Acceleration Programs [Data File] Retrieved from http://www.fldoe.org/articulation/pdf/cfaap.pdf.

Flowers, L.A. (2008). Racial differences in the impact of participating in Advanced Placement programs on educational and labor market outcomes. Educational Foundations, 22(1-2), 121-132.

Ford, D. Y. \& Whiting, G. W. (2007). A mind is a terrible thing to erase: black students' underrepresentation in gifted education. Multiple Voices for Ethnically Diverse Exceptional Learners, 10(1-2), 28-44. 
Ford, L. R. (2000). Cities and urban land use in Advanced Placement Human Geography. Journal of Geography, 99(3-4), 153-168.

Foreigners outdo U.S. students on harder exams, study finds. (1996, Mar 24). New York Times, pp.1.36-36. Retrieved from http;//search.proquest.com/docview/430520048?accountid=10901.

Foucault, M. (1972). The archaeology of knowledge. (A.M. Sheridan Smith, Trans.) New York, NY, Harper Torchbooks.

Foucault, M. (1975) Madness and Civilization: A history of insanity in the age of reason. (R. Howard, Trans.) New York, NY: Pantheon.

Foucault, M. (1977). Discipline \& Punish: The Birth of the Prison. (A. Sheridan Trans.) New York, NY: Random House Inc.

Foust, R. C., Hertberg-Davis, H., \& Callahan, C. M. (2008). "Having it All" at sleep's expense: The forced choice of participation in Advanced Placement courses and International Baccalaureate programs. Roeper Review, 30, 121-129.

Foust, R. C., Hertberg-Davis, H., \& Callahan, C. M. (2009). Students' perceptions of the non-academic advantages and disadvantages of participation in Advanced Placement courses and International Baccalaureate programs. Adolescence, 44(174), 289-312.

French (1958). NASSP Bulletin, 42(242), 154-159.

Fuess, C. M. (1967). The College Board: Its first fifty years. New York: Columbia University Press.

Fuhrman, E. R. \& Oehler, K. (1987). Reflexivity Redux: Reply to Potter. Social Studies of Science, 17(1), 177-181.

Gallagher, S.A. (2009). Myth 19: Is Advanced Placement an adequate program for gifted students? Gifted Child Quarterly, 53(4), 286-288.

Gardner, D. P., Larsen, Y. W., \& Baker, W. (1983). A nation at risk: The imperative for educational reform. Washington, DC: US Government Printing Office.

Garner, J. (2012). The freshman nine: Helping high school freshmen be successful in AP Human Geography. The Geography Teacher, 9(1), 3-5.

Garrity, D. (2004). Detracking with vigilance. School Administrator, 61 (7), 24-27.

Geddes, K. A. (2010). Using tiered assignments to engage learners in Advanced Placement Physics. Gifted Child Today, 33(1), 32-40. 
Geiser, S. \& Santelices, V. (2004). The role of Advanced Placement and honors courses in college admission. Berkeley, CA: Research \& Occasional Paper Series: CSHE.4.04.

German (1958). NASSP Bulletin, 42(242), 160-162.

Gerwertz, C. (2008). Opening AP to all; The Duval County, Fla., district sees the courses as a part of a shift to teaching more students college level skills. Education Week, 27(27), 23-26.

Glaser, B. G. (1965). The constant comparative model of qualitative analysis. Social Problems , 12(4), 436-445.

Glaser, R. \& Strauss, R. (1967). The discovery of grounded theory. Chicago: Aldine.

Gloss, G. G. (1969). Sputnik Plus Ten: Ohio’s program for the gifted 1957-1967. Columbus, OH: Ohio State Department of Education..

Godfrey, K. E. \& Matos-Elefonte, H. (2010). Key indicators of college success: Predicting college enrollment, persistence, and graduation. New York, NY: College Board.

Good, C.V. (1963). Introduction to educational research. New York, NY: Appleton Century-Crofts.

Goss, M. (2004). Strategies for improving the Advanced Placement examination scores of AP social studies students. The History Teacher, 38(1), 115-117.

Gothill, M. \& Armstrong, D. (1999). Dr. no-body: The construction of the doctor as and embodied subject in British general practice 1955-97; Sociology of Heath and Illness, 21(1), 1-12.

Graham, M.A. (2009). AP Studio Art as an enabling constraint for secondary art education. Studio Art Education, 50(2), 201-204.

Graham, M.A. \& Sims-Gunzenhauser, A. (2009). Advanced Placement in studio art and secondary art education policy: Countering the null curriculum. Art Education Policy Review, 110(30), 18-24.

Grenfell, M. (1996). Bourdieu and initial teacher education: A post-structuralist Approach. British Educational Research Journal, 22(3), 287-303.

Grimshaw, A. D. (1982). Comprehensive discourse analysis: an instance of professional peer interaction. Language and Society, 11(1), 15-47. 
Gotthill, M. \& Armstrong, D. (1999). Dr. No-body: The construction of the doctor as an embodied subject in British general practice. Sociology of Health and Illness, 21(1), 1-12.

Grove, R.W. (1988). An analysis of the constant comparative method. Qualitative studies in education, 1(3), 273-280.

Gupta, D. (N.D.) The College Board and Florida. [Data file]. Retrieved from http://www.ncleg.net/DocumentSites/Committees/HSCEdReform/2012_03_07\%2 0Meeting/FLCollegeBoard_AdvancedPlacement_2012_03_07.pdf.

Gutting, G. (1989). Michel Foucault's archaeology of scientific reasoning. Cambridge, UK: Cambridge University Press.

Hakala, C. M. (1999). Some observations of the current state of high school psychology. Teaching psychology, 26(2), 122-123.

Hale, D. P. (2007). The lowest quartile African Americans taking Advanced Placement language and literature. The Clearing House: A Journal of Educational Strategies, Issues and Ideas, 80(3), 123-125.

Hallett, R. E. \& Venegas, K. M. (2011). Is increased access enough? Advanced Placement courses, quality, and success in low-income urban schools. Journal for the Education of the Gifted, 34(3), 468-487.

Hammond, B. G. (2009). Advancing beyond AP courses. Educational Digest 74(5), 2935.

Handwerk, P. (2008). Access to success: Patterns of Advanced Placement participation in US high schools. Policy Information Center, Educational Testing Service.

Hansen, D., Gutman, M., \& Smith, J. (2000). Scheduling AP Classes in a 2x4 block schedule: the Mayfield plan. Phi Delta Kappa, 82(3), 209-211.

Hansen, K., Gonzalez, J., Hatch, G.L., Reeve, S., Sudweeks, R. R., Esplin, P., \& Bradshaw, W.S. (2006). Are Advanced Placement English and first-year college composition equivalent? A comparison of outcomes in the writing of three groups of sophomore college students. Research in the Teaching of English, 40(4), 461501.

Hanson, H.P. (1980). Twenty-five years of the Advanced Placement Program Encouraging able students. The College Board Review, 115, 8-12.

Harris, Z.S. (1952a). Discourse analysis: A sample text. Language, 28(1), 1-30.

Harris, Z.S. (1952b). Discourse analysis: A sample text. Language, 28(4), 474-494. 
Harwood, V. \& Rasmussen, M.L. (2007). Scrutinizing sexuality and psychopathology: A Foucauldian inspired strategy for qualitative data analysis. International Journal of Qualitative Studies in Education, 20(1), 31-50.

Hazari, Z., Sadler, P.M., \& Tai, R.H. (2008). Gender differences in the high school and affective experiences of introductory college physics students. The Physics Teacher, 46(7), 423-427.

Hearn, S.T. (1998). AP physics in American high schools: What to do with the high flyer? Physics Education, 33(7), 405-410.

Heller, G.N. (2003). Historical research in music education and the historiography of Kant, Spengler, and Foucault. Research and Issues in Music Education, 1(1), retrieved from http://www.stthomas.edu/rimeonline/vol1/heller.htm.

Henry, M. (1991). Advanced Placement U.S. History: What happens after the examination. The Social Studies, 82(3), 94-96.

Henry, M.S. (1994). The AP United States history exam: Have free response essays changed in the last thirty years? Social Education, 58(3), 145-148.

Herr, N. E. (1991). The influences of program format on the professional development of science teachers: Teacher perception of AP and honors science courses. Science Education, 75(6), 619-629.

Herr, N. E. (1992). Administrative policies regarding Advanced Placement and Honors coursework. NASSP Bulletin, 76(544), 80-87.

Herr, N. E. (1993). The relationship between Advanced Placement and honors science courses. School Science and Mathematics, 93(4), 183-187.

Hertberg-Davis, H. \& Callahan C. M. (2008). A narrow escape: Gifted students' perceptions of Advanced Placement and International Baccalaureate programs. Gifted Child Quarterly, 52(3), 199-216.

Hertberg-Davis, H., Callahan, C. M., \& Kyburg, R. M. (2006). Advanced Placement and International Baccalaureate Programs: A" Fit" for Gifted Learners?. National Research Center on the Gifted and Talented.

Highsmith, R.J. (1989). The Advanced Placement Program. The Journal of Economics Education, 20(1), 115-120.

Hill, J. (1999). The special role of the AP European History course. The History Teacher, 32(2),265-275.

Hochman, D. R. (1970). Advanced Placement: Can it change with the times? The College Board Review 77, 16-19 
Hoffman, N. (2003). College credit in high school: Increasing post secondary credential rates of underrepresented students. Boston, MA: Jobs for the Future.

Hoven, J. (1995). Exemplary Advanced Placement programs: Comparing AP test scores by subject and school. Silver Spring, MD: Gifted and Talented Association of Montgomery County.

Howell, M. \& Prevenier, W. (2001). From reliable sources: an introduction the historical methods. Ithaca, NY: Cornell University Press.

Hyser, R. M. (1999). Is a 3 a C?: The reliability of the Advanced Placement United States History test for college credit. The History Teacher, 32(2), 223-235.

Iatarola, P., Conger, D., \& Long, M.C. (2011). Determinants of high schools' advanced course offerings. Educational Evaluation and Policy Analysis, 33(3), 340-359.

Irving, K.E. \& Bell, R.L. (2004). Double vision: Educational technology in standards and assessments for science and mathematics. Journal of Science Education and Technology, 13(2), 255-266.

Jackson, C. K. (2008). Cash for test scores: The impact of the Texas Advanced Placement incentive program. Education Next, 8(4), 71-77.

Jackson, C.K. (2010). A little now for a lot later: A look at a Texas Advanced Placement incentive program. The Journal of Human Resources, 45(3), 591-639.

Jäger, S. and Maier, F. (2009). Theoretical and methodological aspects in Foucauldian critical discourse analysis and dispositive analysis. In R. Wodak and M. Meyer (eds.), Methods of Critical Discourse Analysis, 2nd ed. London: Sage. pp. 34-61.

Jennings, J.L. \& Beveridge, A.A. (2009). How does test exemption affect school' and students’ performance?; Educational Evaluation and Policy Analysis, 31(2), 153175.

Jeong, D.W. (2009). Student participation and performance on Advanced Placement exams: Do state-sponsored incentives make a difference? Educational Evaluation and Policy Analysis, 31(4), 346-366.

Jin, Q., \& Shi, Q. (2008). A comparison of the number of hours of sleep in high school students who took advanced placement and/or college courses and those who did not. The Journal of School Nursing, 24(6), 417-424.

Jones, A. (2000). Word and Deed: Why a post-poststructural history is needed and how it might look. The Historical Journal, 43(20), 517-541.

Jones, D. (2009). Time trials- An AP Physics challenge lab. The Physics Teacher, 47(6), 342-344. 
Jones, J. (2001). Recomposing the AP English exam. The English Journal, 91(1), 51-56.

Jones, J. Q. (1975). Advanced Placement-Taking a hard look. NASSP Bulletin, 59(393), 64-69.

Kaase, K. J. \& Paeplow, C.G. (2002). Advanced Placement exam results, 2000-2001. Wake County Public School System, NC. Dept. of Evaluation and Research.

Kaestle, C. F. (1988). Recent methodological developments in the history of American education. In Jaeger, R. M. Ed., Complementary methods for research in education (61-73). Washington DC: AERA.

Kastrino, W. \& Erk, F.C. (1974). The Advanced Placement Exam in Biology. The American Biology Teacher, 36(5), 282-291.

Keller, C.R. (1958). The Advanced Placement program now has a history. NASSP Bulletin, 42(242), 6-12.

Kelley, C. (1994). Determining curricula and exam content in the Advanced Placement program: Implications for national standards. Education and Urban Society, 26 (2), 172-184.

Kelley-Kemple, T., Proger, A., \& Roderick, M. (2011). Engaging High School Students in Advanced Math and Science Courses for Success in College: Is Advanced Placement the Answer?. Evanston, IL: Society for Research on Educational Effectiveness.

Kellner, H. (1987). Narrativity in history: Post-structuralism and since. History and Theory, 26(4), 1-29.

Kelly, G.J. \& Chen, C. (1999). The sound of music: Constructing science as sociocultural practices through oral and written discourse. Journal of Research in Science Teaching, 36(8), 883-915.

Kennedy, P. \& Walstad, W.B. (1997). Combining Multiple-choice and constructed response test scores: An economist's view. Applied Measurement in Education, 10(4), 359-375.

Kenyon College (2008) Historical Markers: Kenyon College. Accessed (September 12, 2011), https://lbis.kenyon.edu/sca/markers/college

Kettler, T., Shiu, A., \& Johnsen, S.K. (2006). AP as an intervention for middle school Hispanic students. Gifted Child Today, 29(1), 39-46.

Kim, E. (2006). Academic pathways that promote student access and success. Brief: Office of Community College Research and Leadership, 1-4. 
Kim, M. (2010). Preferences of high achieving high school students in their career development. Gifted and Talented International, 25(2), 65-75.

Kinzie, J., Palmer, M., Hayek, J., Hossler, D., Jacob, S. A., \& Cummings, H. (2004). Fifty years of college choice: Social, political, and institutional influences on the decision making process. Retrieved from: http://files.eric.ed.gov/fulltext/ED484237.pdf.

Klein, A. (2006). College Board readies plans for AP audits. Education Week, 27(13), 13.

Klonoski, E. (2006). Improving dictation as an aural-skills instructional tool. Music Educators Journal, 93(1), 54-59.

Klopfenstein, K. (2004). Advanced Placement: Do minorities have equal opportunity? Economics of Education Review, 23(2), 115-131.

Klopfenstein, K. (2004). The Advanced Placement expansion of the 1990s: How did traditionally undeserving students fare? Education Policy Analysis Archives, 12(68), Retrieved 6/11/12 from http://epaa.asu.edu/epaa/v12n68.

Kokkelenberg, E. C., \& Sinha, E. (2010). Who succeeds in STEM studies? An analysis of Binghamton University undergraduate students. Economics of Education Review, 29(6), 935-946.

Kotcherlakota, S., \& Brooks, D. W. (2008). A Test of Strategies for Enhanced Learning of AP Descriptive Chemistry. Journal of Science Education and Technology, 17(4), 297-304.

Kumaravadivelu, B. (1999). Critical classroom discourse analysis. TESOL Quarterly, 33(3), 453-484.

Labov, W. (1972). Language in the inner city: studies in the Black English vernacular. Philadelphia, PA: University of Pennsylvania Press.

Labov, W. \& Fanshel, D. (1977). Therapeutic Discourse: Psychotherapy as conversation. New York, NY: Academic Press.

Lanegran, D.A. (2000). Modern agriculture in Advanced Placement Human Geography .Journal of Geography, 99(3-4), 132-141.

Lather, P. (1992). Critical frames in educational research: Feminist and post-structuralist perspectives. Theory into Practice, 31(2), 87-99.

Latin (1958). NASSP Bulletin, 42(242), 163-166. 
Lee, J. (2008). Is Test-Driven External Accountability Effective? Synthesizing the Evidence From Cross-State Causal-Comparative and Correlational Studies. Review of Educational Research, 78(3), 608-644.

Lefkowitz, R. S. (1971). The first nine years- A study of the Advanced Placement Program in mathematics. Journal for Research in Mathematics Education, 2(1), 23-35.

Leonard, S.T., Blasik, K., Dilgen, \& Till, F. (2003). Advanced Placement programs as a means of narrowing the achievement gap. ERS Spectrum, 21(2), 4-14.

Li, Y., Alfred, C., Kennedy, R.P., \& Putallaz, M. (2009). Effects of summer academic programs in middle school on high school test scores, course-taking, and college major. Journal of Advanced Academics, 20(3), 404-436.

Lichten, W. (2000). Whither Advanced Placement? Education Policy Analysis Archives, 8(29), 29.

Lifvendahl, S. (2007). Pursuing rigor at the middle school level. Principal Leadership (Middle School Edition), 8(1), 30-33.

Lillich, H. (1999). Teaching skills and habits of mind in world history. The History Teacher, 32(2), 293-296.

Lim, V. (2008). Expanding the scope of Advanced Placement classes: Hispanic educators launch an effort to create an AP Latin American History course. Diverse Issues in Higher Education, 25(16), 12-13.

Lincoln, Y. \& Guba, E. (1985). Naturalistic Inquiry. New York, NY: Sage.

Lindblad, M. \& Tyler, D. (2001). Advanced Placement exams 1999-2000: Results for WCPSS and EBN districts. Wake County Public School System, NC. Dept. of Evaluation and Research.

Liskin-Gasparro, J. E., Modu, C. C., \& Schriabman, J. (1979). The Validity of the Multiple-Choice Component of the Advanced Placement Spanish Language Examination. Hispania, 62(1), 98-105.

Literature and English composition (1958). NASSP Bulletin, 42(242), 142-154.

Longford, N. T. (1994). A case for adjusting subjectively rated scores in the Advanced Placement tests. Princeton, NJ: Educational Testing Services.

Lorin, J. (Aug 18, 2011). Not-for-profit College Board getting rich as fees hit students. Bloomberg. Retrieved from: http://www.bloomberg.com/news/2011-08-18/notfor-profit-college-board-getting-rich-as-fees-hit-students.html. 
Lorin, J. (Aug 26, 2011). College Board leader paid more than Harvard's. Bloomberg. Retrieved from: http://www.bloomberg.com/news/2011-08-26/nonprofit-head-ofcollege-board-paid-more-than-harvard-s-leader.html.

Lovejoy, A.O. (1938). The historiography of ideas. Proceedings of the American Philosophical Society, 78(4), 529-543.

Lucas, T. A., \& Spivey, J. (2011). A transition course from Advanced Placement to college calculus. PRIMUS: problem, resources, and issues in mathematics undergraduate studies, 21(5), 417-433.

Lucia, R. (1993). AP Music Theory in your school. Music Educators Journal, 80(1), 38$41+59$.

Luke, A. (1995-1996). Text and discourse in education: An introduction to critical discourse analysis. Review of Research in Education, 21, 3-48.

Luke, A. (2000). Critical literacy in Australia: A matter of context and standpoint. Journal of Adolescent and Adult Literacy, 43(5), 448-461.

Lukhele, R., Thissen, D., \& Wainer, H. (1994). On the relative value of multiple-choice, constructed response, and examinee selected items on two achievement tests. Journal of Educational Measurement, 31(3), 234-250.

Lurie, M. N. (2000). AP U.S. History: Beneficial or problematic? The History Teacher, 33(4), 521-525.

Mahala, D. \& Vivion, M. (1993). The role of AP and the composition program. WPA: Writing Program Administration, 17(1-2), 43-56.

Manzo, K. K. (2004). Advanced Placement courses cast a wider net. Education Week, 24(10), 1-4.

Manzo, K. K. (2005). College-based high schools fill growing need. Education week, 24 (38), 1-4.

Marcel, K. W. (2003). Online Advanced Placement courses: Experiences of rural and low-income high school students. Retrieved from http://www.wiche.edu/policy/wcalo/documents/marcelonline_000.pdf.

Marland Jr., S.P. (1975). The College Board and the twentieth century. New York, NY: College Entrance Examination Board.

Maryland State Department of Education (2009). Maryland Ranks \#1 in the nation on Advanced Placement exams for participation and performance. Baltimore, MD. 
Maryland State Department of Education (2011). Maryland's Achievements in public education 2011. Baltimore, MD.

Mason, D. (1996). Life after "ChemCom": Do they succeed in university-level chemistry courses? Paper Presented at the Annual Meeting of the National Association for Research in Science Teaching, St. Louis, MO.

Massachusetts State Department of Education (2003). Promoting high achievement: Policies and programs for academically advanced students in Massachusetts. Retrieved from http://www.doe.mass.edu/famcomm/aaereport.pdf.

Mathematics (1958). NASSP Bulletin, 42(242), 133-142.

Mathews, J (1982, December 2). Jaime Escalante turns students into calculus whizzes. The Washington Post, Retrieved from http://www.washingtonpost.com/wpdyn/content/article/2010/03/30/AR2010033003814.html.

Mathews, J. (2003). The 100 best high schools in America: The surge in the number of students taking AP tests is changing life inside America's classrooms--and altering the rules of the college admissions game. A look at a new set of winners for 2003. Newsweek, p 48-51.

Mathews, J. (2005). Meeting the challenge. Principal Leadership (Middle School Edition), 5(7), 22-26.

Mattimore, P. (2009). 5 fundamental misconceptions about AP courses. The Chronicles of Higher Education, 55(22), 1-3.

McGee, T. (1992). The adolescent novel in AP English: A response to Patricia Spencer. The English Journal, 81(4), 57-58.

McLean, C.D. (2010). Creating a curriculum unit on evaluation of media. Knowledge Quest, 38(3), 18-27.

Meckna, S. H. (1999). Teaching Advanced Placement European History in a multi-ethnic urban setting. The History Teacher, 32(2), 249-258.

Meek, S. \& Morton, J. (2009). Advanced Placement Economics improves both merit and equity. Social Education, 73(2), 82-85.

Menson, R. P., Patelis, T., \& Doyle, A. (2009). New England's state of college readiness: Adding up academic knowledge, success in college-level courses, SAT performance, and college career planning. The New England Journal of Higher Education, 22-23.

Metzger, M. J. (2002). "The villainy you teach me...": Shakespeare and AP English Literature. The English Journal, 92(1), 22-28. 
Milewski, G. B. \& Gillie, J. M. (2002). What are the characteristics of AP teachers? An examination of survey research. New York, NY: College Entrance Examination Board.

Milewski, G. B. \& Patelis, T. (2001). Measuring knowledge of introductory psychology: What are the relevant constructs? New York, NY: College Entrance Examination Board.

Miller, N. P. (1977). Tacitus' narrative style. Greece and Rome, Second Series, 24(1), 1322.

Minnesota Department of Education (2010). Advanced Placement and International Baccalaureate Programs. Roseville, MN.

Mo, L., Hu, X., Yang, F., Calaway, F., \& Nickey, J. (2011). ACT test performance by Advanced Placement students in Memphis City schools. The Journal of Educational Research, 104(5), 354-359.

Mollison, A. (2006) Surviving a midlife crisis: Advanced Placement turns fifty. Education Next, 1(6), 34-39.

Montecel, M.R., Cortez, J.D., \& Cortez, A. (2002). What is valuable and contributes to success in bilingual education programs. San Antonio, TX: Intercultural Development Research Association.

Moore, G. \& Slate, J.R. (2010). Advanced Placement courses and American Indian performance. American Secondary Education, 38(2), 73-94.

Morgan, R. \& Klaric, J. (2007). AP students in college: An analysis of five-year academic careers. Retrieved from: research.collegeboard.org/sites/default/files /publications/2012/7/researchreport-2007-4-ap-students-college-analysis-fiveyear-academic-careers.pdf.

Morgan, R. \& Mazzeo, J. (1988). A comparison of the structural relationship among reading, listening, writing, and speaking components of the AP French language Examination for AP candidates and college students. Princeton, NJ: Educational Testing Service.

Mulderrig, J. (2003). Consuming education: A critical discourse analysis of social actors in New Labour's education policy. Journal for Critical Education Policy Studies 1(1), Retrieved from http://www.jceps.com/?pageID=article\&articleID=2

Murphy, A. B. (2000). Political organization of space in Advanced Placement Human Geography. Journal of Geography, 99(3-4), 120-131.

Murphy, A.B. (2000). Teaching Advanced Placement Human Geography. Journal of Geography, 99(3-4), 93-97. 
Myerberg, N. J. \& Splaine, P. (1987). Performance of MCPS students on College Board tests, 1983-1984. Rockville, MD: Montgomery County Public Schools Department of Educational Accountability.

Neutuch, E. (1999). Advanced Placement United States History: A student's perspective. The History Teacher, 32(2), 245-248.

Ninnes, P. \& Burnett, G. (2003). Comparative educational research: poststructuralist possibilities [1]. Comparative Education, 39(3), 297-297.

No Child Left Behind (2001) §1701- 1707.

Nugent, S.A. \& Karnes, F. A. (2002). The Advanced Placement program and the International Baccalaureate Programme: A history and update. Gifted Child Today, 25(1), 30-39.

Oakes, J., Muir, K., \& Joseph, R. (20002). Course taking \& Achievement in Mathematics and Science: Inequalities that Endure and Change. Retrieved from http://www. wcer.wisc.edu/archive/nise/News_Activities/Forums/Oakespaper.htm.

Oberjuerge, M. (1999). Raising the bar: Historically disadvantaged students can meet the AP challenge. The History Teacher, 32(2), 263-267.

O’Brien, P. (1989). Micehl Foucault's History of Culture, in Hunt, L (Ed.), The new cultural history : Studies on the history of society and culture. Berkley CA: University of California Press.

O’Halloran, K. (2003). Critical discourse analysis and language cognition. Edinburgh, UK: Edinburgh University Press.

Ohrt, J. H., Lambie, G. W., \& Ieva, K. R. (2009). Supporting Latino and AfricanAmerican students in Advanced Placement courses: A school counseling program's Approach. Professional School Counseling, 13(1), 59-63.

Olszewski-Kubilius, P. \& Lee, S. Y. (2004). Gifted adolescents' talent development through distance learning. Journal for the Education of the Gifted, 28(1), 7-35.

Overbeck, J.C. (1969). Tacitus and Dio on Boudicca’s rebellion. The American Journal Of Philology, 90(2), 129-145.

Overby, A. (2009). The new conversation: Using weblogs for reflective practice in the studio art classroom. Art Education, 62(4), 18-24.

Oxtoby, D. W. ( 2007). The rush to take more AP courses hurts students, high schools, and colleges. The Chronicle of Higher Education, 73(2), 43-46.

Palin, R. J. (2001). PSAT and AP Success. OAH Magazine of History, 15(3), 55-56. 
Parker, W., Mosborg, S., Bransford, J., Vye, N., Wilkerson, J., \& Abbott, R. (2011). Rethinking advanced high school coursework: Tackling the depth/ breadth tension in the AP US Government and Politics course. Journal of Curriculum Studies, 43 (4), 533-559.

Patterson, T. C. (1989). Post-structuralism, post-modernism: Implications for historians. Social History, 14(1), 83-88.

Paul Jr., G. T., Hildebrandt, B.S., \& Strauss, T.R. (2006). Advanced Placement Human Geography: The first five years. Journal of Geography, 105(3), 99-107.

Peräkylä, A. (2004). Two traditions of interaction research. British Journal of Social Psychology, 43(1), 1-20.

Peters, F. R. \& Miller, L. H. (1959). A successful advanced placement program in mathematics. Educational Research Bulletin, 38(8), 203-209.

Petrina, S. (1998). The politics of research in technology education: A critical content and discourse analysis of the Journal of or Technology Education, volumes 1-8. Journal of Technology Education, 10(1), 27-57.

Petrone, K. (2000). Life has become more joyous, comrades: Celebrations in the time of Stalin. Bloomington, IN: Indiana University Press.

Physics (1958). NASSP Bulletin, 42(242), 124-132.

Pollock, E. J., \& Chun, H. W. (2008). Why Use Detective Fiction in the AP Classroom?. Paper presented at the AP Summer Institute Conference, Seoul, Korea.

Popham, W. J. (1987). The merits of measurement-driven instruction. The Phi Delta Kappa, 68(9), 679-682.

President and Fellows of Harvard College (2011) Advising program office: General information Accessed (April 15, 2011) retrieved from http://apo.fas.harvard.edu/icb/icb.do?keyword=k73580\&pageid=icb.page388448 \&pageContentId=icb.pagecontent823379\&view=view.do\&viewParam_name=asg eninfo.html\#a_icb_pagecontent823379_a_icb_pagecontent825552_summary.

Pushkin, D. B. (1995). The AP exam and the introductory college course. The Physics Teacher, 33(8), 532-535.

Putti, A. (2011). High school students' attitudes and beliefs on using the science writing heuristic in an Advanced Placement Chemistry class. Journal of Chemical Education, 88(4), 516-521.

Raphael, J. \& Kassissieh, J. (2010). Accelerated support and advanced learning. Principal Leadership, 10(5), 36-39. 
Ravitch, D. (2003). Does education really need more innovation in the age of scientifically based research. Accessed (April 12, 2011) Retrieved from http://www2.ed.gov/about/offices/list/oii/resources/20030415a.html

Regan, R. (2004). Advanced Placement exam results, 2001-2002. Wake County Public School System, NC. Dept. of Evaluation and Research.

Reichard, J. R. (1960). German Advanced Placement under the College Board: Promising signs. The German Quarterly, 33(2), 153-158.

Reichard, G. \& Keirn, T. (1999). The Advanced Placement Exam in History: Growth, Controversies, and New Perspectives. The History Teacher, 32(2), 169-173.

Reshetar, R., \& Melican, G. J. (2010, April). Design and Evaluation of Mixed-Format Large Scale Assessments for the Advanced Placement Program (AP). In Annual Meeting of the American Education Research Association, Denver, CO.

Riccards, M.P. (2010). The College Board and American Higher Education. Madison, NJ: Fairleigh Dickinson University Press.

.Ricoeur, P. (1980). Narrative Time. Critical Inquiry, 7(1), 169-180.

Rigorous courses, fresh enrollment: A multistate effort to draw nontraditional students into Advanced Placement starts to pay off.(2007). Education Week, 26(36), 28-32.

Riley, M. N. (2006). A district where everyone's on the advanced track. School Administrator, 63(1), 33.

Robinson, J. H. (1958). The new history: Essays illustrating the modern historical outlook. Springfield, MA: The Walden Press.

Rogers, R., Malancharuvil-Berkes, E., Mosley, M., Hui, D., \& Joseph, G. O. (2005) Critical discourse analysis in education: A review of the literature. Review of Educational Research 75(3)365-416.

Rosman, A. (1970). Structuralism as a conceptual framework. African Studies Review, 13(1), 69-74.

Rosoff, A. (2007). The reality of the unreality: using imagination as a teaching tool. The English Journal, 96(3), 58-62.

Roth, W. M. \& Lucas, K. B. (1998). From "truth” to "invented reality": A discourse analysis of high school physics students' talk about scientific knowledge. Journal of Research in Science Teaching, 34(2),145-179.

Rothschild, E. (1999). Four decades of the Advanced Placement program. The History Teacher, 32(2), 175-206. 
Rothschild, E. (2000). The impact of the document-based question on the teaching of United States history. The History Teacher, 33(4), 2000.

Ruch, C. (1968). Study of collegiate records of advanced placement and non-advanced placement students. College and University, 43(2), 207-210.

Runciman, W. G. (1969). What is structuralism?. The British Journal of Sociology, 20(3), 253-265.

Sadler, P.M., Sonnert, G., Tai, R. H., \& Klopfenstein, K. (Eds.). (2010). AP: A critical examination of the Advanced Placement program. Cambridge, MA: Harvard Educational Press.

Sadler, P.M. \& Tai, R.H. (2007). Weighting for recognition: Accounting for Advanced Placement and honors courses when calculating high school grade point average. NASSP Bulletin, 91(5), 5-32.

Sadler, P.M. \& Tai, R.H. (2007). Accounting for advanced high school coursework in college admissions decisions. College and University Journal, 82(4), 7-14.

Sadler, P.M. \& Tai, R.H. (2007). Advanced Placement exam scores as a predictor of performance in introductory college biology, chemistry, and physics courses. Science Educator, 16(2), 1-19.

Santoli, S.P. (2002). Is there an Advanced Placement advantage? American Secondary Education, 30(3), 23-35.

Sarup, M. (1993). An introductory guide to post-structuralism and post-modernism ( $2^{\text {nd }}$ ed.). Athens, GA: University of Georgia Press.

Saunders, T. \& Maloney, K. (2005). Boosting Black academic achievement and AP enrollment. The Education Digest, 54-57.

Saunders, T. \& Maloney, K. (2005). Minority scholars-Diversity and achievement. Principal Leadership (High School Edition), 5(4), 39-41.

Sawyer, C. (2010). Brain-webbing and mind-melding in geography. The Geography Teacher, 7(1), 13-15.

Scahill, E. M. \& Melican, C. (2005). The preparation and experience of Advanced Placement in economics instructors. Journal of Economic Education, 36(1), 9398.

Scanlan, R. T. \& Levy, H.L. (1960). University of Michigan Advanced Placement institute and seminar, June- August 1960. The Classical World, 54(2), 50-51. 
Scheurich, J. J., \& McKenzie, K. B. (2008). Foucault's methodologies: archaeology and genealogy. In N. K. Denzin \& Y. S. Lincoln Collecting and Interpreting qualitative materials. Thousand Oaks, CA: Sage Publications Inc.

Schlozman, K. L. (1989). A reply to the evaluation of the AP program in political science. The Political Science Teacher, 2(4), 19-20.

Schwartz, J. (2004). Reflections of an AP reader. The English Journal, 93(4), 53-57.

Spanish (1958). NASSP Bulletin, 42(242), 166-168.

Share, D. H. (2005). Private School Students Surpass National AP Average. Outlook, (307). Retrieved from http://www.capenet.org/pdf/Outlook307.pdf.

Shepherd, C. (2003). Any time, any place: Online advanced placement courses for high school students. In World Conference on Educational Multimedia, Hypermedia and Telecommunications (Vol. 2003, No. 1, pp. 2504-2507).

Shiu, A., Kettler, T., \& Johnson, S. K. (2009). Social effects of Hispanic students enrolled in an AP class in middle school. Journal of Advanced Academics, 21, 5882.

Simpson, R.D. (1973). The Advanced Placement program in science: Another alternative in the curriculum. The Science Teacher, 40(8), 27-29.

Sinclair, J. Coulthard, M. (1975). Toward an analysis of discourse. Oxford, UK: Oxford University Press.

Smith, E. H. (1965). English Composition in the Advanced Placement program. The English Journal, 54(6), 495-501.

Smith, M. A., Place, W. A., Biddle, J. R., Raisch, C. D, Johnson, S. L., \& Wildenhaus, C. (2007). The Ohio post secondary enrollment opportunities (PSEO) program: Understanding its under-utilization. Normes, 7(2), 80-114.

Smith, S. S. \& Mickelson, R.A. (2000). All that glitters is not gold: School reform in Charlotte-Mecklenberg. Educational Evaluation and Policy Analysis, 22(2), 101127.

Solomon, J. (2004-2005). Programming as a second language. Learning and Leading with Technology, 32(4), 34-39.

Solózano, D. G. \& Ornelas, A. (2002). A critical race analysis of Advanced Placement classes: A case of educational inequality. Journal of Latinos and Education, 1(4), 215-225. 
Spencer, P. (1989). YA novels in the AP classroom: Crutcher meets Camus. The English Journal, 78(7), 44-46.

Speroni, C. (2011). Determinants of students' success: The role of Advanced Placement and duel enrollment programs. New York, NY: The National Center for Post Secondary Research.

Sridawruang, C., Crozier, K., \& Pfeil, M. (2010). Attitudes of adolescents and parents towards premarital sex in rural Thailand: A qualitative exploration. Sexual \& Reproductive Healthcare, 1(4), 1981-187.

Stanley, J. C. \& Stumpf, H. (1997). Gender differences, especially on fifty College Board achievement tests. Paper presented at the Annual Meeting of the Eastern Psychological Association. Washington DC.

Stearns, P. N. (1999). The thematic and comparative structure of the new course. The History Teacher, 32(2), 277-281.

Steensma, R. C. (1968). An Advanced Placement student explicates "Fleas". The English Journal, 57(4), 580.

Stellar, A. W. \& Lambert, W. K. (1996). Advanced Placement: Helping to achieve system wide reform in urban schools. NASSP Bulletin, 80, 96-103.

Stephens, W. C. (1965). Advanced Placement and the Secondary School Curriculum. The Classical World, 132-135.

Stern, L. (1990). Narrative versus description in historiography. New Literary History, 21(3), 555-568.

Stovel, J. E. (2000). Document analysis as a tool to strengthen student writing. The History Teacher, 33(4), 501-509.

Stremler, S. E., Sternberg, R. J., Grigorenko, E. L., Jarvin, L., \& Sharpes, K. (2009). Using the theory of successful intelligence as a framework for developing assessments in AP physics. Contemporary Educational Psychology, 34, 195-209.

Stuart, M. (1940). Tacitus and the portraits of Germanicus and Drusus. Classical Philology, 35(1), 64-67.

Swanson, J. (2004). Dual enrollment and Advanced Placement: Partners for student success. Principal Leadership (High School Edition), 7(7), 26-30.

Taliaferro, J.D. \& DeCuir-Gunby, J. T. (2008). African American educators' perspectives on the Advanced Placement opportunity gap. The Urban Review, 40(2), 164-185. 
Tally, B. \& Goldenberg, L. B. (2005). Fostering historical thinking with digital primary sources. Journal of Research Technology in Education, 38 (1), 1-21.

Teo, P. (2000). Racism in news: A critical discourse analysis of news reporting in two Australian newspapers. Discourse and Society, 11(1), 7-49.

Teuscher, D. \& Reys, R. E. (2010). Slope, rate of change, and steepness: Do students understand these concepts? Mathematics Teacher, 103(7), 519-524.

The Abell Foundation. (2007). A "jump start" on college: How early college access programs can help high school students in Baltimore city.

The AP studio art program. (1990). School Arts, 89 (7), 44.

The Newsweek/Daily Beast Company (2011a). Best American high schools: How we compiled the list. Retrieved from http://www.thedailybeast.com/newsweek/2011 /06/20/best-american-high-schools-how-we-compiled-the-list.html Accessed Sept 5, 2011.

The New York Times (2005, Feb. 3). Transcript: President Bush's State of the Union Address. The New York Times. Retrieved from http://www.nytimes.com/2005/ 02/03/politics/03btext.html.

The Washington Post Company (2006). President Bush’s Sate of the Union Address. Retrieved from http://www.washingtonpost.com/wpdyn/content/article/2006/01/31/AR20060131 01468.html Accessed Sept. 5, 2011.

Thompson, J. (1990). Ideology and Modern Culture. Cambridge: Polity Press.

Thompson, T., \& Rust, J. O. (2007). Follow-Up of Advanced Placement Students in College. College Student Journal, 41(2), 416-422.

Tianio, L. (2002). Negotiating gender identities and sexual agency in elderly couples' talk. In Paul McIlvenny Ed. Talking Gender and Sexuality. Philadelphia, PA: Johns Benjamins North America.

Traill, D. \& Harvey, D. (1998). Team-teaching AP history and English. Social Education, 62(2), 77-79.

U.S. Department of Education, National Center for Education Statistics. (2011). Digest of Education Statistics, 2010 (NCES 2011-015) Accessed (September 12, 2011) http://nces.ed.gov/fastfacts/display.asp?id=84

Uy, E. (2007). Report: AP, IB are models for state standards. Education Daily 13, 5. 
Valentine, J. A. (1987). The College Board and the school curriculum: A history of the College Board's influence on the substance and standards of American education, 1900-1980. New York: College Entrance Examination Board.

Vanderbrook, C. A. (2006). Industrialization and economic development in Advanced Placement Human Geography. The Journal of Secondary Gifted Education, 17(3), 5-20.

VanLandingham, G. (2009). Modifying Advanced Placement program incentive funding could produce significant cost savings. Tallahassee, FL: Office of Program Policy Analysis \& Government Accountability.

Van Tassel-Baska, J. (2001). The role of Advanced Placement in talent development. The Journal of Secondary Gifted Education, 12(3), 126-132.

Vaughn, III, E. S. (2010). Reform in an urban school district: The role of the PSAT results in promoting Advanced Placement course taking. Education and Urban Society, 42(4), 394-406.

Venkateswaran, U. (2004). Race and gender issues in the AP United States History exam. The History Teacher, 37(4), 501-512.

Vopat, J. B. (1981). Going APE: Reading the Advanced Placement Examination in English Composition and Literature. College English, 43(3), 284-292.

Wakelyn, D. (2009). Raising rigor, getting results: Lessons learned from the AP examinations. Washington D.C.: NGA Center for Best Practices.

Wang, X. B. (1999). On giving test takers a choice among constructive response items. Newton, PA: Law School Admissions Council.

Wasley, P. (2007). College Board reports more takers, and higher scores, for Advanced Placement tests. The Chronicle of Higher education, 53(25), 1-2.

Wasson, E. A. (2003). Eastern European Elites: Teaching about aristocrats in the AP curriculum. The History Teacher, 37(1), 39-49.

Watt, K. M., Powell, C.A., Mendiola, I. D., \& Cossio, G. (2006). School wide impact and AVID: How have selected Texas high schools addressed the new accountability measures? Journal of Education for Students Placed at Risk, 11(1), 57-73.

Weaver, R. (2010). Having the AP conversation. Independent School, 69(3), 36-38, 4041.

Western Interstate Higher Education Commission. (2006). Accelerated learning options: Moving the needle on access and success, A study of state and institutional policies and practices. 
Whipple, F. H. (1958). Memorial High School's Advanced Placement program. NASSP Bulletin, 42(242), 24-26.

White, D. K. (1974). AP [Advanced Placement] year in Utah. A program of acceleration for gifted, college-bound students. College Board Review,

White, D. O. (1969). Whither the German AP program? Die Unterrichtspraxis. Teaching German, 2(2), 93-102.

White, E .M. (1958). The new unknown quantity-XX. NASSP Bulletin, 42(242), 61-69.

White, H. (1980). The value of narrativity in the representation of reality. Critical Inquiry, 7(1), 5-27.

White, H. (1981). The narrativization of real events. Critical Inquiry, 7(4), 793798.

White, H. (1984). The question of narrative in contemporary historical theory. History and Theory, 23(1), 1-33.

White, H. (1988). Historiography and historiophoty; The American Historical Review, 93(5), 1193-1199.

White, S., \& Tesfaye, C.L. (2011). Under-represented minorities in high school physics. AIP Statistical Research Center. Retrieved from: http://www.aip.org/sites/default /files/statistics/highschool/hs-underrepmin-09.pdf.

Whitman, G. (2003). AP-gate. The History Teacher, 36(3), 357-365.

Widdowson, H. G. (1979). Explorations in applied linguistics. Oxford, UK: Oxford University Press.

Wiersma, W. (1969). Research methods in education: An introduction. Philadelphia, PA: J.B. Lippincott Company.

Wilbur, M. \& Monk, J. (2010). Meeting the challenge for curricular change in Spanish language, literature, and culture. Hispania, 93(1), 101-107.

Wilensky, R. (2007). High schools have got it bad for higher ed- and that ain't good. Phi Delta Kappa, 89(4), 248-259.

Willis, S. (2004). Historical and operational perspectives of the Advanced Placement program in studio art. Art Education, 57(1), 42-46.

Wimmers, E. \& Morgan, R. (1990). Comparing performance of high school and college students on the Advanced Placement French Language examination. The French Review, 63(3), 423-432. 
Winebrenner, S. (2006). Effective teaching strategies for open enrollment honors and AP classes. Journal of Secondary Gifted Education, 17(3), 31-49.

Winerip, M. (1983, June 24). Rich Schools Getting Richer in Computers.. The New York Times, p. B4.

Winkler, D. L. \& Jolly, J. L. (2011). Project TALENT. Gifted Child Today, 43(2), 34-36.

Wolowelsky, J. B. (1982). Secondary school initiative in creating Advanced Placement opportunities. Alternative Higher Education, 7(1), 57-61.

Wood, W. B. (2002). Advanced high school biology in an era of rapid change: A summary of the Biology Panel Report from the NRC committee on programs for advanced study of mathematics and science in American high schools. Cell Biology Education, 1, 123-127.

Woodbridge, F. J. E. (1916). The purpose of history. New York, NY: Columbia University Press.

Xiong, X., Mattern, K. D., \& Shaw, E. J. (2008). The relationship between AP English Language performance and college outcomes. NERA Conference Proceedings 2008

Yang, W. (2004). Sensitivity of linkings between AP multiple-choice scores and composite scores to geographical region: An illustration of checking for population invariance. Journal of Educational Measurement, 41(1), 33-41.

Yardley, L., McDermott, L., Pisarski, S., Ducahine, B., \& Nakayama, K. (2008). Psychosocial consequences of developmental prosopagnosia: A problem of recognition. Journal of sychosomatic Research, 65(5), 445-451.

Zehr, M. A. (2006). More home schoolers taking Advanced Placement tests: students seek outside validation of work and leg up on college admission program. Education Week, 25(33), 12-14. 
APPENDICES 


\section{APPENDIX A}

Excerpt from Yardley et al.’s Thematic Analysis of Prosopagnosia.

Thematic analysis $[23,24]$ was used as a method of inductively identifying and understanding the psychosocial consequences of DP. The process began with immersion in the transcripts, after which initial codes describing the core meaning of each text segment were assigned to all relevant text. Related codes were grouped into themes, which were then progressively defined and refined to detail thoroughly the characteristics of each theme (e.g., variations between individuals with respect to the phenomenon described by the theme). Code definitions and the codes assigned to each text segment were fully documented [21]. This process was undertaken by the second and third authors, in discussion with the first author (who has DP). The first author then checked all final coding and prepared the overview of themes presented here, using constant comparison between cases to search for and explain significant deviations from the dominant pattern of experiences [21,22].

Accounts of the psychosocial consequences of DP included numerous descriptions of the immediate consequences of recognition failure, which caused significant social interaction difficulties. Because participants felt unable to provide a legitimate justification for these difficulties, they resulted in anxiety about offending others and feelings of inadequacy. The accounts also contained descriptions of longerlasting psychosocial consequences, including changes in behavior to avoid occurrences of recognition failure (e.g., avoidance of social situations and dependence on social support for assistance with recognition), chronic stress, and social anxiety, and a long- 
term impact of DP on personality, social relationships, and careers (emphasis added) (Yardley et al., 2008, p. 447). 


\begin{abstract}
APPENDIX B
Excerpts from Sridawruang, Crozier and Pfeil's thematic analysis of premarital sex in rural Thailand.
\end{abstract}

We followed accepted procedures for qualitative data analysis [18,19] to analyse qualitative data in five steps to establish key themes. These were:

(1) Preparing and exploring the data for analysis: the audio-taped focus groups were transcribed verbatim in Thai and translated into English by CS. Informal member checks took place at the end of each focus group [20] when CS summarised the main points of discussion and asked participants to verify that the researcher had interpreted their responses accurately. The process of translating included CS (who is bilingual) reading through the Thai transcripts line-by-line, translating them word-for-word into English and providing a detailed definition of the local words or slang used by participants. To ensure the accuracy of the translated data, translation checks were carried out by three English and Thai speaking academics. One was a native English speaker who is an expert in Thai language who reviewed and checked the correctness of all transcripts before two English speaking Thai academic health professionals also checked the translations for correctness. Following discussion a few English words were revised and changed.

(2) Coding: all data were analysed and coded by CS with a code name that was closest to the data. The process of coding included that CS read through data line-by-line and reduced it into one or two phrases assigning codes of meaning. Two coders independently coded the same transcript repeating the process. They then met to compare 
and discuss differences in their coding and problems with coding structure. As the coding proceeded, codes and definitions were clarified, new codes were added as analysis progressed, and new understanding developed.

(3) Data display: the data were displayed in a thematic map to understanding the flow, location and connection of events and identifying emerging themes (See Fig. 1).

(4) Themes and categories: based on thematic analysis, a manual technique was used to establish key themes. All authors clarified themes in relation to the coded extracts, refined the specifics of each theme and gave clear definitions and names for each theme. All authors met regularly to con- sider and clarify these themes (debriefing by peers) [20] and discuss any coding issues. Together the authors chose extracts to support the themes selected to present the findings.

(5) Representing the data analysis: verbatim quotes were used to present the findings in order to show a clear link to the original data. (Sridawruang, Ryding, and Pfeil, 2010, p. 182)

The findings of this study are presented around four overarching themes: social judgment of girls; boys have nothing to lose; considering risks; and parents as problem solvers. Taken together they highlight the still existing double standards concerning young Thai women and men. (Sridawruang, Ryding, and Pfeil, 2010, p. 183) 


\section{APPENDIX C}

Excerpt from Day, Thorn and Kapoor (2011) including a sample of their thematic

$$
\text { mapping }
$$

First, interviews were reviewed in their entirety by 3 experienced coders (authors). The coding team then went through an iterative process of independently reviewing sets of 5 CBT and 5 EDU interviews, followed by meeting to discuss, resolve discrepancies, and revise the consensus codebook, until all interviews (28 for CBT, and 24 for EDU) were coded. After coding all of the interviews, each coder independently sorted the codes into potential themes and subthemes and all relevant coded data extracts were collated within these themes. The coding team then reconvened to compare their identified themes, and to generate an initial thematic map (i.e., visual representation) depicting a consensus of the candidate main themes and sub- themes emerging from the data. The primary author then reviewed the collated coded extracts for each candidate theme, checking that the themes formed a coherent pattern. The validity of each theme and the accuracy of the thematic map were considered in relation to the overarching meaning inherent in the data set as a whole. The coding team then collectively defined and refined the themes to generate final thematic maps. Content analysis was then conducted to calculate the percentages of participants whose statements were contained within each theme. (Day, Thorn and Kapoor, 2011, p. 943) 


\section{APPENDIX D}

The analysis consisted of 1135 documents. Of those 312 were utilized in the data set to create 417 data extracts. Below is a sample of the analysis consisting of sample of the data organizational table and a sample of the table of extracts and coding for each of the themes.

\section{Launch of Sputnik}

\begin{tabular}{|l|l|l|l|}
\hline Title & Author & $\begin{array}{l}\text { Type of } \\
\text { publication }\end{array}$ & Year \\
\hline $\begin{array}{l}\text { The use of achievement tests in curriculum } \\
\text { development }\end{array}$ & Black, M.M. & $\begin{array}{l}\text { journal } \\
\text { article }\end{array}$ & 1959 \\
\hline
\end{tabular}

\begin{tabular}{|c|c|c|c|}
\hline Extract & Coded for & Source & $\begin{array}{c}\text { Sour } \\
\text { ce } \\
\text { Year }\end{array}$ \\
\hline $\begin{array}{c}\text { it did create a new emphasis } \\
\text { on testing, which carried over } \\
\text { to the public schools. }\end{array}$ & $\begin{array}{c}\text { Sputnik- } \\
\text { reform }\end{array}$ & $\begin{array}{c}\text { Black, M.M. (1959). The use of } \\
\text { achievement tests in curriculum } \\
\text { development. NASSP Bulletin, } \\
\text { 43, 90-93 }\end{array}$ & 1959 \\
& & \\
\hline
\end{tabular}


Publication of “A Nation at Risk"

\begin{tabular}{|l|l|l|l|}
\hline Title & Author & $\begin{array}{l}\text { Type of } \\
\text { publication }\end{array}$ & Year \\
\hline $\begin{array}{l}\text { Advanced Placement World History: A } \\
\text { rigorous but manageable course for high } \\
\text { school }\end{array}$ & Black, L. & $\begin{array}{l}\text { journal } \\
\text { article }\end{array}$ & 1999 \\
\hline
\end{tabular}

\begin{tabular}{|c|c|c|c|}
\hline Extract & Coded for & Source & $\begin{array}{l}\text { Sour } \\
\text { ce } \\
\text { Year }\end{array}$ \\
\hline $\begin{array}{l}\text { the sophomore level gifted } \\
\text { and talented honors classes in } \\
\text { our district. }\end{array}$ & $\begin{array}{l}\text { NAR- } \\
\text { course }\end{array}$ & $\begin{array}{l}\text { Black, L. (1999). Advanced } \\
\text { Placement World History: A } \\
\text { rigorous but manageable course } \\
\text { for high school. The History } \\
\text { Teacher, } 32 \text { (2), 289-292. }\end{array}$ & 1999 \\
\hline
\end{tabular}

Passage of NCLB

\begin{tabular}{|l|l|l|l|}
\hline Title & Author & $\begin{array}{l}\text { Type of } \\
\text { publication }\end{array}$ & Year \\
\hline $\begin{array}{l}\text { The AP descriptive chemistry question: } \\
\text { Student errors }\end{array}$ & $\begin{array}{l}\text { Crippen, K. \& } \\
\text { Brooks, D.W. }\end{array}$ & $\begin{array}{l}\text { journal } \\
\text { article }\end{array}$ & 2005 \\
\hline
\end{tabular}

\begin{tabular}{|c|c|c|c|}
\hline Extract & Coded for & Source & $\begin{array}{c}\text { Sour } \\
\text { ce } \\
\text { Year }\end{array}$ \\
\hline $\begin{array}{c}\text { experiment providing } \\
\text { software for high school } \\
\text { students preparing for the } \\
\text { descriptive question on the } \\
\text { Advanced Placement (AP) } \\
\text { Chemistry Exam. Since 1997, } \\
\text { the software has been } \\
\text { available as a Web site } \\
\text { offering repeatable practice. }\end{array}$ & $\begin{array}{c}\text { NCLB- } \\
\text { college prep }\end{array}$ & $\begin{array}{l}\text { Crippen, K. \& Brooks, D.W. } \\
\text { (2005). The AP descriptive } \\
\text { chemistry question: Student } \\
\text { errors. Journal of Computers in } \\
\text { Mathematics and Science } \\
\text { Teaching, } 24 \text { (4), 357-366. }\end{array}$ & 2005 \\
\hline
\end{tabular}


VITA

JON REHM

1999

B.A., Psychology and Philosophy

University of Miami

Coral Gables, Florida

2001

B.A., History

Florida International University

Miami, Florida

2005

M.S., Social Studies Education

Florida International University

Miami, Florida

2011

Ed.S., Curriculum and Instruction

Florida International University

Miami, Florida

2004-2014

Teacher

South Dade Senior High School

Homestead, Florida

\section{PUBLICATIONS AND PRESENTATIONS}

Rehm, J. (2012, April). The use of Foucault in the creation of educational history: A review of literature. Paper presented at the College of Education and Graduate Student Network Research Conference, Miami, Florida.

Rehm, J. (2013, June). An examination of the AP United States History exam free response section. Paper presented at the South Florida Educational Research Conference.

Rehm, J. (2013, November). Creating your secondary psychology curriculum for common core standards. Poster presented at the National Council for the Social Studies Annual Conference, Miami, Florida. 